SORCIÓN DE RADIOISÓTOPOS EN
SÓLIDOS INORGÁNICOS
FRANCISCO GRANADOS CORREA
DOCTORADO EN CIENCIAS




\title{
SORCIÓN DE RADIOISÓTOPOS EN SÓLIDOS INORGÁNICOS
}

TESIS QUE PRESENTA:

\section{FRANCISCO GRANADOS CORREA}

\author{
PARA OBTENER EL GRADO DE: \\ DOCTOR EN CIENCIAS \\ (QUIMICA)
}

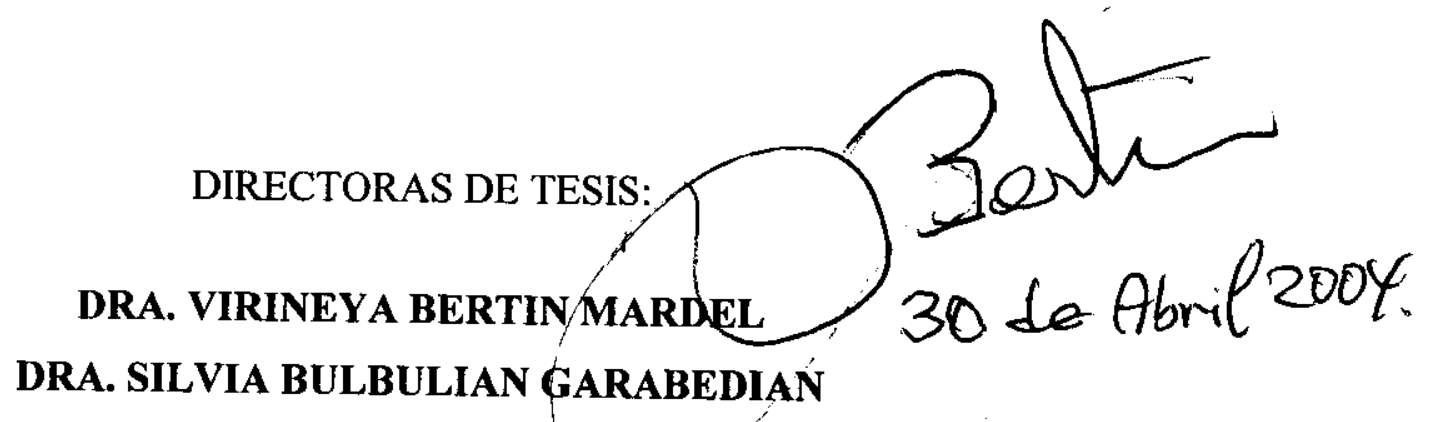

Abril, 2004

UNIVERSIDAD AUTÓNOMA METROPOLITANA, UNIDAD IZTAPALAPA DIVISIÓN DE CIENCIAS BÁSICAS E INGENIERÍA 


\section{$\triangle 07$ UNIVERSIDAD AUTÓNOMA METROPOLITANA}

SORCIÓN DE RADIOISÓTOPOS EN SÓLIDOS INORGÁNICOS

TESIS QUE PRESENTA

FRANCISCO GRANADOS CORREA

PARA OBTENER EL GRADO DE

DOCTOR EN CIENCIAS

DIRECTORAS DE TESIS:

DRA. VIRINEYA BERTIN MARDEL

DRA. SILVIA BULBULIAN GARABEDIAN

Abril de 2004

UNIVERSIDAD AUTONOMA METROPOLITANA-IZTAPALAPA

DIVISIÓN DE CIENCIAS BÁSICAS E INGENIERÍA

DEPARTAMENTO DE QUÍMICA

ÁREA DE CATÁLISIS

San Rafael Atlixco 186 Col. Vicentina, C. P. 09340.

Delegación Iztapalapa, México D. F. 


\section{SORCIÓN DE RADIOISÓTOPOS EN SÓLIDOS INORGÁNICOS}

TESIS QUE PRESENTA:

FRANCISCO GRANADOS CORREA

PARA OBTENER EL GRADO DE:

DOCTOR EN CIENCIAS

DIRECTORAS DE TESIS:

DRA. VIRINEYA BERTIN MARDEL

DRA. SILVIA BULBULIAN GARABEDIAN

UNIVERSIDAD AUTÓNOMA METROPOLITANA-IZTAPALAPA

DIVISIÓN DE CIENCIAS BÁSICAS E INGENIERÍA

DEPARTAMENTO DE QUÍMICA

ÁREA DE CATÁLISIS 
Esta tesis se realizó en las instalaciones del Instituto Nacional de Investigaciones Nucleares (ININ) y de la Universidad Autónoma Metropolitana-Iztapalapa (UAM-I) bajo la dirección de las Dras. Virineya Bertin Mardel y Silvia Bulbulian Garabedian.

Agradezco a las autoridades de ambas instituciones las facilidades que me brindaron para la realización de esta tesis y el apoyo financiero otorgado por la beca CONACYT y el proyecto CONACYT-2002-C01-39893. 


$$
\text { A } \mathcal{D}_{\text {ios }}
$$

Por darme la fuerza y entendimiento para seguir adelante.

Dedico este trabajo a dos grandes personas de mi vida, por quienes soy y existo, como un fruto de su amor, porque siempre han creído en mí, y en reconocimiento a su apoyo y comprensión.

A mi madre María Carmen Correa Moreno, Por brindarme su apoyo incondicional y por estar en todo momento conmigo, por su ejemplo de trabajo incansable, dedicación y amor a todo lo que realiza y,

A mi padre Agustín Granados Guillén, por su estricta rectitud, humildad y honestidad en todos los trabajos que desarrolla en la vida y por todo el amor que me han brindado.

A toda mi gran familia: Abel, Silvia, Genaro, Rosalba, Imelda, Alejandra, Alberto, Armando, Susana, Ángel y Agustin y a mis sobrinos, con todo mi cariño, por su solidaridad para este logro. 
A Rosy, por el amor que me brinda.

A Stefany y Paquito, con todo mi cariño.

A la Dra. Silvia Bulbulian Garabedian, por la acertada dirección de este trabajo, por sus valiosos conocimientos, dedicación, paciencia de quién siempre recibí buenos y certeros consejos y a quién debo gratitud por el enorme y desinteresado apoyo, pero sobre todo por su gran calidad humana y por ser el pilar de mi formación profesional.

A la $\mathcal{D}_{\text {ra }}$. Virineya $V_{\text {ertin }}$ Mardel, por la dirección para la realización de este trabajo de investigación, por todo el apoyo brindado, por la confianza depositada en mí, pero sobre todo, por las atenciones que me brindo.

A los miembros del jurado de examen, por sus valiosas sugerencias y por haber contribuido al mejoramiento del presente trabajo:

Dra. Virineya Bertin Mardel

Dr. Maximiliano Asomoza Palacios

Dr. Armando Dominguez $O_{\text {rtiz }}$

Dr. Marcos José Solache Rios

Dr. Gaime Sanchez Valente

A todo el personal del Departamento de Química del ININ por los momentos compartidos, palabras de aliento y principalmente, por el privilegio de su amistad.

A Jorge, Jaime, $\mathcal{L}_{i z}$, Hilario, Bonis $\mathcal{G}_{u a n}$, por su continuo apoyo durante tantos años, pero sobre todo por su amistad.

Gracias a todas las personas, que me han apoyado de alguna manera a lo largo de mi vida. 


\section{ÍNDICE}

INTRODUCCIÓN $\quad \begin{gathered}\text { Página } \\ 1\end{gathered}$

\section{CAPÍTULO I}

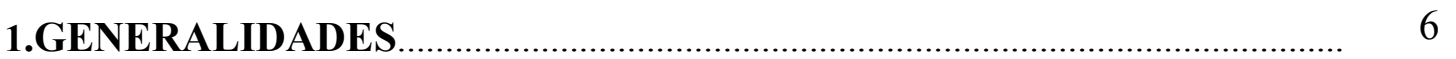

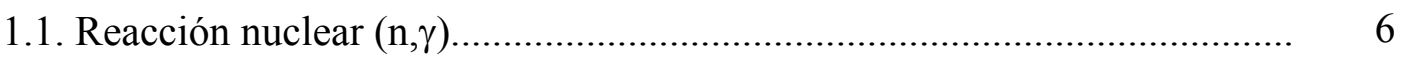

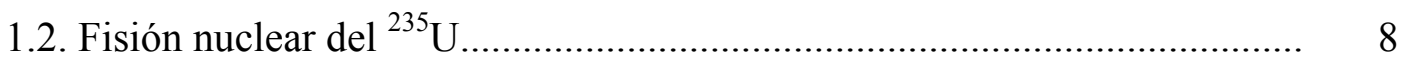

1.2.1. La fisión nuclear.......................................................................... 8

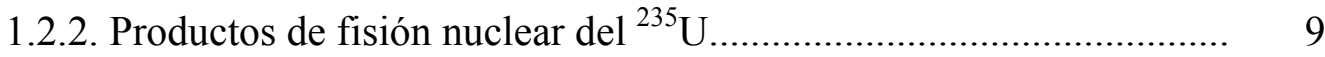

1.3. Procesos de sorción.............................................................................. 11

1.3.1. Fisisorción............................................................................. 12

1.3.2. Quimisorción.......................................................................... 12

1.3.3. Intercambio iónico...................................................................... 14

1.4. Sólidos inorgánicos......................................................................... 15

1.4.1. Materiales sorbentes.................................................................. 15

1.4.1.1. Óxidos hidratados........................................................ 16

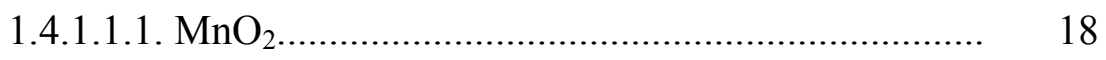

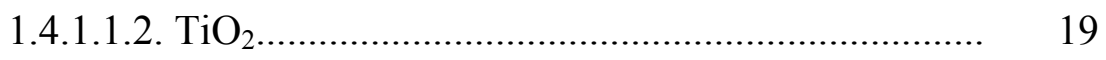

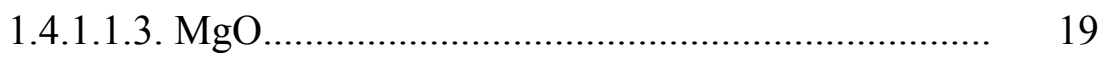

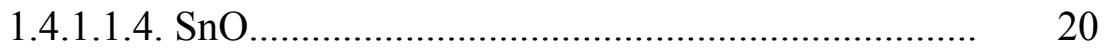

1.4.1.2. Hidrotalcita................................................................ 21

1.4.1.3. Carbón activado................................................................ 23 


\section{CAPÍTULO II}

\section{PARTE EXPERIMENTAL}

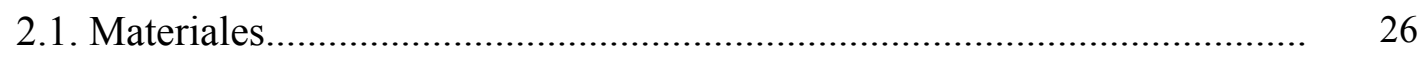

2.1.1. Reactivos y materiales.................................................................. 26

2.2. Caracterización de los materiales.............................................................. 27

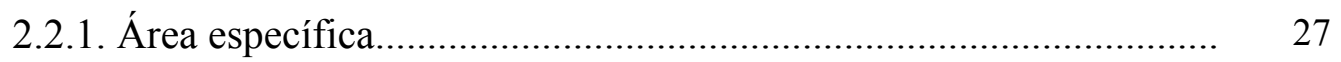

2.2.2. Análisis termogravimétrico......................................................... 28

2.2.3. Análisis por difracción de rayos X.............................................. 28

2.2.4. Análisis por microscopía electrónica de barrido.............................. 28

2.3. Preparación del ${ }^{60} \mathrm{Co} y$ de los productos de fisión del ${ }^{235} \mathrm{U}$.......................... 29

2.4. Identificación nuclear del ${ }^{60} \mathrm{Co}$ y de los productos de fisión del ${ }^{235} \mathrm{U}$......... $\quad 30$

2.5. Estimación de las especies químicas de ${ }^{60} \mathrm{Co}$ y de los productos de fisión $\mathrm{del}^{235} \mathrm{U}$ en solución acuosa por electroforesis............................................. 35

2.6. Experimentos de sorción........................................................................ 36

2.6.1. Sorción del ${ }^{60} \mathrm{Co}$ y de los productos de fisión del ${ }^{235} \mathrm{U}$ en solución acuosa en materiales inorgánicos a diferentes valores $\mathrm{pH}$............... $\quad 36$

2.7. Estudio cinético sobre la sorción de ${ }^{60} \mathrm{Co}$ en dióxido de manganeso

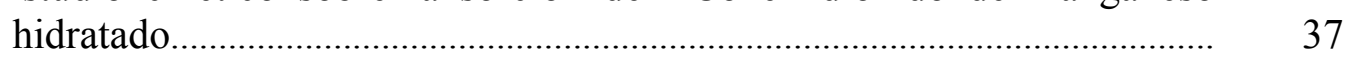

2.7.1. Efecto de la concentración................................................................ 37

2.7.2. Efecto de la temperatura................................................................ 37

2.7.3. Estudio de desorción....................................................................... 38

\section{CAPÍTULO III}

3. RESULTADOS Y DISCUSIÓN ……………………………………………..... 39

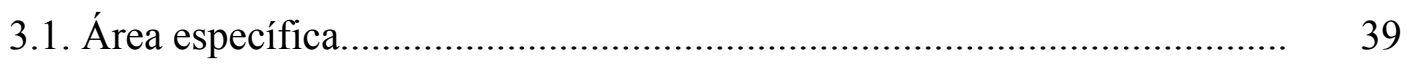


3.2. Radioisótopos obtenidos.

3.3. Especiación del ${ }^{60} \mathrm{Co},{ }^{132} \mathrm{Te},{ }^{95} \mathrm{Zr},{ }^{99} \mathrm{Mo} \mathrm{y}{ }^{103} \mathrm{Ru}$ en solución acuosa por electroforesis.

3.4. Sorción de ${ }^{60} \mathrm{Co} y$ de los productos de fisión del ${ }^{235} \mathrm{U}$ en materiales inorgánicos...

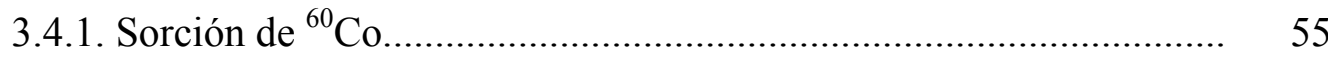

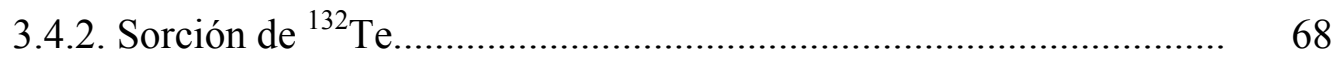

3.4.3. Sorción de ${ }^{95} \mathrm{Zr}$..................................................................... 73

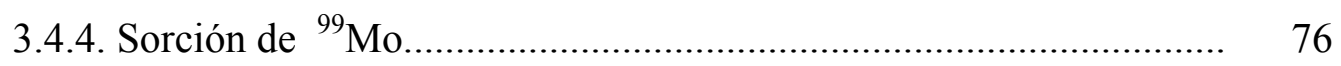

3.4.5. Sorción de ${ }^{103} \mathrm{Ru}$................................................................. 79

3.5. Cinética de sorción del ${ }^{60} \mathrm{Co}$ sobre dióxido de manganeso hidratado........ 83

3.5.1. Efecto de la concentración........................................................... 83

3.5.2. Efecto de la temperatura........................................................... 87

3.5.3. Estudio de desorción................................................................... 95

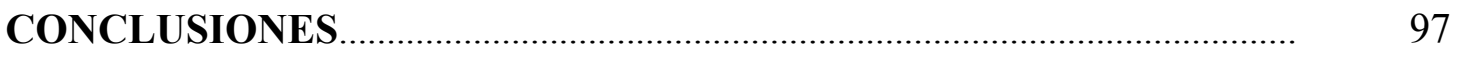

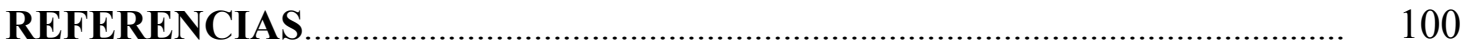




\section{Glosario de símbolos y abreviaciones}

\begin{tabular}{|c|c|}
\hline$e V$ & electrón volt \\
\hline keV & Kiloelectrón volt \\
\hline $\mathrm{TiO}_{2}$ & Dióxido de titanio \\
\hline $\mathrm{MnO}_{2}$ & Dióxido de manganeso \\
\hline $\mathrm{MgO}$ & Dióxido de magnesio \\
\hline $\mathrm{SnO}$ & Óxido de estaño \\
\hline$z p c$ & Punto de carga cero \\
\hline$Z$ & Número atómico \\
\hline $\boldsymbol{A}$ & Masa atómica \\
\hline $\mathrm{MOxH}_{2} \mathrm{O}$ & Óxido hidratado \\
\hline$M$ & Concentración molar \\
\hline$(n, \gamma)$ & Reacción n, gamma \\
\hline$V_{p}$ & Volumen total de poros \\
\hline$S_{B E T}$ & Área específica BET \\
\hline$B E T$ & Método Brunauer-Emmett-Teller \\
\hline$M E B$ & Microscopía electrónica de Barrido \\
\hline$D R X$ & Difracción de rayos $X$ \\
\hline$I R$ & Infrarrojo \\
\hline$T G A$ & Análisis termogravimétrico \\
\hline$r_{p}$ & Radio de poro \\
\hline pH & Potencial de hidrógeno \\
\hline$p H_{i}$ & Valor de pH inicial \\
\hline$p H_{f}$ & Valor de $p H$ final \\
\hline MEDUSA & $\begin{array}{l}\text { Siglas en inglés del programa Make Equilibrium Diagrams } \\
\text { Using Sophisticated Algrithms }\end{array}$ \\
\hline $\boldsymbol{R P M}$ & Revoluciones por minuto \\
\hline
\end{tabular}




\begin{tabular}{|c|c|}
\hline $\boldsymbol{K}$ & Grado Kelvin \\
\hline$\mu m$ & Micrómetros \\
\hline Ae & Cantidad de especies químicas sorbidas en el equilibrio \\
\hline$C e$ & Concentración de solución radiactiva \\
\hline$I / n$ & Constante de Freundlich, intensidad de sorción \\
\hline $\boldsymbol{k}$ & Capacidad máxima de sorción \\
\hline$r^{2}$ & Valor de correlación \\
\hline$A_{t}$ & Cantidad sorbida en el equilibrio al tiempo $t$ \\
\hline $\boldsymbol{k}_{1}$ & Constante de velocidad para la sorción \\
\hline $\boldsymbol{E}_{\boldsymbol{a}}$ & Energía de activación \\
\hline $\boldsymbol{R}$ & Constante de los gases $(8.314 \mathrm{~J} / \mathrm{K} \mathrm{mol})$ \\
\hline$T$ & Temperatura absoluta \\
\hline$e$ & Base de la escala de logaritmos naturales \\
\hline$A$ & Frecuencia de colisiones \\
\hline $\boldsymbol{K}_{\boldsymbol{d}}$ & Coeficiente de distribución \\
\hline $\boldsymbol{H}^{0}$ & Entalpía para el proceso de sorción \\
\hline$G^{0}$ & Energía libre de Gibbs \\
\hline$A_{b}$ & Actividad relativa en solución después de la sorción \\
\hline$A_{a}$ & Actividad relativa en solución antes de la sorción \\
\hline$C$ & Concentración inicial de la solución radiactiva \\
\hline$A_{i}$ & Actividad especifica de solución radiactiva al tiempo i \\
\hline$A_{o}$ & Actividad especifica de solución radiactiva al tiempo cero \\
\hline$A_{1}$ & Actividad relativa en solución antes de la sorción \\
\hline$A_{2}$ & Actividad relativa en solución después de la sorción \\
\hline$A_{t}$ & Actividad especifica de solución radiactiva al tiempo t \\
\hline$M$ & Masa del sorbente \\
\hline $\boldsymbol{V}$ & Volumen de solución \\
\hline$\Delta G^{0}$ & Cambio de energía libre de Gibbs \\
\hline$\Delta S^{o}$ & Cambio de entropía del proceso de sorción \\
\hline
\end{tabular}


JCPDS "Joint Comitte on Powder Difraction Standards"

TGA Análisis termogravimétrico 


\section{INTRODUCCIÓN}

Los desechos radiactivos líquidos plantean graves problemas en los tratamientos de descontaminación, por el gran volumen que ocupan y por su variada composición química. La fisión nuclear del ${ }^{235} \mathrm{U}$ produce un gran número de productos radiactivos que en ocasiones han contaminado el refrigerante, y/o agua de los reactores nucleares de fisión. Debido a lo anterior se emplean diferentes tratamientos para concentrar los isótopos radiactivos presentes en agua contaminada.

La descarga de materiales radiactivos en solución acuosa al ambiente, es un problema actual que puede resolverse por sorción en materiales sólidos. La selección del sólido inorgánico en particular, está gobernada principalmente por su capacidad y selectividad para remover ciertas especies de un desecho líquido. En la literatura especializada se conocen numerosos compuestos con buenas propiedades de sorción (aluminosilicatos, óxidos hidratados, ferrocianuros metálicos, etc), (Hernández y Granados, 1999; Tranter et al., 2002; Shahwan y Erten, 2002; Abou-Mesalam, 2002; López y Canoba 2002; Raje y Swain, 2002; Kim et al., 2002; Vaseley y Pekárek, 1972; Loos-Neskovic y Fedoroff, 1989; Aly y El-Naggar, 1998; Dyer y Aggarwal, 1995; Clark et. al., 1980; Yllera de Llano et al., 1998; Mondino et al., 2002; Atun y Bodur, 2002). Hasta ahora la mayoría de las publicaciones tratan de la sorción de productos radiactivos catiónicos y sus mezclas como productos de fisión del ${ }^{235} \mathrm{U}$ (Mishra y Tiwary, 1995) o de desechos radioquímicos acuosos. Sin embargo hay pocos resultados referentes a la sorción de aniones en sólidos (Serrano et al., 2002; Bayri et al, 2001; Bhutani et al., 1992; Mishra et al., 1991; Fetter et al., 1997). 
Los materiales inorgánicos que se han utilizado para la retención de impurezas presentes en el agua, son: $\mathrm{MnO}_{2}$ (Murray, 1974; Fukuda et al., 1998; Serrano y Granados, 2002), $\mathrm{TiO}_{2}$ (Hayden y Lu, 1996; Jakobsson y Albinsson, 1998; Bhutani y Kumari, 1994; Miyake et al., 1994; Samanta, 1996), SnO (Donaldson y Fuller, 1968), la hidrotalcita (Chátelet et al., 1996; Hermosín et al., 1996) y el carbón activado (Ganzerli et al., 2002; Saleem et al., 1993; Flores et al.,1998). Estos sólidos también son útiles para las separaciones radioquímicas (Guiin et al., 2002; Aslani et al., 2001; Bernard, 1994; Choppin y Nash, 1995; Olguín et al., 1996; Dyer y Kadhim, 1989; Rajec et al., 1996), ya que son altamente selectivos, resistentes a los procesos químicos, a los cambios de temperatura y a la radiación, y presentan propiedades más convenientes que los sorbentes orgánicos comerciales o naturales, puesto que estos últimos se descomponen con la radiación.

Los materiales inorgánicos $\mathrm{MnO}_{2}, \mathrm{TiO}_{2}, \mathrm{MgO}$ y $\mathrm{SnO}$ estudiados en este trabajo, se describen como óxidos hidratados, que son óxidos metálicos polivalentes que poseen un número indefinido de moléculas de agua en su estructura, son generalmente insolubles en agua y poseen propiedades de intercambio iónico debido a la presencia de grupos hidroxilo en su superficie (Samanta, 1996). La mayoría de estos sorbentes, bajo diferentes condiciones físicas y bajo condiciones especiales pueden comportarse tanto como intercambiadores aniónicos y como catiónicos (Mishra y Tiwary, 1995). El ${ }^{60} \mathrm{Co}$ es un componente común de los desechos radiactivos líquidos que se producen en los procesos nucleares (Carrera et al., 1993). Debido a su amplia aplicación en el campo de la medicina nuclear, por su vida media radiactiva de 5.3 años y por su energía gamma, es importante retenerlo y separarlo del agua de desechos radiactivos (Hernández y Granados, 1999). Olguín et al., (1996), estudiaron el comportamiento de sorción de algunos productos de fisión del ${ }^{235} \mathrm{U}$ a nivel traza $\left(\sim 10^{-11} \mathrm{mg} / \mathrm{L}\right)$ presentes en solución acuosa sobre los siguientes sólidos inorgánicos: zeolita $\mathrm{Y}$, erionita y bentonita. Ellos encontraron que la sorción de los productos de fisión en estos aluminosilicatos se lleva acabo por diferentes mecanismos, principalmente por intercambio iónico, precipitación e 
interacción electrostática. En una investigación realizada por Serrano et al., (2000) se encontró que el ${ }^{99} \mathrm{Mo}$ a nivel traza presente en solución acuosa, es capturado eficientemente por la hidrotalcita calcinada, material que retiene principalmente aniones.

Para el estudio de esta tesis se escogieron: el ${ }^{60} \mathrm{Co}$ radiactivo producido por la reacción nuclear ${ }^{59} \mathrm{Co}(\mathrm{n}, \gamma){ }^{60} \mathrm{Co}$ de vida media de 5.3 años y los productos de fisión del ${ }^{235} \mathrm{U}$ con vidas medias comprendidas entre 3 y 65 días, que nos permiten realizar adecuadamente el estudio. El propósito de este trabajo se centra en cuatro temas, primero, estudiar el comportamiento de sorción del ${ }^{60} \mathrm{Co}$ y de los siguientes productos de fisión del ${ }^{235} \mathrm{U}:{ }^{132} \mathrm{Te},{ }^{95} \mathrm{Zr}$, ${ }^{99} \mathrm{Mo} \mathrm{y}{ }^{103} \mathrm{Ru}$ en varios materiales inorgánicos, como una función del pH de las soluciones; segundo, determinar las especies químicas presentes a los diferentes valores de $\mathrm{pH}$ estudiados; tercero, explicar la sorción de los elementos en los sólidos en función de las diferentes especies formadas a diferentes valores de $\mathrm{pH}$ y cuarto, realizar un estudio cinético de uno de estos radioisótopos, en uno de los sólidos seleccionados. Para este estudio cinético se escogió el ${ }^{60} \mathrm{Co}$ porque se pudo obtener como un radioisótopo único en solución, mientras que los productos de fisión del ${ }^{235} \mathrm{U}$ se obtienen mezclados. Así mismo, para el estudio cinético, se escogió como sorbente el $\mathrm{MnO}_{2}$ que ha sido estudiado y se ha probado como sorbente de radioisótopos en la forma de cationes o aniones (Kim, 2003; Fukuda, et al., 1998; Mishra y Tiwary, 1998). Como los óxidos metálicos hidratados presentan diferente punto de carga cero (zpc), que es un parámetro que influye sobre la sorción de especies químicas sobre una superficie, en este estudio se ha seleccionado al $\mathrm{MnO}_{2}$ por tener un valor medio de punto de carga cero, $\mathrm{zpc}=4.5$, valor reportado por Parks, (1965), esta característica nos permite realizar estudios sobre el comportamiento de sorción de iones sobre un amplio intervalo de $\mathrm{pH}$, además de que nos permite realizar una intercomparación entre los diferentes radioisótopos. Otra ventaja de este material es que es insoluble en agua, resistente a las radiaciones y a los cambios químicos (Jakobsson et al., 1998). 
El trabajo realizado, en el marco de esta investigación, está estructurado de la siguiente manera:

En el capítulo I se presenta la forma de producción del ${ }^{60} \mathrm{Co}$ y el proceso de la fisión nuclear del ${ }^{235} \mathrm{U}$.

También en el capítulo I, se describen los procesos de sorción que se presentan en sólidos inorgánicos, y así mismo las propiedades y características de los materiales sorbentes que se utilizaron en este trabajo.

En el capítulo II se presenta la metodología empleada para la caracterización de los materiales empleados como sorbentes y de la sorción en experimentos por lotes (batch, en inglés), tanto del ${ }^{60} \mathrm{Co}$ como trazas de los productos de fisión del ${ }^{235} \mathrm{U}:{ }^{132} \mathrm{Te}$, ${ }^{95} \mathrm{Zr},{ }^{99} \mathrm{Mo} \mathrm{y}{ }^{103} \mathrm{Ru}$, presentes en solución acuosa a diferentes valores de $\mathrm{pH}(1,3,5,7 \mathrm{y}$ 10), en los sólidos inorgánicos siguientes: carbón activado, hidrotalcita calcinada, $\mathrm{TiO}_{2}$, $\mathrm{MnO}_{2}, \mathrm{MgO}$ y $\mathrm{SnO}$. En este capítulo se presenta, además, la metodología empleada para el estudio de las especies aniónicas, neutras y catiónicas formadas en solución acuosa del ${ }^{60} \mathrm{Co}$ y de los productos de fisión del ${ }^{235} \mathrm{U}$ estudiados, por medio de la electroforesis de alto voltaje. Por último, se describe la técnica empleada para la estimación cuantitativa de las especies químicas del ${ }^{60} \mathrm{Co} y$ de los productos de fisión del ${ }^{235} \mathrm{U}$, retenidas en los sólidos inorgánicos. En este mismo capítulo se presenta además el comportamiento cinético de sorción del ${ }^{60} \mathrm{Co}$ sobre el dióxido de manganeso hidratado.

En el capítulo III se presentan y discuten los resultados de la caracterización de los sorbentes y de los valores de sorción del ${ }^{60} \mathrm{Co} y$ de los productos de fisión del ${ }^{235} \mathrm{U}$ en los sólidos inorgánicos estudiados a diferentes valores de $\mathrm{pH}$. Se presentan las curvas de sorción obtenidas para cada caso. Además se presentan las especies químicas encontradas para cada radioisótopo estudiado a diferentes valores de $\mathrm{pH}$. Así mismo se presenta el estudio cinético de la sorción de ${ }^{60} \mathrm{Co}$ en el dióxido de manganeso hidratado. 
Finalmente en este mismo capítulo se describen y discuten los resultados de la sorción de las diferentes especies químicas del ${ }^{60} \mathrm{Co}$ y de los productos de fisión del ${ }^{235} \mathrm{U}$ en los sólidos inorgánicos.

El último capítulo de la tesis contiene las conclusiones de esta investigación. 


\section{CAPítULO I}

\section{GENERALIDADES}

\subsection{Reacción nuclear $(\mathbf{n}, \gamma)$.}

El análisis por activación neutrónica, se basa en hacer radiactivos, a ciertos elementos constituyentes de una muestra, por medio de su exposición a un flujo de neutrones térmicos y en determinar la radiactividad de esos elementos (Travesi, 1975). Los neutrones térmicos, cuya energía cinética es menor que $1 \mathrm{eV}$, inducen a varias reacciones nucleares del tipo $(n, \gamma)$. Por ejemplo el ${ }^{60} \mathrm{Co}$ se produce por la reacción nuclear:

\footnotetext{
${ }^{59} \mathrm{Co}(\mathrm{n}, \gamma){ }^{60} \mathrm{Co}$
} 
La excitación del núcleo compuesto que se forma por la captura de un neutrón del ${ }^{59} \mathrm{Co}$, hace que éste tenga un exceso de energía el cual libera por la emisión de radiación gamma inmediata. Las energías del ${ }^{60} \mathrm{Co}$ producido de $1.17 \mathrm{MeV}$ y $1.33 \mathrm{MeV}$ fueron las que se midieron para determinar al Co.

La Comisión Internacional de Protección Radiológica establece los límites de la máxima concentración permisible de ${ }^{60} \mathrm{Co}$ tanto en el agua y en el aire, como $3 \times 10^{-9} \mathrm{y}$ $3 \times 10^{-4} \mu \mathrm{Ci} / \mathrm{cm}^{3}$ respectivamente, de aquí el interés de eliminar este elemento de aguas contaminadas con este radioisótopo, debido principalmente a su larga vida media de 5.3 años. 


\subsection{La fisión nuclear del ${ }^{235} \mathrm{U}$.}

\subsubsection{La fisión nuclear.}

La fisión nuclear es la fragmentación de núcleos pesados $(\mathrm{A}>230, \mathrm{~A}=$ número másico) que se descomponen en otros más ligeros, desprendiendo una gran cantidad de energía ( $200 \mathrm{MeV}$ por fisión). Los núcleos pesados fisionables, cuyos números de masas (A) son de aproximadamente 240 , tienen energías de enlace de aproximadamente 7.6 MeV/nucleón mientras que aquellos con números de masa de 120 tienen energías de enlace de $8.5 \mathrm{MeV} /$ nucleón. Por lo tanto, al fisionarse los núcleos pesados, se liberan alrededor de $0.9 \mathrm{MeV} /$ nucleón durante la fisión (Figura 1). La mayor parte se transforma en energía cinética de los fragmentos de fisión y de los neutrones. A los rayos beta y gamma y a los neutrinos emitidos, les corresponde cuando mucho el $15 \%$ de la energía total. Estas cantidades son enormes comparadas con las reacciones químicas, por ejemplo en el caso de la combustión del carbón y del petróleo, se liberan unos pocos eV/átomo. La captura de un neutrón térmico por el ${ }^{235} \mathrm{U}$, da lugar a un núcleo compuesto que al desexcitarse, se rompe, generalmente en dos núcleos más pequeños. A estos núcleos se les llaman productos de fisión, en su mayoría son radiactivos y en la mayoría de los casos decaen por emisión $\beta$ (Halliday, 1950; Navarrete y Cabrera, 1979). 


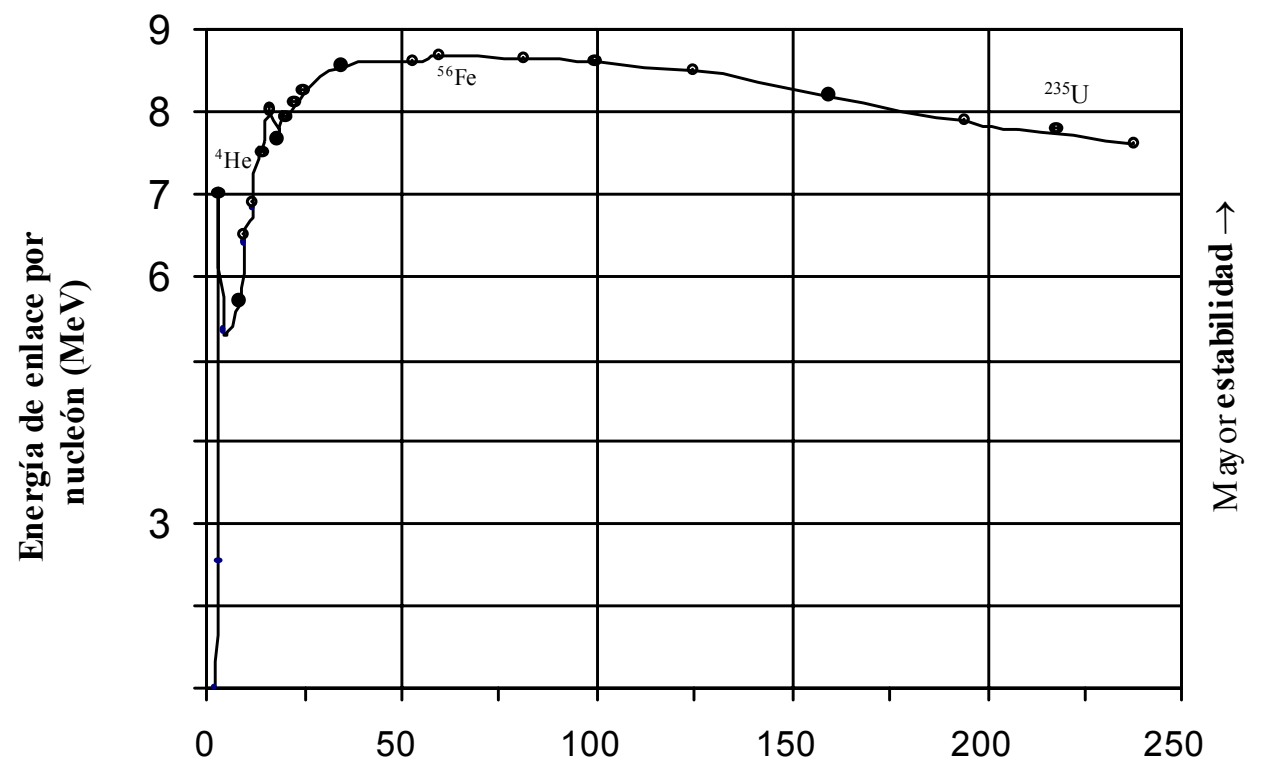

Número de masa

Fig. 1. Energía de enlace promedio por partícula para núclidos de varios números de masa.

\subsubsection{Productos de fisión nuclear $\operatorname{del}^{235} \mathrm{U}$.}

Al irradiar el uranio con neutrones se lleva a cabo la reacción nuclear:

$$
{ }^{235} \mathrm{U}_{92}+{ }^{1} \mathrm{n}_{\mathrm{o}} \rightarrow \text { productos de fisión }+{ }^{1} \mathrm{n}_{\mathrm{o}}
$$


En la reacción de fisión nuclear del ${ }^{235} \mathrm{U}$, se han encontrado más de 30 elementos distintos en los productos de la fisión, tal como se muestra en la Figura 2, donde se observan los porcentajes de rendimiento de los productos de fisión como una función de la masa atómica (A). En general la fisión nuclear es asimétrica y hay una probabilidad muy pequeña de que se formen fragmentos iguales. La proporción entre el número de fisiones que conducen a un radioisótopo y el número total de fisiones producidas, se conoce como rendimiento de fisión de un radionúclido determinado. Como se muestra en la Figura 2, la curva es asimétrica alrededor del mínimo $(A=233.5 / 2)$ y tiene dos máximos que son bastante anchos alrededor de los números de masa 95 a 138 (Halliday, 1950).

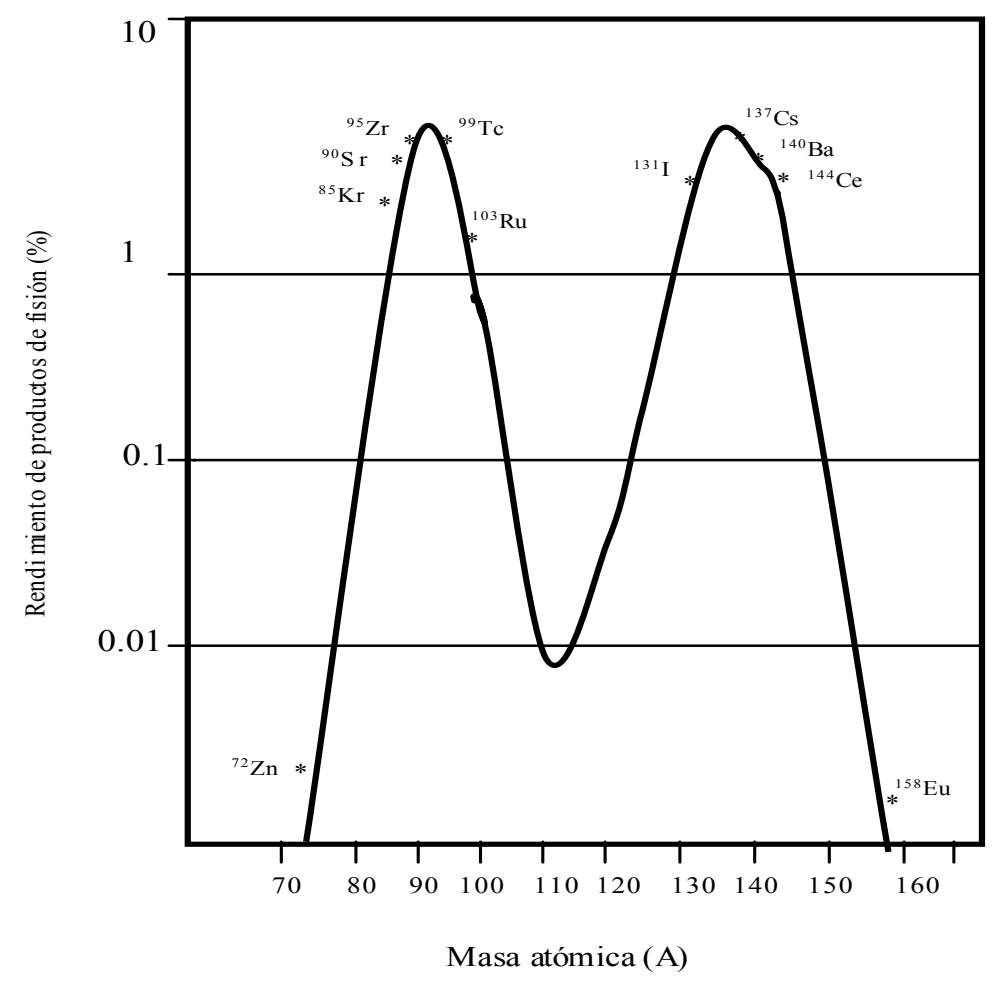

Fig. 2. Rendimiento de los productos de fisión del ${ }^{235} U$. 
Entre los productos de fisión del ${ }^{235} \mathrm{U}$ de vidas medias radiactivas entre 2.7 días y 64 días se encuentran los siguientes: ${ }^{132} \mathrm{Te},{ }^{95} \mathrm{Zr}$, ${ }^{99} \mathrm{Mo} \mathrm{y}{ }^{103} \mathrm{Ru}$. Estos son los que se estudiaron en el presente trabajo y se han escogido por tener una vida media adecuada que permite producirlos a través de cortos tiempos de irradiación con neutrones, y producirse en cantidades suficientes para medirlos (Lederer et al., 1983).

\subsection{Procesos de sorción.}

El término sorción incluye la absorción y la adsorción, conjuntamente, y es una expresión general para un proceso en el cual el componente se mueve desde una fase para acumularse en otra. Por adsorción se entiende procesos de adhesión de una sustancia sobre la superficie de sólidos sorbentes, mientras que la absorción es la penetración de las sustancias dentro de los sólidos absorbentes. Cuando ocurren simultáneamente los dos procesos se llama al fenómeno sorción, el proceso inverso de la sorción se le conoce como desorción. El intercambio iónico también lo consideramos en este trabajo, como parte del proceso de sorción (Slejko, 1985; Droguett, 1983).

La sustancia que se mueve desde una fase para acumularse en otra se denomina sorbato y el material sobre el que lo hace es el sorbente. Durante la sorción de un gas o un soluto en solución, sus partículas se acumulan sobre la superficie del material como un resultado de las fuerzas de enlace entre los átomos, iones o moléculas del sorbato y la superficie del sorbente.

En general se identifican tres principales tipos de sorción: la sorción física, o fisisorción, la sorción química, o quimisorción y el intercambio iónico. La diferencia entre la sorción física y la química radica en el tipo y la magnitud de la interacción entre el sorbente y el sorbato. A continuación se describen cada uno de los procesos de sorción. 


\section{I.3.1. Fisisorción.}

La sorción física o fisisorción, es una interacción débil que ocurre cuando un sorbato entra en contacto con la superficie de un sólido (el sorbente) (Sing y Tandon, 1977). Estas interacciones son similares a las fuerzas de van der Waals). Estas interacciones incluyen todas las fuerzas interactivas y repulsivas que no se puedan describir como enlaces, tales como las fuerzas electrostáticas.

\section{I.3.2. Quimisorción.}

La sorción química o quimisorción involucra una reacción entre un sorbato y un sorbente resultando un cambio en la forma química del sorbato. El enlace resultante de la quimisorción es más fuerte que el formado por las fuerzas de van der Waals de la fisisorción. En la sorción química las interacciones se llevan a cabo por medio de enlaces químicos. Esto da lugar a entalpías de sorción muy diferentes: alrededor de -20 $\mathrm{kJ} / \mathrm{mol}$ para la fisisorción y cerca de $-200 \mathrm{~kJ} / \mathrm{mol}$ para la quimisorción (Atkins, 1994).

La formación de enlaces durante la sorción química hace que el proceso sea más selectivo, es decir que depende marcadamente de la naturaleza de las sustancias involucradas.

La eficiencia de los procesos de sorción, depende de las características del sorbente (área específica, estructura y tamaño de partícula, entre otras) y de las propiedades de las especies químicas en solución (cationes y aniones, tamaño y carga eléctrica), además del tipo de mecanismo de sorción que pueda ocurrir entre las fases, las condiciones del proceso ( $\mathrm{pH}$, temperatura, concentración) y las fuerzas que controlan el proceso (van der Waals, electrostáticas, enlaces químicos) (Reynolds, 1982). En la mayoría de los procesos de sorción se ha observado una disminución de calor de sorción 
(entalpía) con el recubrimiento de la superficie del sorbente, ello indica la existencia de sitios activos con distinta fuerza atractiva; los más intensos se cubren inicialmente y generan el máximo calor de sorción. En los sitios restantes la atracción disminuye gradualmente y por lo tanto la energía desprendida como calor, se reduce con el progreso de la sorción, por lo que se dice que las reacciones de sorción son generalmente exotérmicas, sin embargo existen varios parámetros que pueden modificar la entalpia de sorción, como son la temperatura del sistema, el grado de recubrimiento del sistema, etc. Por lo tanto, es posible obtener distintos valores de entalpía de los procesos de sorción, según las condiciones experimentales usadas (Droguett, 1983).

La concentración del sorbato, define la distribución del soluto entre las fases líquida y sólida, y además establece el equilibrio dinámico en la superficie, entre la concentración del soluto que permanece en solución y la concentración superficial del soluto. El área específica, influye sobre la capacidad de sorción del sorbente, debido a que le confiere al material, una gran cantidad de sitios activos en su superficie, que están disponibles para los sorbatos, $\mathrm{El} \mathrm{pH}$ influye considerablemente en la sorción ya que gobierna la formación de especies químicas.

La cantidad de material sorbido en un sistema depende de la temperatura y la concentración del sorbato. Si la temperatura se mantiene constante durante el experimento, el grado de sorción puede estudiarse como una función de la concentración y generar así lo que se conoce como isoterma de sorción.

En el laboratorio se puede estudiar el fenómeno de sorción con relativa facilidad. Para ello se han desarrollado métodos diversos entre los que se encuentran los métodos de flujo, la sorción por lotes, y los métodos con trazadores radiactivos (Atkins, 1994).

Una de las técnicas más sencillas para analizar el grado de sorción de un material sobre un sorbente consiste en trabajar con disoluciones del sorbato a diferentes concentraciones, que comúnmente se les conoce como experimentos por lotes. El 
problema se reduce entonces a comparar la concentración del soluto antes y después de llegar al equilibrio con el sorbente.

\subsubsection{Intercambio iónico.}

En el proceso de intercambio iónico hay una reacción química entre los iones de una fase líquida y los iones de una fase sólida. El intercambio iónico es considerado como un proceso de sorción, ya que ocurre entre los iones mantenidos en la superficie del sólido por fuerzas electrostáticas, que se intercambian por otros iones de carga similar, desde una solución en la cual el sólido está inmerso; o sea hay una transferencia de iones, desde una fase en solución a una fase superficial donde quedan adheridos.

En la superficie del sólido pueden existir iones que atraen a iones de carga opuesta. La retención es relativamente débil por lo que estos iones adheridos pueden ser reemplazados o intercambiados por otros iones del mismo signo presentes en el agua (Custodio y Llamas, 1983). Este fenómeno de intercambio es una reacción química reversible, donde las cantidades intercambiadas en la fracción sólida y en la solución, son químicamente equivalentes.

Entre las sustancias que presentan capacidad de intercambio iónico se encuentran las arcillas, algunos óxidos e hidróxidos inorgánicos, sustancias orgánicas (ácidos húmicos) y las zeolitas (Kooli et al., 1997; Rey et al., 1992; Kim et al., 2002, Tranten et al., 2002). 


\subsection{Sólidos inorgánicos.}

\subsubsection{Materiales sorbentes.}

Por muchos años se han utilizado resinas orgánicas para atrapar iones metálicos de soluciones, sin embargo las resinas son térmicamente inestables y se degradan fácilmente por efecto de las radiaciones, agentes oxidantes y $\mathrm{pH}$; tal comportamiento las hace incompatibles para la sorción de materiales radiactivos (Reynolds, 1982). Se ha demostrado que los sólidos inorgánicos poseen estructuras porosas, y cierta selectividad, lo que favorece la sorción de iones.

Los materiales inorgánicos estudiados, principalmente por sus propiedades de sorción, se han dividido en este trabajo en los siguientes grupos:

1.- Óxidos hidratados: $\mathrm{MnO}_{2}, \mathrm{TiO}_{2}, \mathrm{MgO}$ y $\mathrm{SnO}$.

2.- Hidrotalcita calcinada.

3.- Carbón activado.

Se han estudiado las propiedades de sorción, de una diversidad de sólidos inorgánicos (Akay, 1998; Hyun et al., 2001; Khalid et al., 1998; Moosa et al., 1998; Bayri et al., 2001; El-Said et al., 2001) algunos más extensamente que otros, pero con particular interés en sus mecanismos de sorción para su aplicación en procesos químicos de materiales radiactivos y en procesos de desmineralización del agua. A continuación se mencionan algunos de estos sólidos inorgánicos que tienen la característica de que debido a su alta estabilidad a los agentes químicos y a la radiación son materiales apropiados para la sorción de radioisótopos. Estos sólidos han sido utilizados para la sorción de plutonio y ciertos productos de fisión en medios alcalinos o de soluciones altamente radiactivas (Bhután y Kumari, 1994; Miyake et al., 1994; Samanta, 1996). 


\subsubsection{1. Óxidos hidratados.}

Una importante clase de sólidos inorgánicos con buenas propiedades de sorción, son los óxidos hidratados $\left(\mathrm{MO} \cdot \mathrm{xH}_{2} \mathrm{O}\right.$, donde $\mathrm{M}$ representa el metal central); estos materiales son óxidos metálicos polivalentes que en general no poseen un número definido de moléculas de agua; después de secarse a baja temperatura retienen de 5 a $50 \%$ en peso de agua, son generalmente insolubles en agua y poseen propiedades de intercambio iónico debido a la presencia de grupos hidroxilo en su superficie (Samanta, 1996). Estos materiales se secan por medio de un tratamiento térmico y entonces adquieren dureza, gran área específica y acción catalítica. Si se calientan a altas temperaturas, pueden convertirse en óxidos más cristalinos. Al sumergir a estos óxidos en soluciones acuosas adquieren grupos hidroxilos al hidratarse. Además el agua penetra en el espacio entre sus capas. Los grupos hidroxilos y las moléculas de agua no están en una proporción estequiométrica con el metal y su contenido puede cambiar espontáneamente o bajo la influencia de condiciones externas.

Los óxidos hidratados se usan potencialmente como sorbentes (Vaselý y Pekárek, 1972): en separaciones y purificaciones químicas, en particular de materiales radiactivos, en catálisis a altas temperaturas y en tratamientos de agua. Por supuesto, un uso racional de los óxidos hidratados necesita un buen conocimiento de sus propiedades generales y en particular, de sus propiedades de sorción. Los óxidos hidratados presentan una estructura de uniones del metal central con grupos $\mathrm{OH}$. Estos materiales muestran propiedades de intercambio iónico y dependiendo del $\mathrm{pH}$, actúan como intercambiadores aniónicos (a pH bajos) o como intercambiadores catiónicos (a altos valores de $\mathrm{pH}$ ). El intercambio aniónico toma lugar por dos diferentes formas:

1) En condiciones ácidas de las soluciones el grupo hidroxilo unido al metal del óxido $\mathrm{MOH}$ toma un ion hidrógeno del medio y se forma el grupo $\mathrm{MOH}_{2}^{+}$(ecuación 1), al mismo tiempo una cantidad equivalente de aniones son unidos como contraiones. A 
modo de simplificar, estos iones podrían ser considerados monovalentes $A^{-}$pero esto es aplicable para un caso general donde existan más cargas como $A^{n-}$. Entonces el intercambio con otro anión $B$, procede de acuerdo a la ecuación 2.

$$
\begin{aligned}
& \mathrm{MOH}+\mathrm{H}^{+} \rightarrow \mathrm{MOH}_{2}^{+} \\
& \mathrm{MOH}_{2} \mathrm{~A} \leftrightarrows \mathrm{MOH}_{2} \mathrm{~B}+\mathrm{A}^{-}
\end{aligned}
$$

2) El intercambio aniónico también puede tomar lugar por la sustitución directa del grupo $O H$ con el anión $B^{-}$, procediendo de acuerdo a la siguiente reacción:

$$
\mathrm{MOH}+\mathrm{B}^{-}+\mathrm{H}^{+} \leftrightarrows \mathrm{MB}+\mathrm{H}_{2} \mathrm{O}
$$

A altos valores de $\mathrm{pH}$, toma lugar el intercambio aniónico, la reacción podría ser para el caso simple de un catión monovalente como se muestra a continuación:

$$
\mathrm{MOH}+\mathrm{M}_{e}^{+} \leftrightarrows \mathrm{MOM}_{e}+H^{+}
$$

La mecanismo anterior depende de la basicidad electrónica del grupo $\mathrm{MO}^{-}$en donde su fuerza permite la disponibilidad de intercambiar el catión $\mathrm{Me}^{+}$por el $\mathrm{H}^{+}$.

En los procesos de sorción de contaminantes en medio acuoso, los óxidos, al sorber ciertos iones, desplazan un número equivalente de iones de la misma carga, por ello frecuentemente se les llama intercambiadores iónicos inorgánicos, de cationes en medio alcalino y aniones en medio ácido. La transición de la naturaleza aniónica a la catiónica, está entonces asociada con el pH de la solución y depende de la naturaleza del ión metálico central (ejemplo carga iónica, radio iónico) y de las fuerzas de enlace entre metal-oxígeno y oxígeno-hidrógeno de los grupos hidroxilos unidos a la superficie 
(Samanta, 1996). Cuando esta transición no está bien definida, entonces, ambos intercambios catiónico y aniónico, pueden ocurrir simultáneamente.

Parks (1965) definió el punto de carga cero (zpc), por sus siglas en inglés, para los óxidos metálicos, como el pH al cual la carga superficial neta sobre la superficie del óxido en una solución acuosa es cero. La acidez relativa y las propiedades básicas de la superficie del óxido están determinadas por el zpc, y están en función de variables como el tamaño del catión, del anión y de la valencia.

\subsubsection{1. $\mathrm{MnO}_{2}$.}

El dióxido de manganeso hidratado, se prepara mezclando soluciones de $\mathrm{KMnO}_{4}$ y $\mathrm{MnSO}_{4}$ a $363 \mathrm{~K}$ (Biglioca et al., 1967) o por electrodeposición de una solución de $\mathrm{MnSO}_{4}$ a $373 \mathrm{~K}$ (Kosawa, 1959). Dependiendo del método de preparación, se forman diferentes productos con diferentes estructuras las que pueden ser $\alpha-\beta-, \gamma-\mathrm{MnO}_{2}$. Específicamente el $\alpha-\mathrm{MnO}_{2}$ se ha empleado como sorbente de iones metálicos en solución acuosa y presenta cierta selectividad para cationes de metales alcalinotérreos. Malati et al., (1969) reportan un mecanismo de intercambio iónico para la sorción de iones metálicos sobre el $\mathrm{MnO}_{2 \cdot \mathrm{x}} \mathrm{H}_{2} \mathrm{O}$ y también para $\mathrm{Ag}^{+}, \mathrm{Ba}^{2+}, \mathrm{Ca}^{2+}, \mathrm{Sr}^{2+}, \mathrm{Mg}^{2+}$ y $\mathrm{Nd}^{3+}$ sobre dióxido de manganeso. Por otra parte el $\alpha-\mathrm{MnO}_{2}$ exhibe una alta capacidad de sorción para $\mathrm{NH}_{4}^{+}, \mathrm{Zn}^{2+}$ y para los iones de metales de transición bivalentes (Vaselý y Pekárek, 1972). Momma e Iwashima (1967), reportaron la sorción de especies

radiactivas en solución acuosa de ${ }^{60} \mathrm{Co},{ }^{106} \mathrm{Ru}$ y ${ }^{65} \mathrm{Zn}$ sobre el $\mathrm{MnO}_{2}$ hidratado, otras investigaciones han probado la capacidad de sorción del $\mathrm{MnO}_{2}$ por iones metálicos en solución (Kim et al., 2002; Mishra y Tiwary, 1993; Raje y Swaim, 2002; Fukuda et al., 1998). 


\subsubsection{2. $\mathrm{TiO}_{2}$.}

El dióxido de titanio se prepara mezclando el oxalato de titanio o soluciones de $\mathrm{TiCl}_{4}$ con hidróxido de sodio (Heitner y Albu-Yaron, 1966) los precipitados obtenidos usualmente se calcinan a $673 \mathrm{~K}$, obteniéndose polvos blancos. Los enlaces entre los átomos de titanio y oxígeno muestran cierto carácter iónico, su red cristalina es octaédrica, ya que cada átomo de titanio se encuentra rodeado de seis átomos de oxígeno, dispuestos en los vértices de un octaedro y cada átomo de oxígeno ocupa el centro de un triángulo equilátero formado por tres átomos de titanio (Greenwood y Earnshaw, 1984). El dióxido de titanio comercial funde a $1833 \mathrm{~K}$, es insoluble en agua, resistente a los ácidos e hidróxidos concentrados; se descompone en titanio y $\mathrm{Ti}_{2} \mathrm{O}_{3}$ a elevada temperatura. Tiene carácter anfótero, puesto que forma sales en las que el titanio forma parte en ocasiones del catión y en otras del anión. Su carácter ácido es débil mientras que su carácter básico es fuerte. Mediciones de IR indican la presencia de moléculas de agua unidas al sólido y también de grupos $\mathrm{OH}^{-}$unidos al metal por lo que generalmente se encuentra hidratado (Vivien et al., 1970).

\subsection{MgO.}

El óxido de magnesio se produce por la calcinación del mineral magnesita (hidróxido de magnesio) a altas temperaturas. Un aspecto que influye en la estructura cristalina del óxido de magnesio, durante la calcinación, son las impurezas a nivel traza que pueden provenir del yacimiento del mineral. Comercialmente el óxido de magnesio está disponible como óxido de magnesio hidratado, que es un compuesto alcalino que se produce por calcinación del hidróxido de magnesio carbonatado, $\mathrm{Mg}_{2}(\mathrm{OH})_{2} \mathrm{CO}_{3}$, a temperatura de $1033 \mathrm{~K}$, acompañado de la liberación de $\mathrm{CO}_{2}$. Se caracteriza por tener tamaños de cristales alrededor de $1 \mu \mathrm{m}$ de diámetro y presenta alta reactividad frente a los agentes químicos y tiende a hidratarse rápidamente. El óxido de magnesio presenta además una presión de vapor alta a elevadas temperaturas y se reduce fácilmente al 
metal. Cuando los polvos se ponen en contacto con soluciones acuosas, parte del óxido de magnesio se hidroliza y empieza a formarse una mezcla de $\mathrm{Mg}(\mathrm{OH})_{2}$ y $\mathrm{MgO}$, incrementando el $\mathrm{pH}$ de las soluciones. Este incremento está en función de la cantidad de $\mathrm{MgO}$ en la solución acuosa (Lin et al., 1998). Además la alcalinidad de sus soluciones, puede ser debida a la formación de carbonatos de magnesio por la presencia de $\mathrm{CO}_{2}$ presente en el medio ambiente o disuelto en el agua.

\subsection{SnO.}

El óxido de estaño hidratado se prepara acidificando una solución de estanato de sodio con ácido nítrico en presencia de estaño metálico (Donaldson et al., 1968). El producto formado es un polvo blanco amorfo, insoluble en agua, es inestable frente a soluciones de ácidos ó álcalis muy concentrados. Estudios de difracción de rayos $\mathrm{X}$ (DRX), análisis térmico diferencial (DTA) y espectroscopia Mössbauer, muestran que el $\mathrm{SnO}$ retiene humedad la cual beneficia sus propiedades de intercambio, razón por la cual se formula como $\mathrm{SnO} \cdot \mathrm{xH}_{2} \mathrm{O}$.

El óxido hidratado de estaño presenta propiedades de intercambio tanto catiónicas como aniónicas (Donaldson, 1968). Es especialmente selectivo para metales bivalentes de transición y iones uranilo y su selectividad para cationes bivalentes se ordena en la forma siguiente: $\mathrm{Cu}>\mathrm{Zn}>\mathrm{Co}>\mathrm{Fe}(\mathrm{II})>\mathrm{Ni}>\mathrm{Mn}$ (Donaldson, 1968). Esta selectividad está en función del tamaño efectivo de los iones (de menor a mayor) debido al radio iónico que presentan las especies químicas.

Los cationes de metales alcalinotérreos se sorben débilmente (Donaldson, 1968)

mientras que los iones de metales trivalentes como el $\mathrm{Al}^{3+} \mathrm{y} \mathrm{Cr}^{3+}$ se fijan fuertemente. Estos últimos posiblemente se retienen en los sólidos por coprecipitación con los iones carbonato que pueden producirse con la presencia de $\mathrm{CO}_{2}$ disuelto en la solución acuosa 
o del $\mathrm{CO}_{2}$ gaseoso del ambiente. El óxido de estaño es apropiado para ser utilizado en columna para separar iones metálicos de transición como $(\mathrm{Cu}-\mathrm{Zn}, \mathrm{Cu}-\mathrm{Co}, \mathrm{Cu}-\mathrm{Fe}, \mathrm{Cu}-\mathrm{Ni}$, $\mathrm{Cu}-\mathrm{Mn}, \mathrm{Mn}-\mathrm{Zn}, \mathrm{Mn}-\mathrm{Ca}, \mathrm{Co}^{2+}, \mathrm{Fe}^{3+}$ ) (Kirk, 1992). También se ha logrado las separaciones de W(IV) de soluciones conteniendo Mo(V) y Fe(III) (Donaldson, 1968) y la sorción de $\mathrm{UO}_{2}{ }^{2+}$ en solución acuosa. Además, el óxido de estaño hidratado se usa como intercambiador aniónico en la separación de iones $\mathrm{Cr}_{2} \mathrm{O}_{7}{ }^{2-} \mathrm{y} \mathrm{MnO}_{4}{ }^{-}$.

\subsubsection{Hidrotalcita.}

Las arcillas, dependiendo de sus características en el intercambio iónico se clasifican en catiónicas, que son la mayor parte de las arcillas naturales, y en aniónicas, como la hidrotalcita.

Las hidrotalcitas son arcillas de tamaño coloidal (menores a 2 micrómetros), que presentan áreas específicas grandes. Su estructura es laminar de capas cargadas positivamente; constituyen una clase de minerales complementaria a las arcillas catiónicas bidimensionales (esmectitas) y al igual que ellas, pueden separar sus láminas para acomodar en el espacio interlaminar moléculas de agua o de otras sustancias. Estos compuestos tienen la fórmula mineralógica:

$$
\left[\mathrm{M}_{1-\mathrm{x}}{ }^{2+} \mathrm{M}_{\mathrm{x}}{ }^{3+}(\mathrm{OH})_{2}\right]^{\mathrm{x}+}\left[\mathrm{A}_{\mathrm{x} / \mathrm{m}}{ }^{\mathrm{m}-} \cdot \mathrm{nH}_{2} \mathrm{O}\right]
$$

donde: $\mathrm{M}^{2+}=\mathrm{Mg}^{2+}, \mathrm{Zn}^{2+}, \mathrm{Ni}^{2+} ; \mathrm{M}^{3+}=\mathrm{Al}^{3+}, \mathrm{Fe}^{3+} ; \mathrm{A}^{\mathrm{m}-}=\mathrm{OH}^{-}, \mathrm{CO}_{3}{ }^{2-}, \mathrm{NO}_{3}{ }^{-}, \mathrm{SO}_{4}{ }^{2-}, \mathrm{Cl}^{-} ; \mathrm{X}=$ $\mathrm{M}^{3+} /\left(\mathrm{M}^{2+}+\mathrm{M}^{3+}\right)$ y $0.20 \leq \mathrm{X} \leq 0.33$. Esta relación muestra que la cantidad de iones $\mathrm{Al}^{3+}$ no puede ser muy alta. 
La estructura de estos minerales se puede describir a partir de la brucita, $\left[\mathrm{Mg}(\mathrm{OH})_{2}\right]$, en la que el $\mathrm{Mg}^{2+}$ está rodeado octaédricamente por 6 oxígenos circundantes en forma de hidróxidos. Las aristas del octaedro se comparten para formar láminas u hojas infinitas, como se muestra en la Figura 3. Las hojas están colocadas una sobre otras, de tal modo que la superficie de cada una, está unida a la otra por puentes de hidrógeno (Cavan et al., 1991). Para obtener la estructura de la hidrotalcita se sustituye en la estructura de la brucita algunos iones de $\mathrm{Mg}^{2+}$ por iones trivalentes con radio cercano al del $\mathrm{Mg}^{2+}(0.65 \AA)$, tal como el $\mathrm{Al}^{3+}$. Esta estructura resulta entonces cargada positivamente: una unidad de carga positiva por cada ión $\mathrm{Mg}^{2+}$ sustituido. Para recuperar la neutralidad eléctrica, se ubican una serie de aniones en el espacio interlaminar, generando así la estructura de la hidrotalcita. En el espacio interlaminar quedan, además, retenidas moléculas de agua (Fetter et al., 1997).

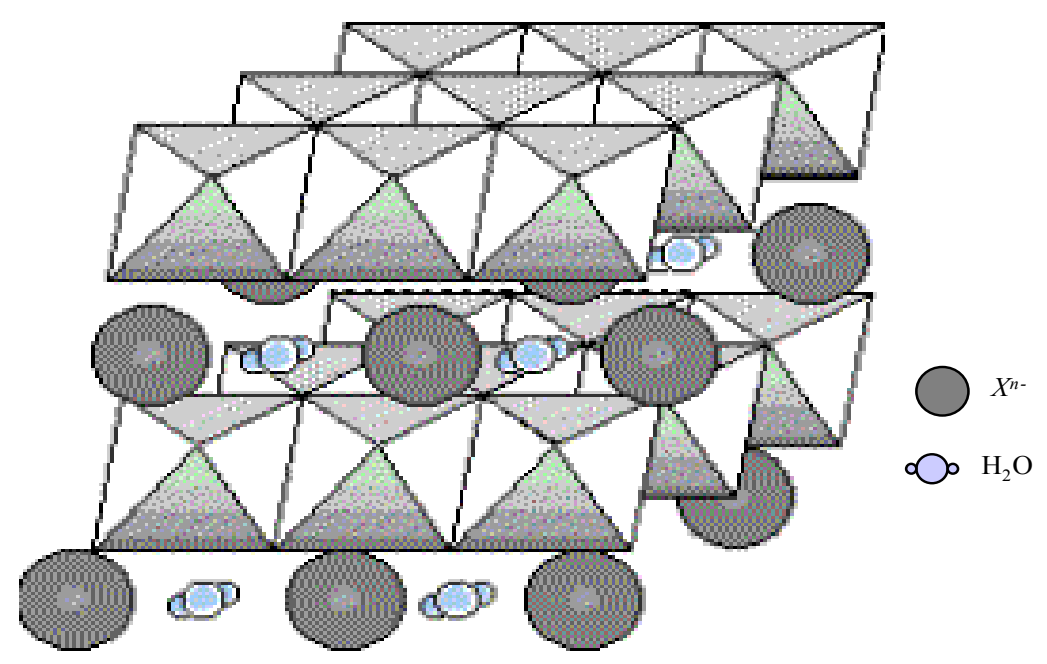

Fig. 3. Estructura de la hidrotalcita donde: $X^{n-}=$ aniones de compensación. 
El interés de la hidrotalcita se basa en su capacidad de intercambio de aniones. En efecto, gracias a la carga positiva en su estructura, la hidrotalcita es un intercambiador aniónico. Se ha encontrado que de todos los aniones estudiados hasta ahora, el ion carbonato presenta la afinidad más alta por la hidrotalcita (Miyata, 1980) y por esta misma situación, la hidrotalcita intercalada con iones carbonato presenta una capacidad de intercambio casi nula. Otras hidrotalcitas con aniones distintos al carbonato pueden intercambiarse con mayor facilidad con otros aniones. Sin embargo el empleo específico de las hidrotalcitas como sorbentes (Fetter et al., 1997; Kooli et al., 1997; Kang et al., 1996; Miyata, 1975; Rey et al., 1992) se debe, en gran medida, a las

propiedades de los óxidos obtenidos por calcinación de los compuestos laminares originales, que tienen iones carbonato en su región interlaminar.

Cuando la hidrotalcita con iones carbonato en su región interlaminar se calienta a temperaturas entre 773 a $873 \mathrm{~K}$, sufre deshidroxilación y descarbonatación a través de la eliminación de agua y $\mathrm{CO}_{2}$ para obtener finalmente un óxido de magnesio con aluminio disperso (Miyata, 1980), los óxidos obtenidos de la calcificación de la hidrotalcita tienen una gran capacidad aceptora de aniones en solución. La hidrotalcita calcinada puede ser rehidratada por contacto con una solución acuosa conteniendo aniones. En estas condiciones la estructura laminar original tiende a regenerarse por el llamado "efecto de memoria" (Sato et al., 1998).

\subsubsection{Carbón activado.}

El carbón activado es un material que tiene suficiente estabilidad química y una gran resistencia a altas temperaturas y radiación. Es ampliamente usado para la sorción de iones inorgánicos y productos de fisión del ${ }^{235} \mathrm{U}$ en soluciones acuosas. Puede ser preparado a partir de cualquier material que contenga carbono en su estructura, ejemplo, cáscara de coco, madera, carbón mineral, etc. por calentamiento, con o sin adición de 
agentes químicos deshidratantes, en ausencia de aire para liberar carbón de sus átomos asociados. Esta etapa es la carbonización. La activación del carbón ocurre mediante gases oxidantes en caliente $\left(\mathrm{CO}_{2}\right)$ a temperaturas entre 588 y $1198 \mathrm{~K}$. Este tratamiento produce la formación de fisuras o poros.

Son dos las características fundamentales en las que se basan las aplicaciones del carbón activado: elevada capacidad de sorción y baja selectividad ante los sorbatos, por lo que se dice que es un sorbente universal. La elevada capacidad de sorción se debe a la alta superficie interna que posee, así como a una gran distribución del tamaño de poros. En general, los microporos (tamaño inferior a $2 \mathrm{~nm}$ ) le confieren la elevada área específica y elevada capacidad de sorción, mientras que los mesoporos (tamaño comprendido entre $2-50 \mathrm{~nm}$ ) y macroporos (tamaño mayor que $50 \mathrm{~nm}$ ) son necesarios para retener moléculas de gran tamaño, como colorantes o coloides, y favorecer el acceso por la difusión de las moléculas a la superficie interna del sólido (Ganzerli et al., 2002).

El carbón activado debido a su naturaleza polar y por el tipo de fuerzas implicadas en el proceso de sorción, retiene preferentemente moléculas polares y de alto peso molecular, sin embargo es un material que remueve eficientemente muchos contaminantes inorgánicos. En general, una mayor área específica del carbón conlleva mayor capacidad de sorción de contaminantes, y la forma de aumentarla es prolongando el nivel o grado de activación. 


\section{CAPÍTULO II}

PARTE EXPERIMENTAL

El desarrollo de la parte experimental tanto para ${ }^{60} \mathrm{Co}$, como para los productos de fisión del ${ }^{235} \mathrm{U}$, se llevó a cabo de acuerdo con el siguiente diagrama de flujo:

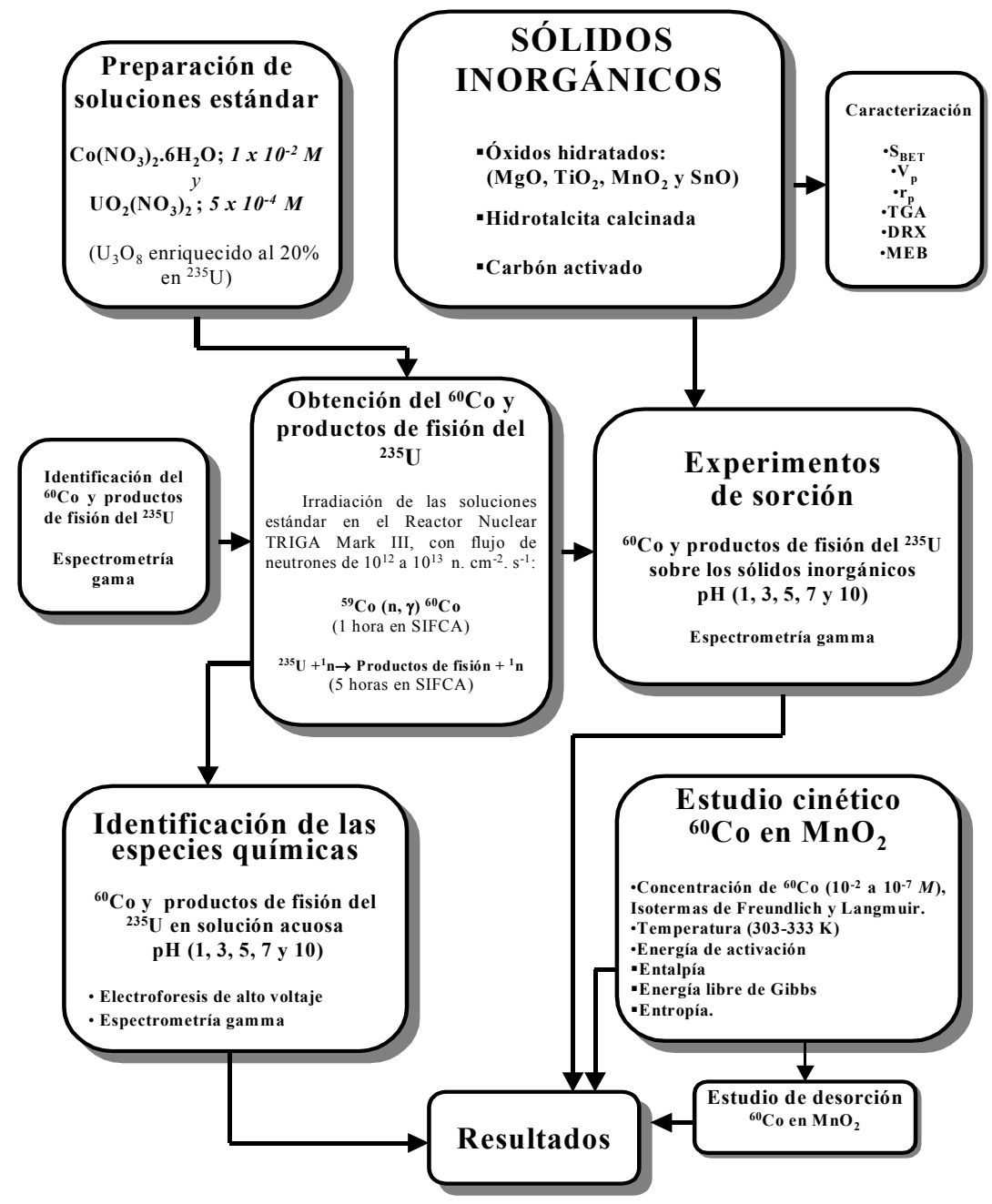




\subsection{MATERIALES.}

\subsubsection{Reactivos y materiales.}

Se usaron los siguientes materiales de grado analítico, sin posterior purificación: $\mathrm{MnO}_{2}\left(\right.$ Baker, 99\% de pureza; zpc= 4.5), $\mathrm{TiO}_{2}($ Baker, 99.9\% de pureza; zpc= 6.7), $\mathrm{MgO}($ Merk, 97\% de pureza; zpc= 12.4), y SnO (Baker, 99.7\% de pureza; zpc=6.6), carbón activado, (Aldrich Co.). La hidrotalcita fue preparada según Sato et al., (1998) de acuerdo al siguiente procedimiento: Se agregó gota a gota $1000 \mathrm{~mL}$ de una solución 0.25 $M$ de $\mathrm{AlCl}_{3}$ y $0.75 M$ de $\mathrm{MgCl}_{2} \cdot 6 \mathrm{H}_{2} \mathrm{O}$ a $1000 \mathrm{~mL}$ de otra solución $0.5 M$ de $\mathrm{NaCO}_{3}$ y 2.5 $M$ de $\mathrm{NaOH}$ bajo agitación vigorosa. Ambas soluciones se calentaron a $333 \mathrm{~K}$ previamente y se conservaron a esa temperatura durante la agitación. Una vez producida la hidrotalcita se separó por filtración y posteriormente se lavó con agua desionizada hasta no detectar el ión cloruro por medio de su precipitación con nitrato de plata en solución. La hidrotalcita se secó a temperatura ambiente por 5 días y después a $353 \mathrm{~K}$ en aire por tres horas, se pulverizó en un mortero de ágata y después se tamizó para obtener muestras con tamaño de grano de $250 \mu \mathrm{m}$. La hidrotalcita calcinada se obtuvo mediante el calentamiento de la hidrotalcita a $773 \mathrm{~K}$ durante 5 horas, se guardó en un desecador con silica gel deshidratada después de retirarla de la mufla y se utilizó de manera inmediata en los experimentos de sorción. Se uso agua desionizada. 


\subsection{Caracterización de los materiales.}

Los sólidos inorgánicos empleados como sorbentes en esta investigación fueron caracterizados por su área específica. Propiedad que indica su capacidad de sorción. Se realizaron además caracterizaciones por difracción de rayos X (DRX) de los materiales comerciales utilizados, que identificaron plenamente a los sorbentes. En virtud de que los sorbatos utilizados son radiactivos, no se realizaron estudios de DRX, análisis térmico y microscopía de los sorbentes después del contacto con los radioisótopos. Se presenta sólo la caracterización del $\mathrm{MnO}_{2}$ original y después de utilizarlo como sorbente del ion $\mathrm{Co}^{2+}$ no radiactivo, considerando que este material mostró ser el sorbente más eficiente de cobalto en solución acuosa en el intervalo de $\mathrm{pH}$ estudiado. En vista que la concentración del cobalto se encuentra en muy pequeñas concentraciones, no se espera ver su presencia en los patrones de difracción de rayos $\mathrm{X}$, sin embargo se realizó el estudio para ver los cambios en el $\mathrm{MnO}_{2}$ después de la sorción. Se realizó un análisis térmico y de microscopía electrónica de barrido a este mismo material intercambiado con cobalto.

\section{2.1. Área específica.}

Las áreas específicas de los sorbentes, se determinaron por el método de Brunauer-Emmett-Teller (BET) mediante un analizador Micromeritics Gemini 2360 a una tiempo de calentamiento de $2 \mathrm{~h}$ a $473 \mathrm{~K}$. Se midió el volumen total de poro $\left(\mathrm{V}_{\mathrm{p}}\right)$ de todos los sólidos y se calcularon los valores de radio promedio de poro $\left(\mathrm{r}_{\mathrm{p}}\right)$ relacionando el volumen total de poro $\left(\mathrm{V}_{\mathrm{p}}\right)$ y el área específica BET $\left(\mathrm{S}_{\mathrm{BET}}\right)$ mediante la siguiente ecuación (Lowel, 1979).

$$
\frac{V_{p}}{S_{B E T}}=\frac{r_{p}}{2}
$$




\subsubsection{Análisis termogravimétrico.}

El análisis termogravimétrico se realizó con 5-30 mg de las muestras, las cuales se colocaron en el crisol de platino del equipo termoanalizador TA Instruments modelo TGA-51, previamente calibrado, sometido al proceso de calentamiento programado desde $291 \mathrm{~K}$ hasta $1173 \mathrm{~K}$, con una tiempo de calentamiento de $20 \mathrm{~K} /$ minuto, los experimentos se realizaron usando un gas inerte $\left(\mathrm{N}_{2}\right.$ grado ultra alta pureza marca LINDE).

\subsubsection{Análisis por difracción de rayos $X$.}

La difracción de rayos $\mathrm{X}$, se realizó utilizando un difractómetro de polvos SIEMENS D-5000 acoplado a un tubo de rayos X de ánodo de cobre. La selección de la k $\alpha$ se logró mediante un monocromador de haz difractado. En un portamuestras se colocaron de 30 a $50 \mathrm{mg}$ del material seco, éste se paso por al goniómetro y se hizo incidir el haz de rayos X sobre la muestra. Se obtuvieron los difractogramas con un barrido de $4^{\circ}$ a $70^{\circ} 20^{\circ}$. Los resultados obtenidos se confrontaron con las tarjetas de los patrones reportados por el "Joint Committe on Powder Diffraction Standards" (JCPDS).

\subsubsection{Análisis por microscopía electrónica de barrido.}

Se caracterizó el material sorbente $\left(\mathrm{MnO}_{2}\right)$ y se determinó su análisis químico elemental y tamaño de las partículas, utilizando un microscopio electrónico de barrido Philips XL-30, con $3.5 \mathrm{~nm}$ de resolución, un voltaje de aceleración de $30 \mathrm{keV}$ y una máxima ampliación de 1500X. 


\subsection{Preparación del ${ }^{60} \mathrm{Co}$ y de los productos de fisión del ${ }^{235} \mathrm{U}$.}

El ${ }^{60} \mathrm{Co}$ radiactivo se obtuvo por medio de la reacción nuclear ${ }^{59} \mathrm{Co}(\mathrm{n}, \gamma){ }^{60} \mathrm{Co}$ irradiando una solución de $1 \mathrm{~mL} 1.0 \times 10^{-2} M$ de $\mathrm{Co}\left(\mathrm{NO}_{3}\right)_{2}$, en el reactor TRIGA Mark III del Centro Nuclear con un flujo de neutrones de $10^{12}$ a $10^{13} \mathrm{n} . \mathrm{cm}^{-2} \cdot \mathrm{s}^{-1}$ en la posición SIFCA (sistema fijo de cápsulas) durante 1 hora. $\mathrm{El} \mathrm{pH}$ de las soluciones de cobalto fue ajustado por adición de soluciones acuosas $0.001 M$ de $\mathrm{NH}_{4} \mathrm{OH}$ o $\mathrm{HNO}_{3}$ y se midió con un potenciómetro Cole-Parmer, modelo 05669-20.

El $\mathrm{U}_{3} \mathrm{O}_{8}$ (enriquecido al $20 \%$ en peso en ${ }^{235} \mathrm{U}$ ) se disolvió en $\mathrm{HNO}_{3}$ concentrado en caliente y en exceso. Se evaporó la muestra a sequedad eliminando el ácido nítrico en exceso y se redisolvió con agua desionizada formando así el nitrato de uranilo $5 \times 10^{-4}$ M. $1 \mathrm{~mL}$ de la solución de $\mathrm{UO}_{2}\left(\mathrm{NO}_{3}\right)_{2}$, fue irradiada durante 5 horas en el reactor nuclear TRIGA Mark III del ININ, con un flujo neutrónico de $10^{12}$ a $10^{13} \mathrm{n} . \mathrm{cm}^{-2} \cdot \mathrm{s}^{-1}$, en el sistema de irradiación fijo. La muestra se almacenó durante 5 días antes del análisis para permitir el decaimiento de los productos de fisión de vida media corta, los

productos de fisión del ${ }^{235} \mathrm{U}$ escogidos fueron los siguientes ${ }^{132} \mathrm{Te},{ }^{95} \mathrm{Zr},{ }^{99} \mathrm{Mo} \mathrm{y}{ }^{103} \mathrm{Ru}$ por sus características nucleares adecuadas (obtenidos con rendimiento de fisión mayores al $2 \%$, ser emisores gamma y contar con tiempos de vida media radiactiva que permitan realizar el estudio correspondiente). Se utilizaron alícuotas de esta solución para estudiar el comportamiento de sorción de los productos de fisión a diferentes valores de $\mathrm{pH}$. Se ajustó el pH de las soluciones de los productos de fisión a nivel traza con soluciones $0.001 M$ de $\mathrm{NH}_{4} \mathrm{OH}$ o $\mathrm{HNO}_{3}$ usando un potenciómetro Cole-Parmer, modelo 05669-20. $\mathrm{El} \mathrm{pH}$ de las soluciones radiactivas fue medido antes $\left(\mathrm{pH}\right.$ inicial $\left.=\mathrm{pH}_{\mathrm{i}}\right)$ y después de poner en contacto la solución radiactiva con la fase sólida al equilibrio $\left(\mathrm{pH}\right.$ final $\left.=\mathrm{pH}_{\mathrm{f}}\right)$. 


\subsection{Identificación nuclear del ${ }^{60} \mathrm{Co}$ y de los productos de fisión del ${ }^{235} \mathrm{U}$.}

$\mathrm{E}{ }^{60} \mathrm{Co}$ y los productos de fisión del ${ }^{235} \mathrm{U}$ fueron identificados por sus espectros de radiación gamma (Lederer et al., 1968), usando un detector de Ge/hiperpuro acoplado a un analizador multicanal de 4096 canales, previamente calibrado con fuentes radiactivas de: ${ }^{204} \mathrm{Tl}(70.84 \mathrm{keV}),{ }^{22} \mathrm{Na}(511$ y $1274.5 \mathrm{keV})$ y ${ }^{137} \mathrm{Cs}(662 \mathrm{keV})$.

La Tabla 1 muestra las propiedades nucleares del ${ }^{60} \mathrm{Co}$ y de los productos de fisión del ${ }^{235} \mathrm{U}$ estudiados. Las especies químicas encontradas en solución acuosa de los radioisótopos estudiados, fueron identificadas con la ayuda del programa MEDUSA (Puigdomenech, 1999).

Tabla 1. Propiedades nucleares del ${ }^{60}$ Co y de los productos de fisión del ${ }^{235} \mathrm{U}$ en estudio.

\begin{tabular}{cccc}
\hline Radioisótopos & $\begin{array}{c}\text { Energía gamma } \\
\text { del fotopico } \\
(\mathrm{keV})\end{array}$ & $\begin{array}{c}\text { Vida media } \\
\text { radiactiva }\end{array}$ & $\begin{array}{c}\text { Rendimiento de } \\
\text { fisión }\end{array}$ \\
\hline${ }^{60} \mathrm{Co}$ & 1322 y 1173$)$ & 5.3 años & - \\
${ }^{132} \mathrm{Te}$ & 230 & 3.2 días & 4.2 \\
${ }^{95} \mathrm{Zr}$ & 726 & 64.0 días & 6.4 \\
${ }^{99} \mathrm{Mo}$ & 740 & 2.7 días & 6.3 \\
${ }^{103} \mathrm{Ru}$ & 497 & 39.0 días & 2.9 \\
\hline
\end{tabular}


El programa MEDUSA (Puigdomenech, 1999) que fue empleado para verificar las especies químicas encontradas en este trabajo, está constituido de tres componentes principales:

1. HYDRA: Hydrochemical Equilibrium Constant Database. Se utiliza para crear archivos de datos de las constantes de equilibrio disponibles en la base de datos (Fig. 4).

2. MEDUSA: "Make Equilibrium Diagrams Using Sophisticated Algoritms". Es una interface de Windows que calcula los diagramas de equilibrio (Fig. 5).

3. El paquete INPUT-SED-FREEDOM software (Programa de MS-DOS).

- INPUT, utilizado para el manejo de archivo de datos, su creación y edición.

- SED, crea diagramas logarítmicos, por compuestos y por solubilidad.

- FREEDOM, crea diagramas de áreas de predominio o distribución.

La base de datos utilizada para el cálculo de los diagramas de distribución de especies químicas (Figuras 6 y 7) fue desarrollada y proporcionada por la Inorganic Chemistry, Royal Institute of Technology, Estocolmo Suecia (Puigdomenech, 1999). 


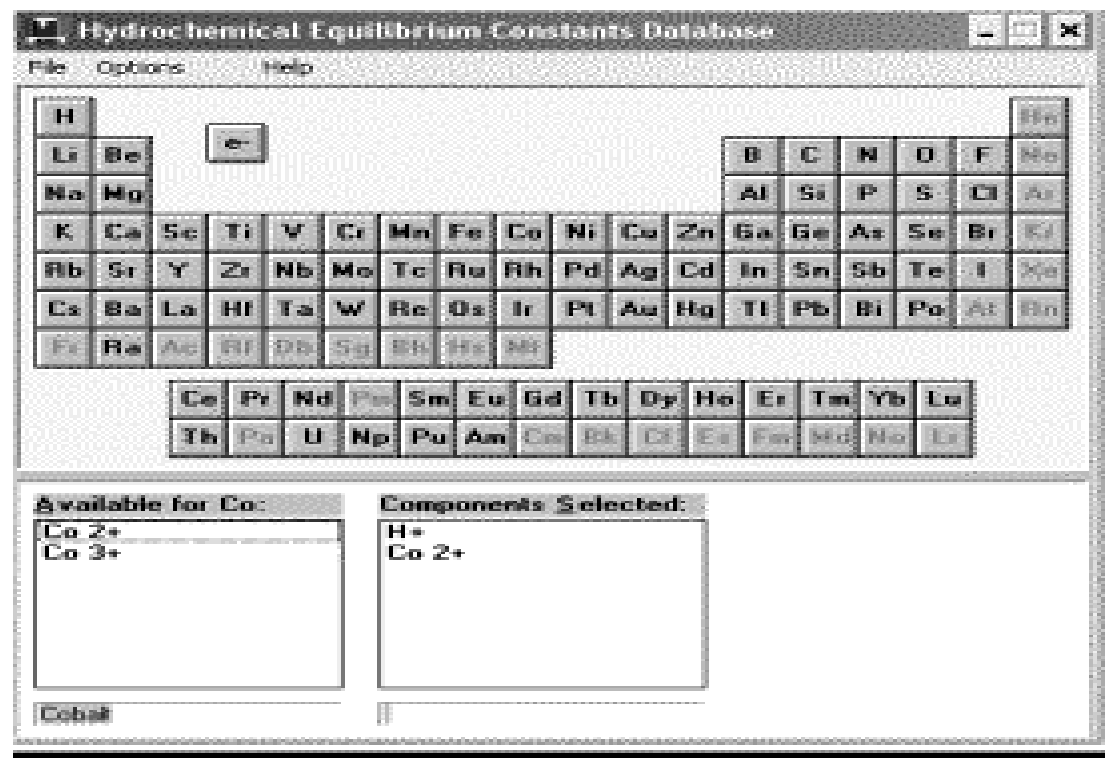

Fig. 4. Base de datos que se utiliza para la creación y edición de archivos.

Los diagramas de distribución de especies químicas se elaboraron de la siguiente manera: Con el paquete HYDRA se eligieron los elementos de interés en el estudio; una vez seleccionados, se conformó la base de datos con todas las posibles especies que se pueden encontrar en el sistema. Esta base de datos se guardó y posteriormente fue utilizada por MEDUSA, a su vez, en MEDUSA se alimentaron los valores experimentales de los elementos de interés, en molaridad. A continuación, se elaboró, computacionalmente, el diagrama de distribución de especies químicas. Éste se construyó seleccionando un intervalo específico de $\mathrm{pH}$, que en este caso particular fue entre 1 y 12. Además se seleccionaron las especies que participaron en el sistema; así mismo, se incluyó la fuerza iónica, ya que este parámetro es importante debido a que está relacionado con la mayor o menor solubilidad de especies en el sistema (Kaplan et al., 1998). 


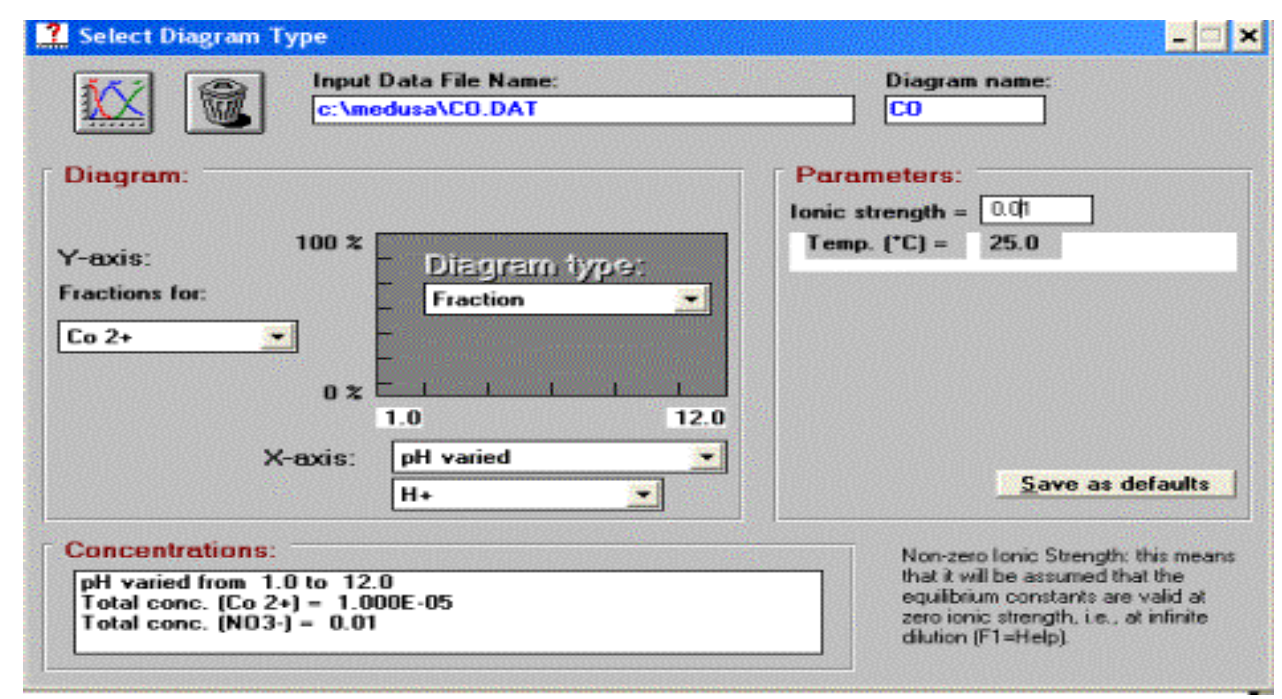

Fig. 5. Interface para el cálculo de los diagramas de distribución de especies químicas.

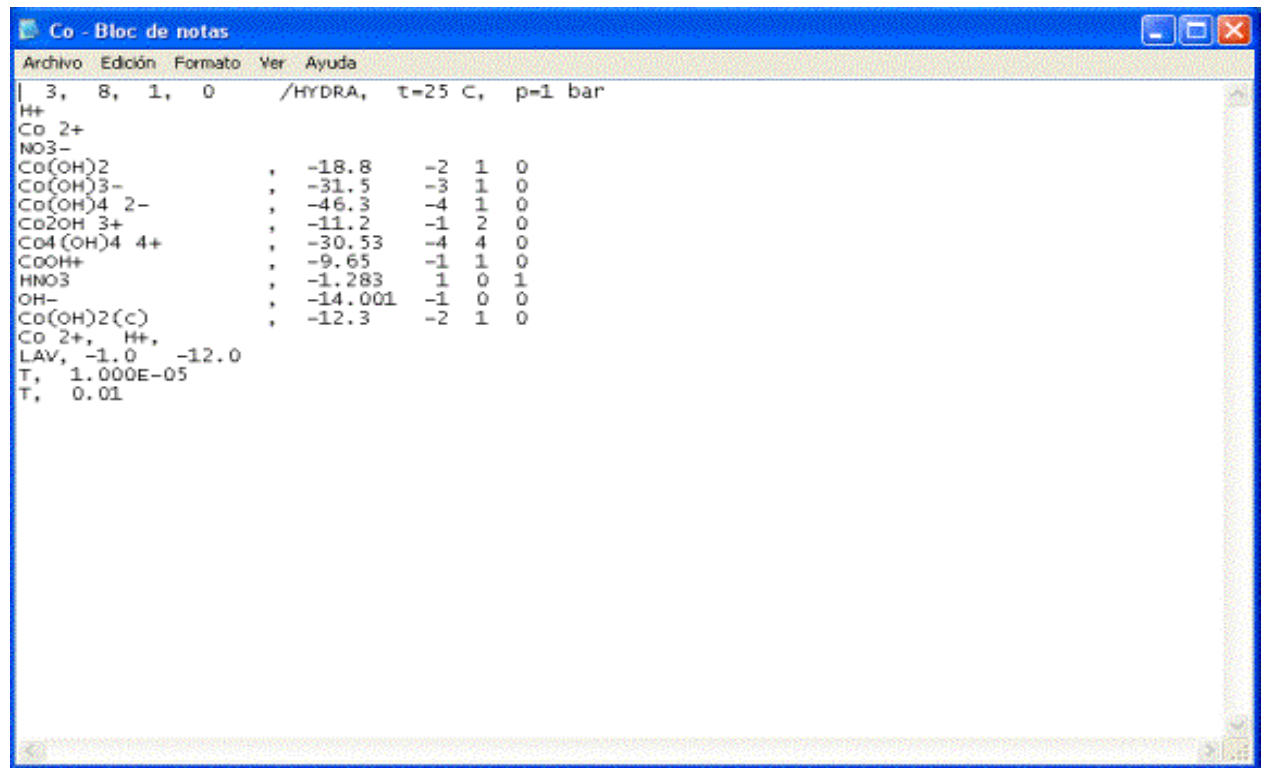

Fig. 6. Ejemplo de la base de datos incluida en el programa para el cálculo de los diagramas de distribución de especies. 


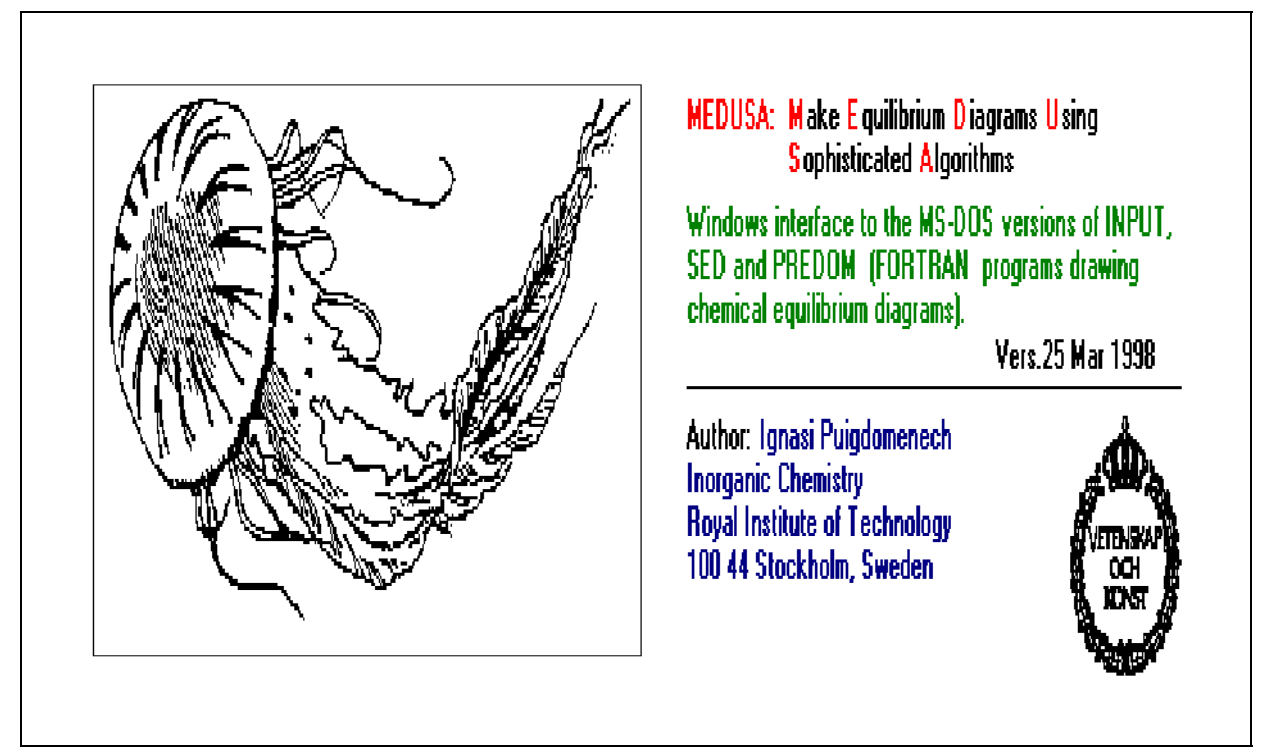

Fig. 7. Paquete MEDUSA para el cálculo de diagramas de distribución de especies.

Una vez obtenido los diagramas de las concentraciones de los elementos químicos que muestra las especies predominantes en solución acuosa a diferentes valores de $\mathrm{pH}$, estas especies fueron comparadas con los resultados obtenidos mediante electroforesis de alto voltaje. Como fundamento, este programa computacional toma en cuenta para su base de datos las constantes de equilibrio de la literatura, que están en función de la fuerza iónica de las especies químicas, de la temperatura del sistema y es una herramienta muy útil que nos permite determinar los diagramas de predominio de especies químicas en solución. 


\subsection{Estimación de las especies químicas del ${ }^{60} \mathrm{Co}$ y de los productos de fisión del ${ }^{235} \mathrm{U}$ en solución acuosa por electroforesis.}

Las diferentes especies químicas de ${ }^{60} \mathrm{Co}$ y trazas de los productos de fisión del ${ }^{235} \mathrm{U}:{ }^{132} \mathrm{Te},{ }^{95} \mathrm{Zr}$, ${ }^{99} \mathrm{Mo} \mathrm{y}{ }^{103} \mathrm{Ru}$, se separaron por electroforesis de alto voltaje. Esta separación se llevó a cabo ajustando las soluciones del ${ }^{60} \mathrm{Co}$ y de los productos de físión nuclear a diferentes valores de $\mathrm{pH}_{\mathrm{i}}$. Posteriormente se analizaron por espectrometría gamma cada uno de los radioisótopos escogidos. Los valores de $\mathrm{pH}_{\mathrm{i}}$ fueron $1,3,5,7$ y 10. La electroforesis de alto voltaje permitió analizar concentraciones muy bajas de material radiactivo presente en soluciones acuosas. Las especies químicas tanto catiónicas como aniónicas de los isótopos radiactivos, se desplazan en una tira de papel según su carga y masa. Para este propósito, se usaron tiras de papel Whatman de $1.0 \mathrm{~cm}$ de ancho por $60 \mathrm{~cm}$ de largo, marcadas con lápiz por separaciones de $1.0 \mathrm{~cm}$ de largo en ambos lados del centro de la tira de papel. Las tiras de papel se impregnaron con una solución electrolítica. Esta se preparó mezclando diferentes proporciones de soluciones $0.01 M$ de $\mathrm{HNO}_{3}$ y $\mathrm{NH}_{4} \mathrm{OH}$ según el valor del $\mathrm{pH}$ estudiado. Se depositaron $100 \mu \mathrm{L}$ de cada solución irradiada obtenida, tanto de $\mathrm{Co}\left(\mathrm{NO}_{3}\right)_{2} \cdot 6 \mathrm{H}_{2} \mathrm{O}$ como de la solución de $\mathrm{UO}_{2}\left(\mathrm{NO}_{3}\right)_{2}$, en el centro de la tira de papel $(0 \mathrm{~cm})$. Se utilizó un voltaje de $2000 \mathrm{~V}$ durante 30 minutos. Una vez completada la electroforesis, se secó el papel con aire y se cortó en fracciones de $1 \mathrm{~cm}$ de largo. Se analizó cada producto de fisión del ${ }^{235} \mathrm{U}$ y del ${ }^{60} \mathrm{Co}$ en cada fracción de papel por espectrometría gamma. Los porcentajes de las especies químicas se calcularon usando la actividad relativa de cada radioisótopo estudiado. 


\subsection{Experimentos de sorción.}

\subsubsection{Sorción del ${ }^{60} \mathrm{Co}$ y de los productos de fisión del ${ }^{235} \mathrm{U}$ en solución acuosa en materiales inorgánicos a diferentes valores de pH.}

Para medir la sorción de los radionúclidos: ${ }^{60} \mathrm{Co}$ y trazas de ${ }^{132} \mathrm{Te},{ }^{95} \mathrm{Zr},{ }^{99} \mathrm{Mo} \mathrm{y}$

${ }^{103} \mathrm{Ru}$ en los materiales inorgánicos, a diferentes valores de $\mathrm{pH}$, se llevaron a cabo experimentos de sorción a temperatura ambiente. Se mezclaron, en viales de vidrio, porciones de $100 \mathrm{mg}$ del sorbente inorgánico con $10 \mathrm{~mL}$ de solución original de ${ }^{60} \mathrm{Co} o$ de los productos de fisión del ${ }^{235} \mathrm{U}$ a diferentes valores de $\mathrm{pH}_{\mathrm{i}}(1,3,5,7$ y 10). Se agitaron las mezclas de sorbente y solución durante 72 horas para asegurar la distribución en el equilibrio del ${ }^{60} \mathrm{Co}$ y de los productos de fisión del ${ }^{235} \mathrm{U}$. El líquido fue separado de la fase sólida por centrifugación (5 minutos a 3000 RPM). Se determinó el $\mathrm{pH}$ final o del equilibrio de la solución $\left(\mathrm{pH}_{\mathrm{f}}\right)$ con un potenciómetro Cole-Parmer, modelo 05669-20. Se tomó una alícuota de $5 \mathrm{~mL}$ para medir la actividad gamma residual del ${ }^{60} \mathrm{Co}$ y de los productos de fisión del ${ }^{235} \mathrm{U}$ en cada solución. Finalmente se comparó la radiactividad de la alícuota con una muestra patrón de las soluciones originales respectivas. Los resultados fueron presentados en términos de porcentaje de sorción para cada radioisótopo estudiado. 


\subsection{Estudio cinético sobre la sorción de ${ }^{60}$ Co en dióxido de manganeso hidratado.}

Para estudiar la cinética de sorción del ${ }^{60} \mathrm{Co}$ en el dióxido de manganeso hidratado como una función de la concentración del cobalto y temperatura de la solución acuosa, se realizaron los estudios señalados a continuación.

\subsubsection{Efecto de la concentración.}

La sorción del ${ }^{60} \mathrm{Co}$ en el dióxido de manganeso como una función de la concentración del cobalto, fue medida utilizando una concentración de cobalto de $10^{-2}$ -

$10^{-7} \mathrm{M}$ a una temperatura de $303 \mathrm{~K} \mathrm{y} \mathrm{pH} \mathrm{6.2,} \mathrm{con} \mathrm{un} \mathrm{tiempo} \mathrm{de} \mathrm{agitación} \mathrm{de} 5$ a 150 minutos. La actividad del ${ }^{60} \mathrm{Co}$ fue medida por medio de espectrometría gamma en los fotopicos 1173 y $1332 \mathrm{keV}$.

\subsubsection{Efecto de la temperatura.}

La velocidad de reacción, la sorción del ${ }^{60} \mathrm{Co}$ sobre el sólido y la difusión de los iones dentro de los poros del sorbente están controlados principalmente por la temperatura. Para investigar el efecto de la temperatura sobre la sorción del cobalto en el $\mathrm{MnO}_{2}$, se realizaron estudios variando la temperatura del sistema de 303 a $333 \mathrm{~K}$ y utilizando una concentración inicial constante de $\mathrm{Co}\left(\mathrm{NO}_{3}\right)_{2} \cdot 6 \mathrm{H}_{2} \mathrm{O} 1.0 \times 10^{-5} M$. Se determinó la energía de activación, la entalpía, la energía libre de Gibbs y la entropía del proceso de sorción. 


\subsubsection{Estudio de desorción.}

Una vez obtenida la sorción del ${ }^{60} \mathrm{Co}$ en el sólido $\mathrm{MnO}_{2}$ en función de la temperatura en el equilibrio; se estudió su desorción para comprobar que el proceso de sorción fue por intercambio iónico. Se secó el $\mathrm{MnO}_{2}$ con ${ }^{60} \mathrm{Co}$, sobre un vidrio de reloj. Se realizó la desorción de ${ }^{60} \mathrm{Co}$ de cada fase sólida, poniéndola en contacto con $5 \mathrm{~mL}$ de una solución acuosa no radiactiva de $\mathrm{Co}\left(\mathrm{NO}_{3}\right)_{2} \cdot 6 \mathrm{H}_{2} \mathrm{O} 1.0 \times 10^{-5} M$, dejando cada fase en reposo durante 24 horas, para posteriormente medir mediante espectrometría gamma, el ${ }^{60}$ Co que se transfirió a la fase acuosa. 


\section{CAPÍTULO III}

\section{RESULTADOS Y DISCUSIÓN}

\section{1. Área específica.}

En la Tabla 2, se muestran las áreas específicas, volumen total de poro y radio promedio de poro de los materiales inorgánicos usados como sorbentes. El carbón activado es el único que tiene un área específica BET muy grande de $1247.78 \mathrm{~m}^{2} / \mathrm{g}$, le siguen la hidrotalcita calcinada y el $\mathrm{MgO}$ con áreas específicas de $335.47 \mathrm{~m}^{2} / \mathrm{g}$ y 27.66 $\mathrm{m}^{2} / \mathrm{g}$ respectivamente, las cuales se encuentran entre los intervalos reportados en la literatura para cada sólido inorgánico [de 0.11 a $270 \mathrm{~m}^{2} / \mathrm{g}$ para $\mathrm{MnO}_{2}$ (Trivedi et al., 2001; Fukuda et al., 1998; Murray, 1974), de 7.7 a $134.5 \mathrm{~m}^{2} / \mathrm{g}$ para $\mathrm{TiO}_{2}$ (Sun y Berg, 2002); Jakobsson y Albinsson, 1998; Hasany et al., 1997), y de 0.29 a $32.1 \mathrm{~m}^{2} / \mathrm{g}$ para SnO (Pereira et al., 2002)]. 
Tabla 2. Áreas específicas, volumen total de poro y radio promedio de poro de los materiales inorgánicos estudiados. Tiempo de calentamiento $=2$ horas a $473 \mathrm{~K}$.

\begin{tabular}{|c|c|c|c|}
\hline Sorbente & $\begin{array}{c}\text { Área específica } \\
\text { BET } \\
\left(\mathrm{m}^{2} / \mathrm{g}\right)\end{array}$ & $\begin{array}{l}\text { Volumen total } \\
\text { de poro } \\
\left(\mathrm{cm}^{3} / \mathrm{g}\right)\end{array}$ & $\begin{array}{l}\text { Radio promedio de } \\
\text { poro } \\
(\mathrm{nm})\end{array}$ \\
\hline $\mathrm{MnO}_{2}$ & $0.56 \pm 0.2$ & $0.0010 \pm 0.0009$ & $3.559 \pm 0.464$ \\
\hline $\mathrm{TiO}_{2}$ & $10.57 \pm 2.5$ & $0.0201 \pm 0.001$ & $3.800 \pm 0.789$ \\
\hline $\mathrm{MgO}$ & $27.66 \pm 3.2$ & $0.0450 \pm 0.003$ & $3.253 \pm 0.124$ \\
\hline $\mathrm{SnO}$ & $0.47 \pm 0.34$ & $0.0001 \pm 0.00001$ & $0.424 \pm 0.061$ \\
\hline $\begin{array}{l}\text { Hidrotalcita } \\
\text { calcinada }\end{array}$ & $336.37 \pm 27.5$ & $0.0585 \pm 0.0011$ & $0.348 \pm 0.021$ \\
\hline $\begin{array}{c}\text { Carbón } \\
\text { activado }\end{array}$ & $1247.78 \pm 86.1$ & $0.7002 \pm 0.002$ & $1.122 \pm 0.019$ \\
\hline
\end{tabular}

De los resultados mostrados en la Tabla 2, el radio promedio de poro nos indica que los sorbentes carbón activado, hidrotalcita calcinada y $\mathrm{SnO}$ son microporosos y el $\mathrm{MnO}_{2}, \mathrm{TiO}_{2}$ y $\mathrm{MgO}$ son mesoporosos, de acuerdo a la clasificación del tamaño de poro de Gregg y Sing, (1982) según la cual los microporos son $<2 \mathrm{~nm}$, los mesoporos son entre 2 y $50 \mathrm{~nm}$ y los macroporos son $>50 \mathrm{~nm}$. Para los materiales microporosos, la interacción de los sorbatos con los pequeños poros es significativamente más alto que en 
poros más anchos debido a la mayor proximidad de las paredes del poro pequeño con la cantidad del sorbato, a una presión dada (Gregg y Sing, 1982). De acuerdo con la recomendación de Lowel, (1979) los radios promedio de poros $\left(\mathrm{r}_{\mathrm{p}}\right)$ de geometría desconocida se pueden obtener de acuerdo a la ecuación (6), que supone una geometría cilíndrica de los poros.

\subsection{Radioisótopos obtenidos.}

En la Figura 8 se muestran un espectro gamma de una solución radiactiva diluida $5 \times 10^{-4} M$ de nitrato de cobalto después de 24 horas de decaimiento y de una solución radiactiva $5 \times 10^{-4} M$ de nitrato de uranilo después de 5 días de decaimiento. Como se puede apreciar, se presentan diversas señales correspondientes a los diversos radioisótopos estudiados. Cada uno de los fotopicos fue identificado de acuerdo a su energía gamma correspondiente Tabla 1 (Lederer et al., 1968).

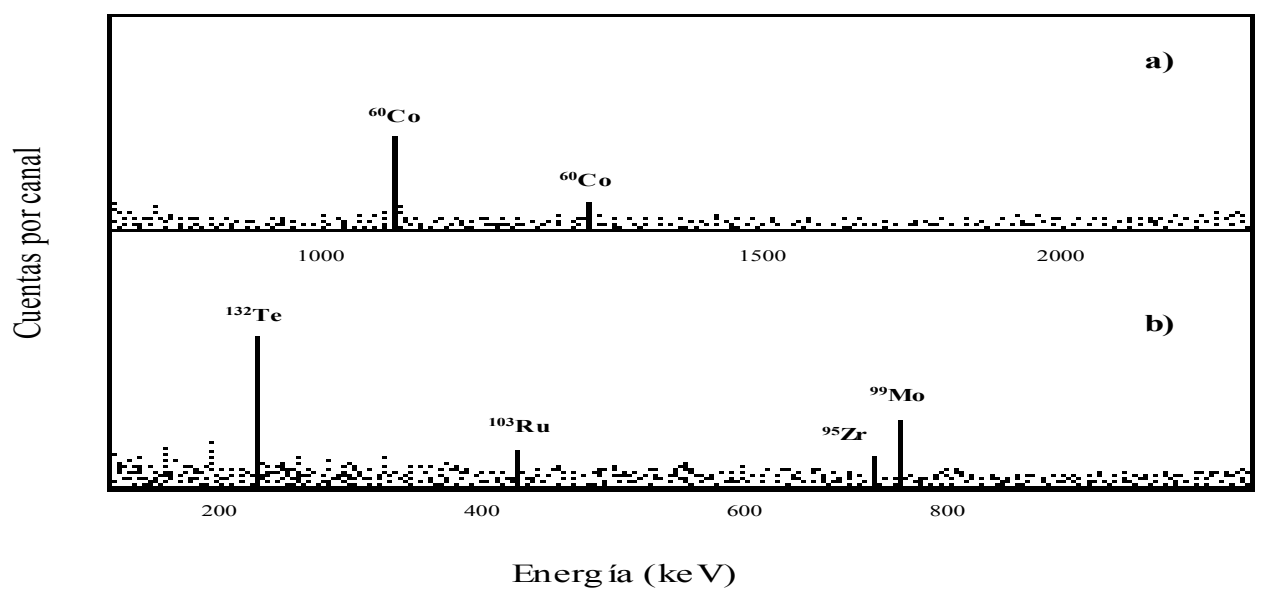

Fig. 8. Espectro gamma de: a) Solución radiactiva $5 \times 10^{-4} \mathrm{M}$ de $\mathrm{Co}\left(\mathrm{NO}_{3}\right)_{2}$ después de 24 horas de decaimiento. b) Solución radiactiva $5 \times 10^{-4} \mathrm{M}$ de $\mathrm{UO}_{2}\left(\mathrm{NO}_{3}\right)_{2}$ después de 5 días de decaimiento. 


\subsection{Especiación del ${ }^{60} \mathrm{Co},{ }^{132} \mathrm{Te},{ }^{95} \mathrm{Zr},{ }^{99} \mathrm{Mo} \mathrm{y}{ }^{103} \mathrm{Ru}$ en solución acuosa por electroforesis.}

Las Figuras 9 - 13 muestran los análisis obtenidos por electroforesis de alto voltaje del ${ }^{60} \mathrm{Co}$ y de los productos de fisión nuclear del ${ }^{235} \mathrm{U}$ en solución: ${ }^{132} \mathrm{Te},{ }^{95} \mathrm{Zr}$, ${ }^{99} \mathrm{Mo} \mathrm{y}{ }^{103} \mathrm{Ru}$, en función de los valores de $\mathrm{pH}_{\mathrm{i}}$ de la solución $(1,3,5,7$ y 10).

El ${ }^{60} \mathrm{Co}$, forma cationes bivalentes en solución acuosa, en el intervalo de $\mathrm{pH}$ estudiado tal como se muestra en la Fig. 9. Mediante electroforesis de alto voltaje, se encontró una especie catiónica, probablemente $\mathrm{Co}^{2+}$, de acuerdo al diagrama de distribución de las especies químicas del cobalto a 298 K (Fig. 9A) obtenido por el programa MEDUSA (Puigdomenech, 1999). Los trabajos reportados por Flores et al., (1998) y por Baes y Mesmer, 1976, indican que la especie catiónica de cobalto bivalente se encuentra como la especie química octaédrica $\mathrm{Co}\left(\mathrm{H}_{2} \mathrm{O}\right)_{6}{ }^{2+}$. En nuestras condiciones experimentales, la especie bivalente del cobalto, es el producto predominante que aparece en el intervalo de $\mathrm{pH}$ estudiado. Sin embargo en condiciones alcalinas, $\mathrm{pH}$ 10, se encontró una especie neutra (Fig. 9), probablemente se trata de la especie química $\mathrm{Co}(\mathrm{OH})_{2}$ de acuerdo a la Figura 9A (Puigdomenech, 1999). 

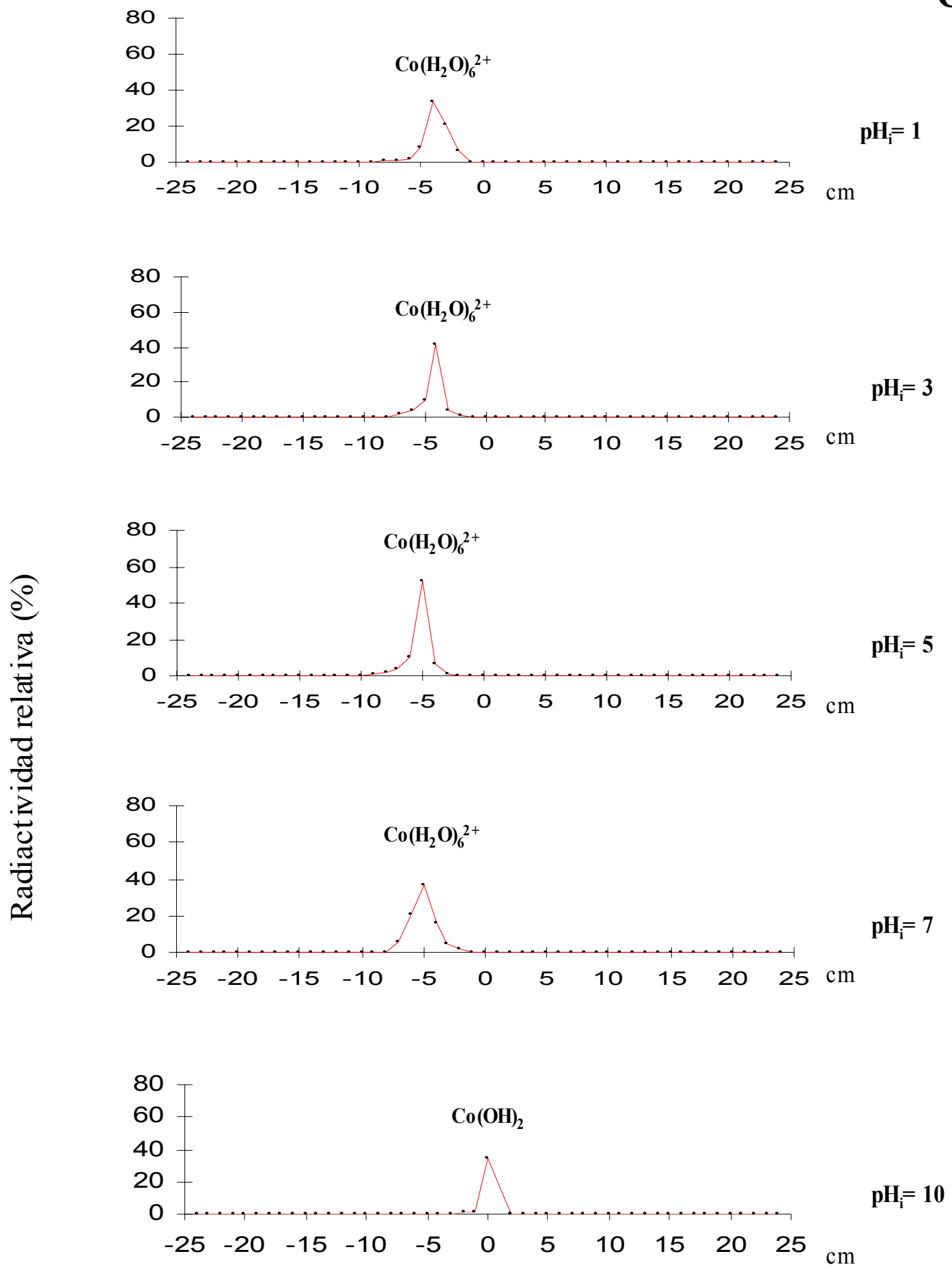

Fig. 9. Electroforegramas del ${ }^{60} \mathrm{Co}$ a diferentes valores de $p H_{i}$. 


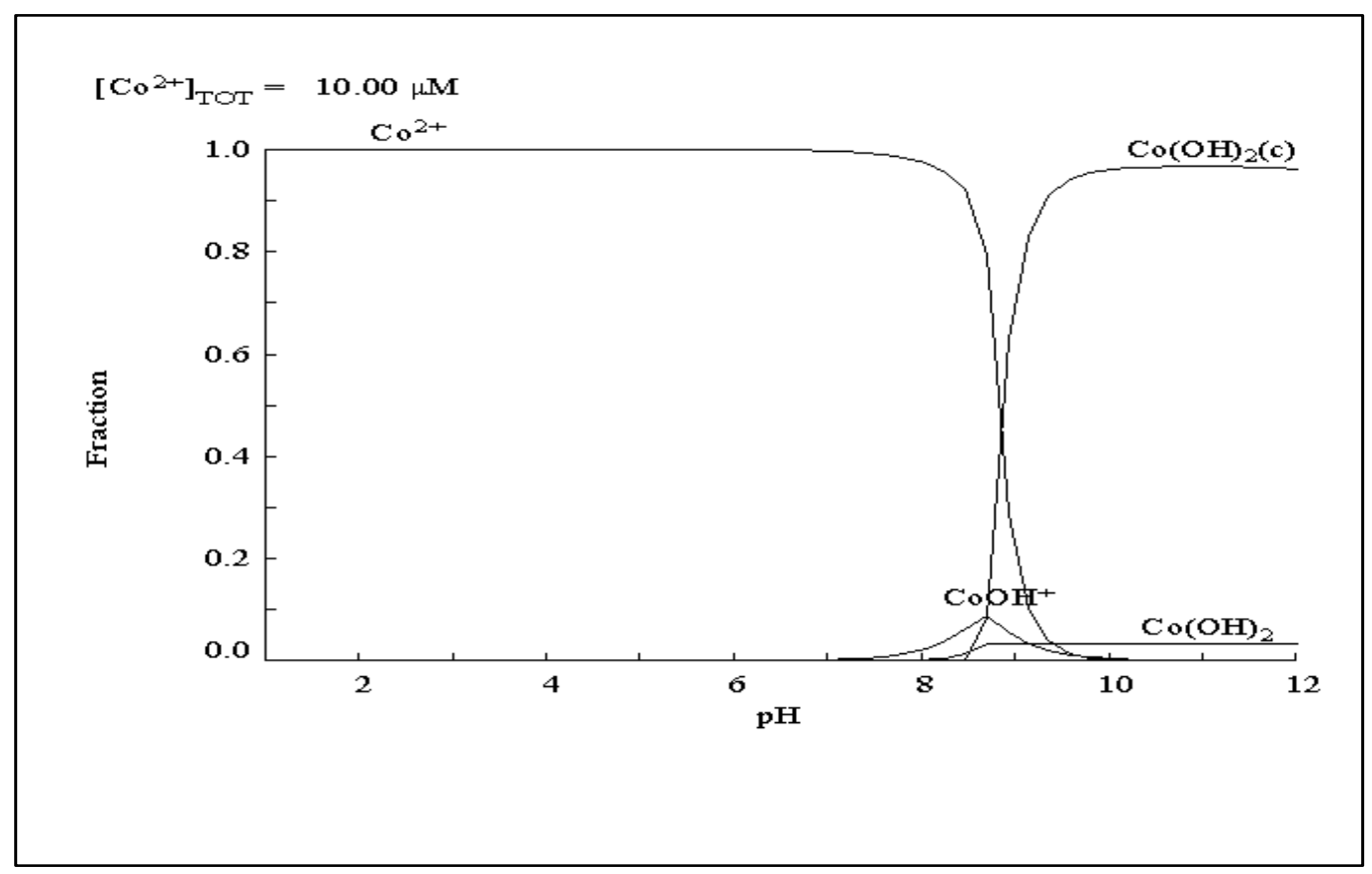

Fig. 9A. Diagrama de distribución de las especies químicas del cobalto a $298 \mathrm{~K}$.

$\mathrm{El}{ }^{132} \mathrm{Te}$, forma cationes y especies neutras en medio ácido a $\mathrm{pH}_{\mathrm{i}}$ de 1 a 3 (Figura 10). La técnica de electroforesis mostró que se encuentra una especie catiónica, posiblemente como ${ }^{132} \mathrm{TeOOH}^{+}$y una especie neutra, probablemente como ${ }^{132} \mathrm{Te}(\mathrm{OH})_{4}$, de acuerdo al diagrama de distribución de las especies para el telurio a 298 K (Fig. 10A) obtenido por el programa MEDUSA (Puigdomenech, 1999). Cuando el $\mathrm{pH}_{\mathrm{i}}$ cambia de 1 a 3, las especies catiónicas se encuentran con abundancias relativas de 38.6 \pm 1.3 y $24.4 \pm 1.5 \%$ y las especies neutras de $61.3 \pm 0.9 \%$ a $75.6 \pm 1.6 \%$ respectivamente. $\mathrm{A} \mathrm{pH}_{\mathrm{i}} 5$ se encontró al ${ }^{132} \mathrm{Te}$ como una especie aniónica como único producto, el programa MEDUSA indica el anión $\mathrm{TeO}(\mathrm{OH})_{3}{ }^{-}$como la especie aniónica más probable. Esta especie aniónica se encuentra también a $\mathrm{pH}_{\mathrm{i}} 7$ como único producto. $\mathrm{A} \mathrm{pH}_{\mathrm{i}} 10$, se encuentran dos especies aniónicas de ${ }^{132} \mathrm{Te}$, probablemente $\mathrm{TeO}_{2}(\mathrm{OH})_{2}{ }^{2-} \mathrm{y} \mathrm{TeO}(\mathrm{OH})_{3}{ }^{-}$, con abundancias relativas de $56.7 \pm 1.3 \%$ y $43.3 \pm 1.2 \%$ respectivamente. 
${ }^{132} \mathrm{Te}$
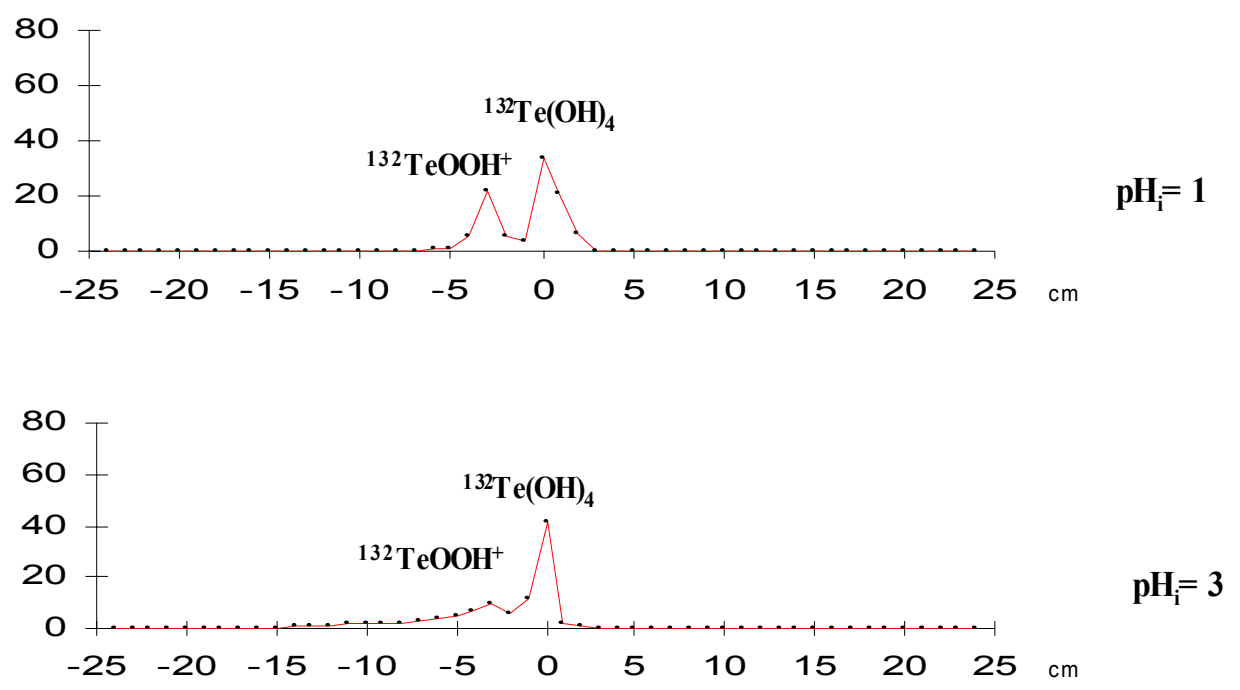

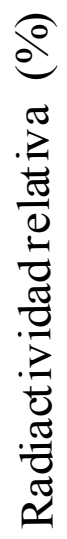
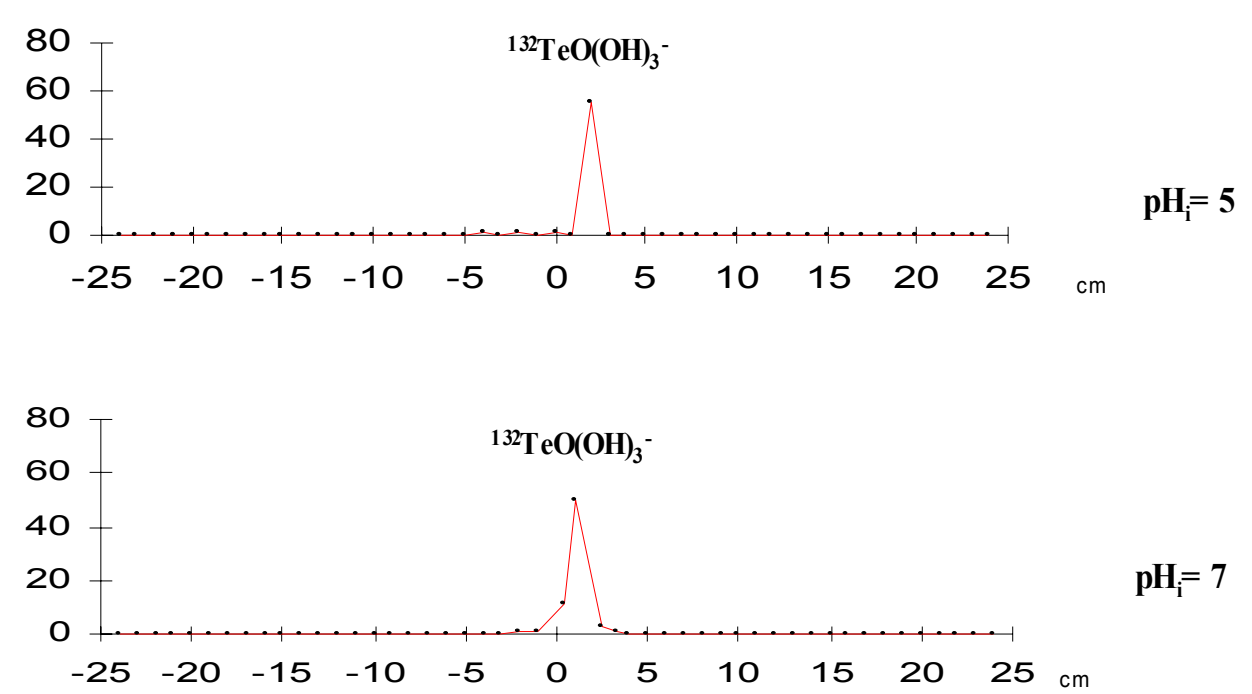

$$
\mathrm{pH}_{\mathrm{i}}=7
$$

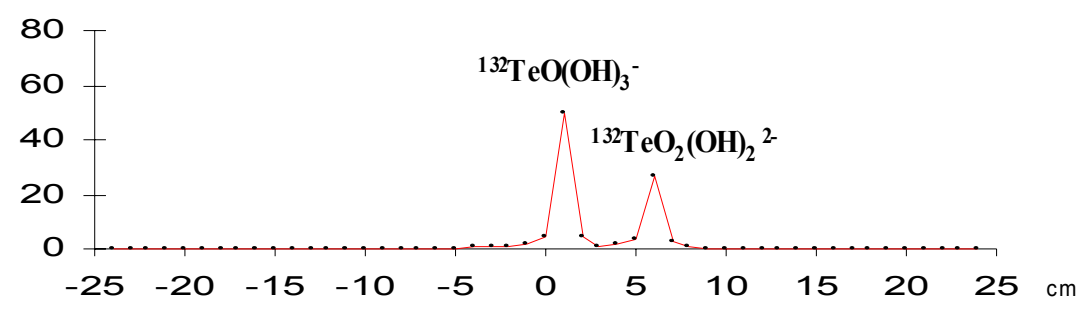

$\mathrm{pH}_{\mathrm{i}}=\mathbf{1 0}$

Fig.10. Electroforegramas del ${ }^{132}$ Te a diferentes valores de $p H_{i}$. 


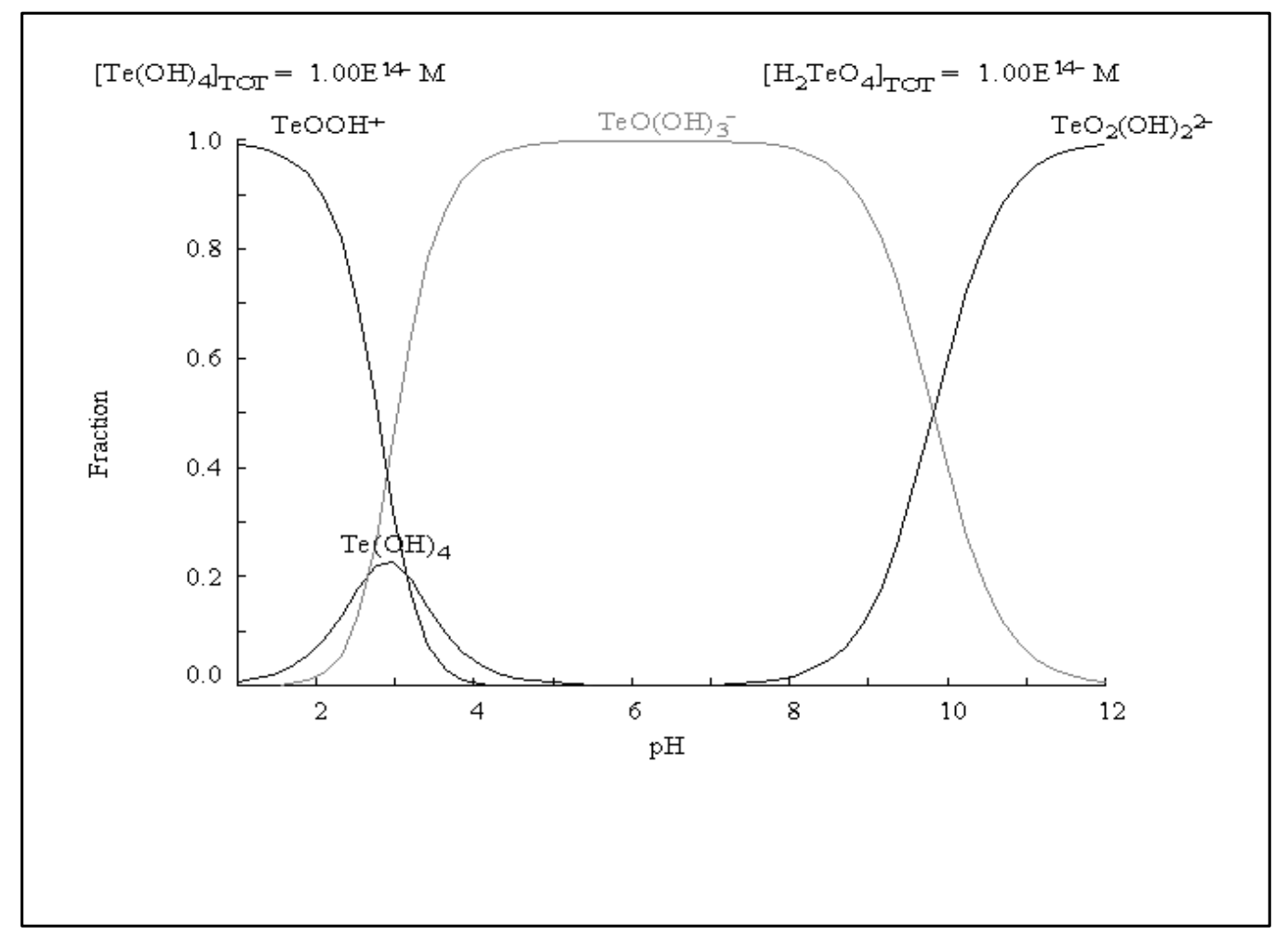

Fig. 10A. Diagrama de distribución de las especies químicas del telurio a $298 \mathrm{~K}$.

En la Figura 11 se muestra que a $\mathrm{pH}_{\mathrm{i}} 1$ se encuentra solamente una especie del ${ }^{95} \mathrm{Zr}$; el diagrama de distribución de especies del zirconio a $298 \mathrm{~K}$ de la Fig. 11A, obtenido por MEDUSA (Puigdomenech, 1999) indica que esta especie catiónica puede ser $\mathrm{Zr}(\mathrm{OH})^{3+}$. A $\mathrm{pH}_{\mathrm{i}} 3$ y 5 se encuentran dos especies de ${ }^{95} \mathrm{Zr}$, una catiónica probablemente $\mathrm{Zr}(\mathrm{OH})_{3}{ }^{+}$y una especie neutra $\mathrm{Zr}(\mathrm{OH})_{4}$ la cual se quedó en el punto de aplicación de la muestra. Sin embargo los rendimientos de estas dos especies son diferentes para los diferentes valores de $\mathrm{pH}_{\mathrm{i}}$ : a $\mathrm{pH}_{\mathrm{i}} 3,3.5 \pm 0.6 \%$ y $96.4 \pm 1.2 \%$ respectivamente y a $\mathrm{pH}_{\mathrm{i}} 5,17.6 \pm 0.5 \%$ y $82.4 \pm 0.4 \%$. A $\mathrm{pH}_{\mathrm{i}} 7$ se observa sólo la especie neutra $\mathrm{Zr}(\mathrm{OH})_{4}$. Por otro lado, a $\mathrm{pH}_{\mathrm{i}} 10$ se encuentra una especie aniónica de ${ }^{95} \mathrm{Zr}$ como único producto, probablemente $\mathrm{Zr}(\mathrm{OH})_{5}{ }^{\circ}$, según el programa MEDUSA (Puigdomenech, 1999) y Pourbaix, (1966). 

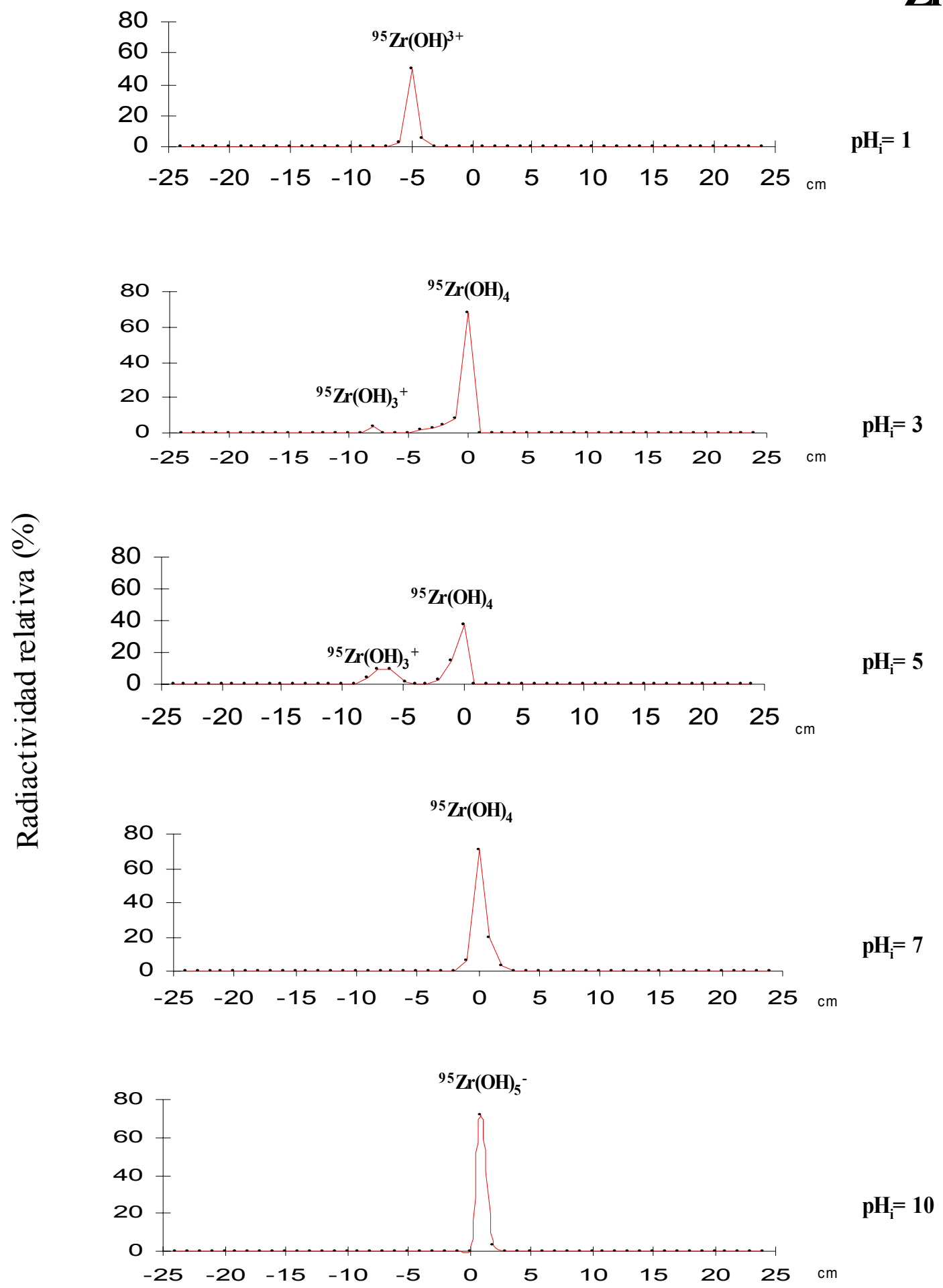

Fig. 11. Electroforegramas del ${ }^{95} \mathrm{Zr}$ a diferentes valores de $p H_{i}$ 


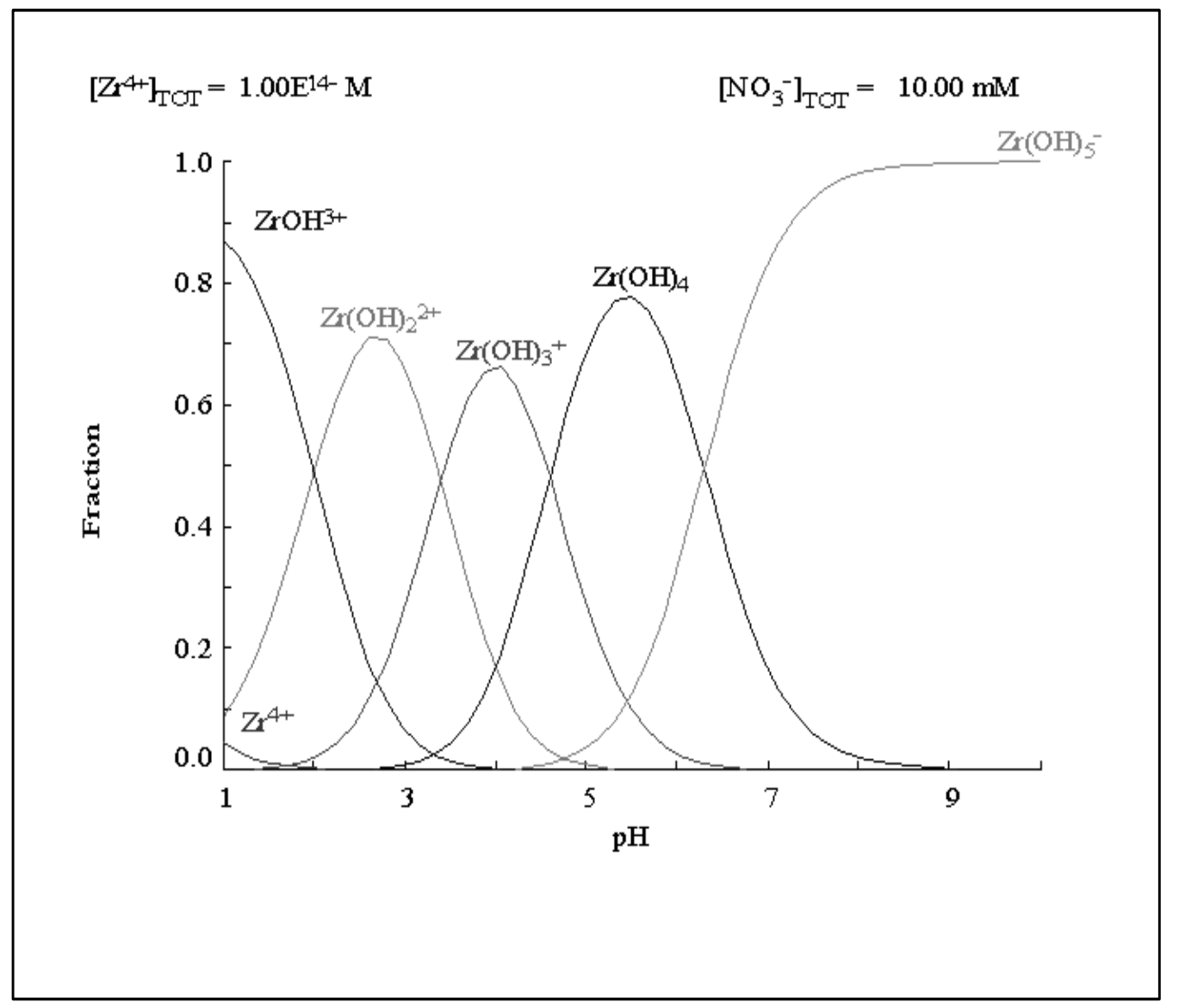

Fig. 11A. Diagrama de distribución de las especies químicas del zirconio a $298 \mathrm{~K}$.

Para el ${ }^{99} \mathrm{Mo}$, como se muestra en la Figura 12, a $\mathrm{pH}_{\mathrm{i}} 1$ y 3 , se encuentra una especie neutra observada en el punto de aplicación del papel en la electroforesis, con un rendimiento de $91.7 \pm 1.8 \%$ y $80.2 \pm 4.1 \%$ respectivamente. Esta especie neutra podría ser $\mathrm{H}_{2} \mathrm{MoO}_{4}$, como se observa en el diagrama de distribución de especies químicas del molibdeno a $298 \mathrm{~K}$ (Fig. 12A) obtenido por el programa MEDUSA (Puigdomenech, 1999). $\mathrm{A} \mathrm{pH}_{\mathrm{i}} 1$ y 3 la electroforesis muestra la presencia de una especie catiónica no 
identificada. $\mathrm{A} \mathrm{pH}_{\mathrm{i}} 5$ se encuentra una cantidad de iones $\mathrm{HMoO}_{4}{ }^{-}(38.9 \pm 0.7 \%)$ y otra cantidad mayor de iones molibdato $\mathrm{MoO}_{4}{ }^{2-}(61.1 \pm 0.2 \%)$. A pH 7 se observan los mismos aniones antes descritos pero en diferentes proporciones. Los iones $\mathrm{MoO}_{4}{ }^{2-} \mathrm{se}$ incrementan a $82.5 \pm 1.8 \%$. A $\mathrm{pH}_{\mathrm{i}} 10$ se encuentra una pequeña cantidad de una especie aniónica de molibdeno no identificada, la cual probablemente es una especie neutra formada durante la electroforesis, además de la especie aniónica predominante, el ion $\mathrm{MoO}_{4}{ }^{2-}$

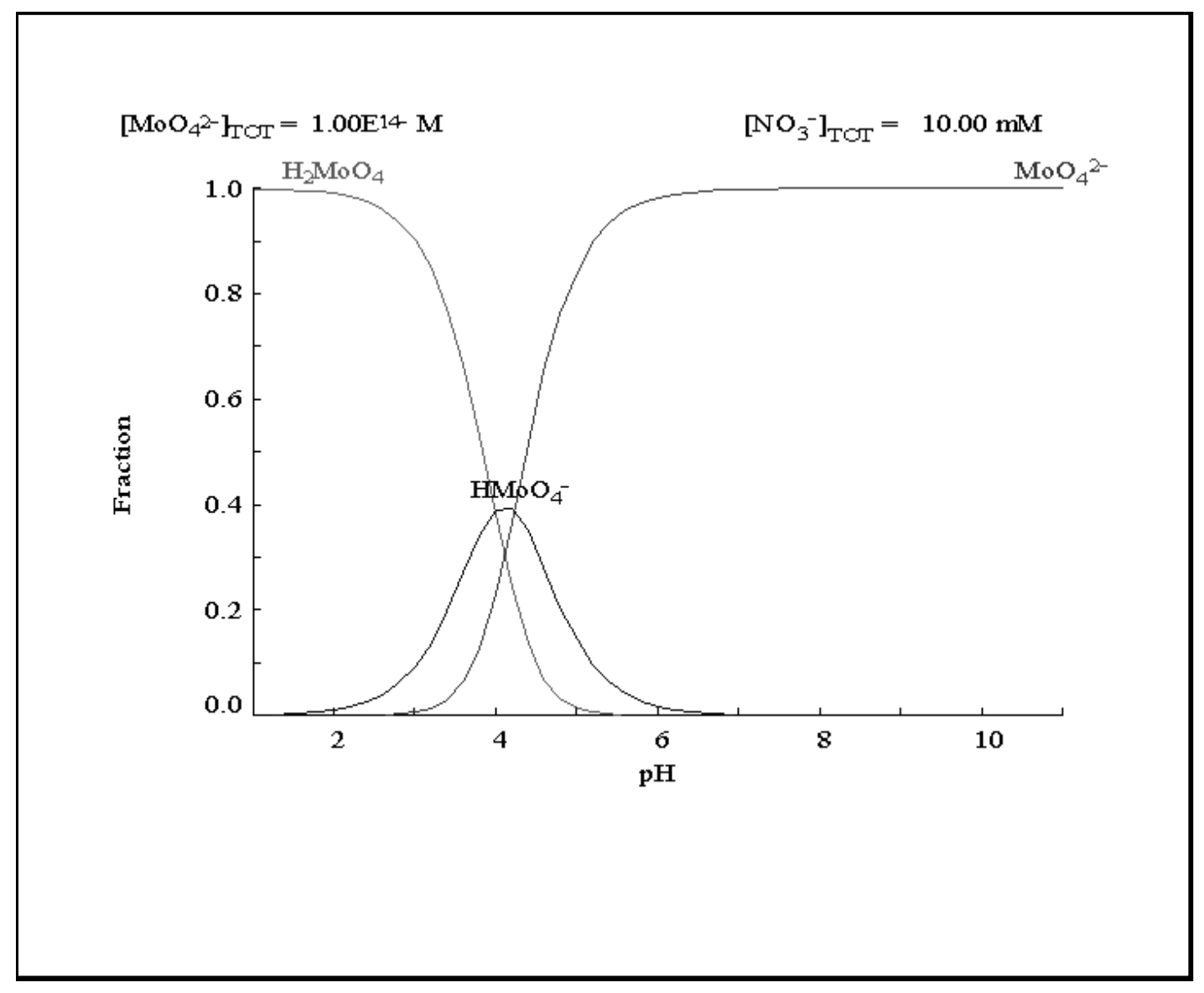

Fig. 12A. Diagrama de distribución de las especies químicas del molibdeno a $298 \mathrm{~K}$. 

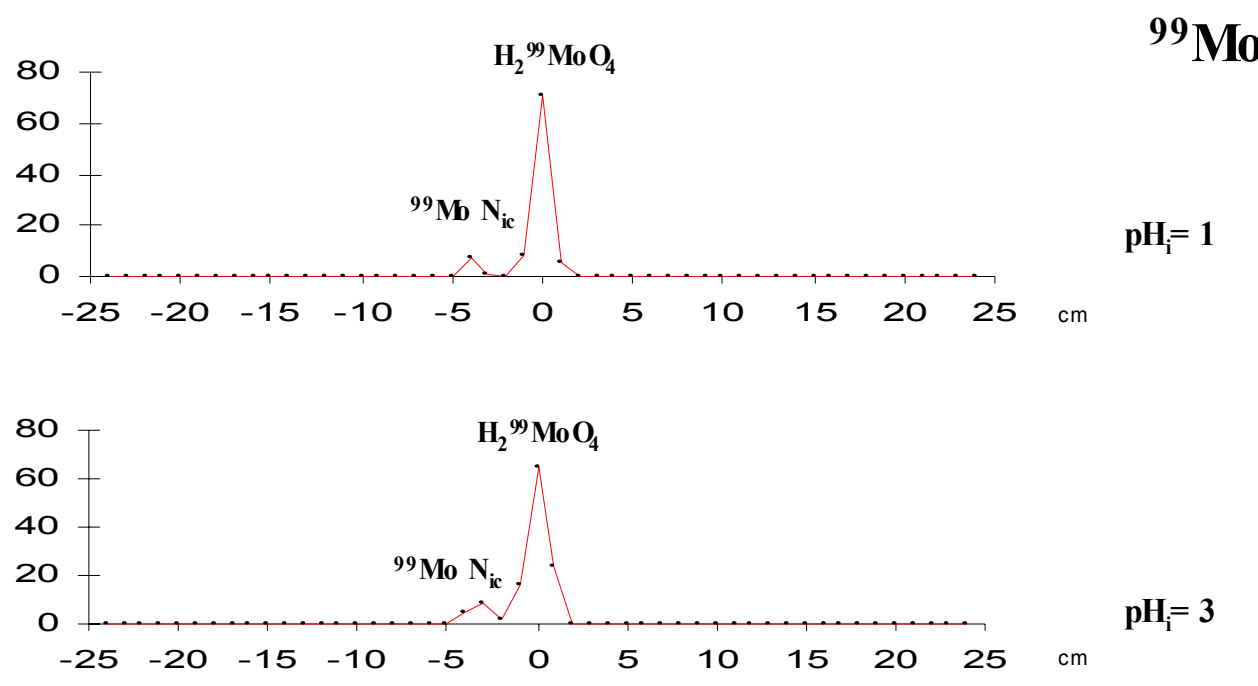

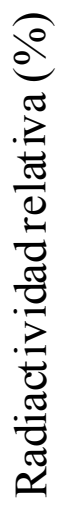
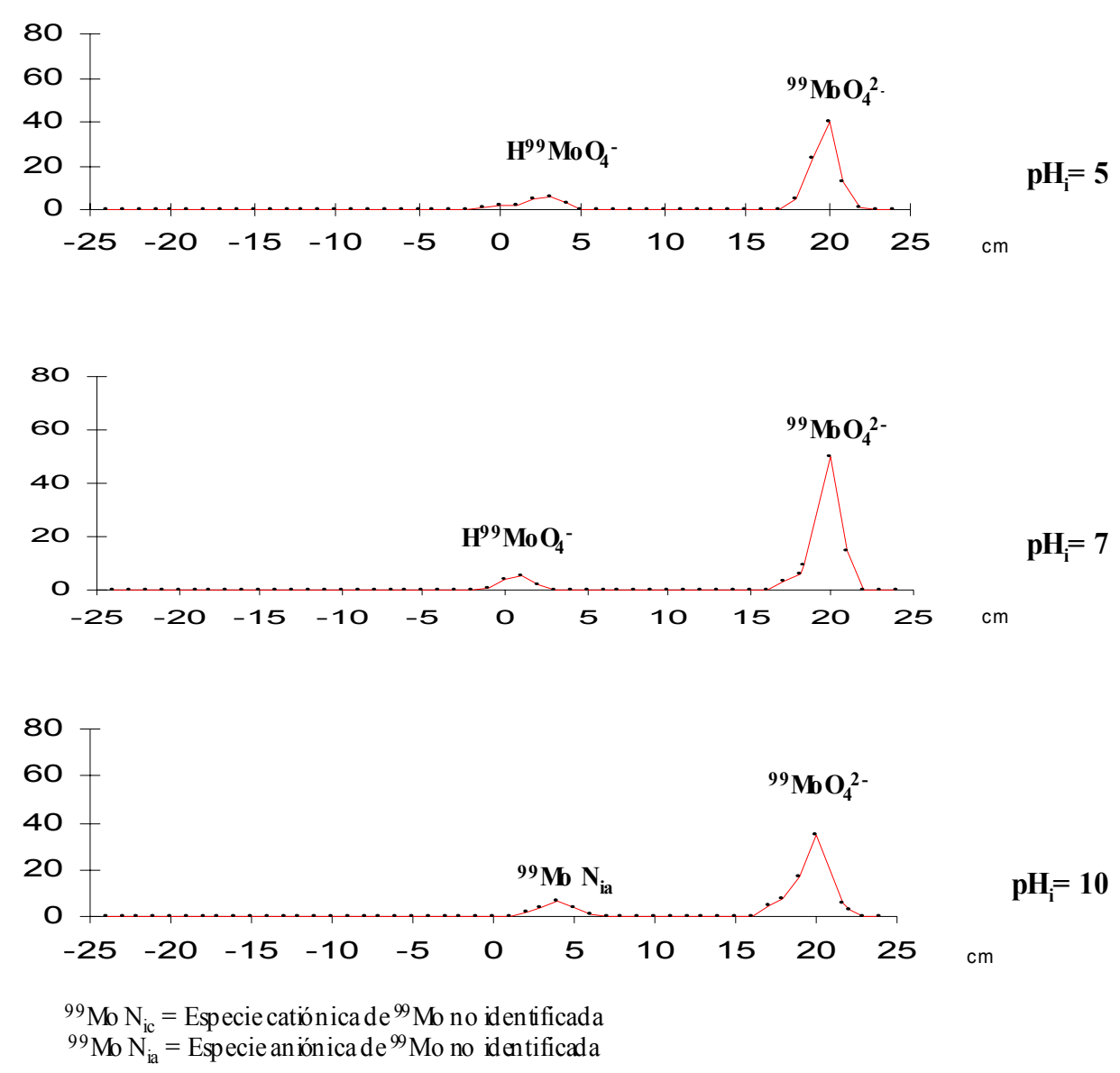

Fig. 12. Electroforegramas del ${ }^{99} \mathrm{Mo}$ a diferentes valores de $p H_{\mathrm{i}}$. 
Entre muchos otros productos de fisión, se encuentra también el ${ }^{103} \mathrm{Ru}$. En la disolución del ${ }^{235} \mathrm{U}$ irradiado con neutrones en $\mathrm{HNO}_{3}$, se forman numerosas especies neutras, aniónicas y particularmente complejos catiónicos de nitrosil rutenio, los cuales se transforman unos en otros más o menos rápidamente, dependiendo de las condiciones externas (Blasius et al., 1981). En nuestras condiciones experimentales encontramos cuatro especies del rutenio (Figura 13): una catiónica (probablemente $\left[{ }^{103} \mathrm{RuNO}(\mathrm{OH})_{2}\left(\mathrm{H}_{2} \mathrm{O}\right)_{3}\right]^{1+}$ ), una neutra (probablemente $\left.{ }^{103} \mathrm{RuNO}(\mathrm{OH})_{2}\left(\mathrm{H}_{2} \mathrm{O}\right)_{2}\right)$ y dos aniónicas (probablemente $\left.\left[{ }^{103} \mathrm{RuNO}(\mathrm{OH})_{4} \mathrm{H}_{2} \mathrm{O}\right]\right]^{1-}$ y $\left[{ }^{103} \mathrm{RuNO}(\mathrm{OH})_{5}\right]^{2-}$ ) (Sato y Motoki, 1983; Seddon y Seddon, 1984; Cotton y Wilkinson, 1988; Pourbaix, 1966; Griffith, 1967). Los resultados muestran que a muy bajas concentraciones y a valores de $\mathrm{pH}_{\mathrm{i}} 1,3$, 5,7 y 10 el principal producto formado es la especie neutra ${ }^{103} \mathrm{RuNO}(\mathrm{OH})_{2}\left(\mathrm{H}_{2} \mathrm{O}\right)_{2}$ y la cantidad formada aumenta con el $\mathrm{pH}_{\mathrm{i}}$. $\mathrm{A} \mathrm{pH}_{\mathrm{i}} 10$ se encuentra sólo la especie neutra en la solución. La especie aniónica monovalente $\left[{ }^{103} \mathrm{RuNO}(\mathrm{OH})_{4} \mathrm{H}_{2} \mathrm{O}\right]{ }^{1-}$ se encuentra sólo a valores de $\mathrm{pH}_{\mathrm{i}} 1$ y la especie aniónica bivalente se encuentra desde $\mathrm{pH}_{\mathrm{i}} 1$ hasta $\mathrm{pH}_{\mathrm{i}} 7$. La especie catiónica aparece sólo a $\mathrm{pH}_{\mathrm{i}} 5$ y 7. Los complejos de nitrosilo de rutenio cambian de uno a otro muy rápidamente. Las tres especies encontradas a $\mathrm{pH}_{\mathrm{i}} 1$ se encuentran también a $\mathrm{pH}_{\mathrm{i}} 3$, sin embargo el producto principal obtenido a $\mathrm{pH}_{\mathrm{i}} 3$ es la especie aniónica monovalente y no la especie neutra como la encontrada a otros valores de $\mathrm{pH}_{\mathrm{i}}$.

En la Tabla 3 se resumen los resultados anteriores, en donde se muestran las abundancias relativas de las principales especies químicas en solución acuosa del ${ }^{60} \mathrm{Co}$ y de los productos de fisión del ${ }^{235} \mathrm{U}$ encontradas por electroforesis de alto voltaje, a diferentes valores de $\mathrm{pH}$. 
${ }^{103} \mathrm{Ru}$
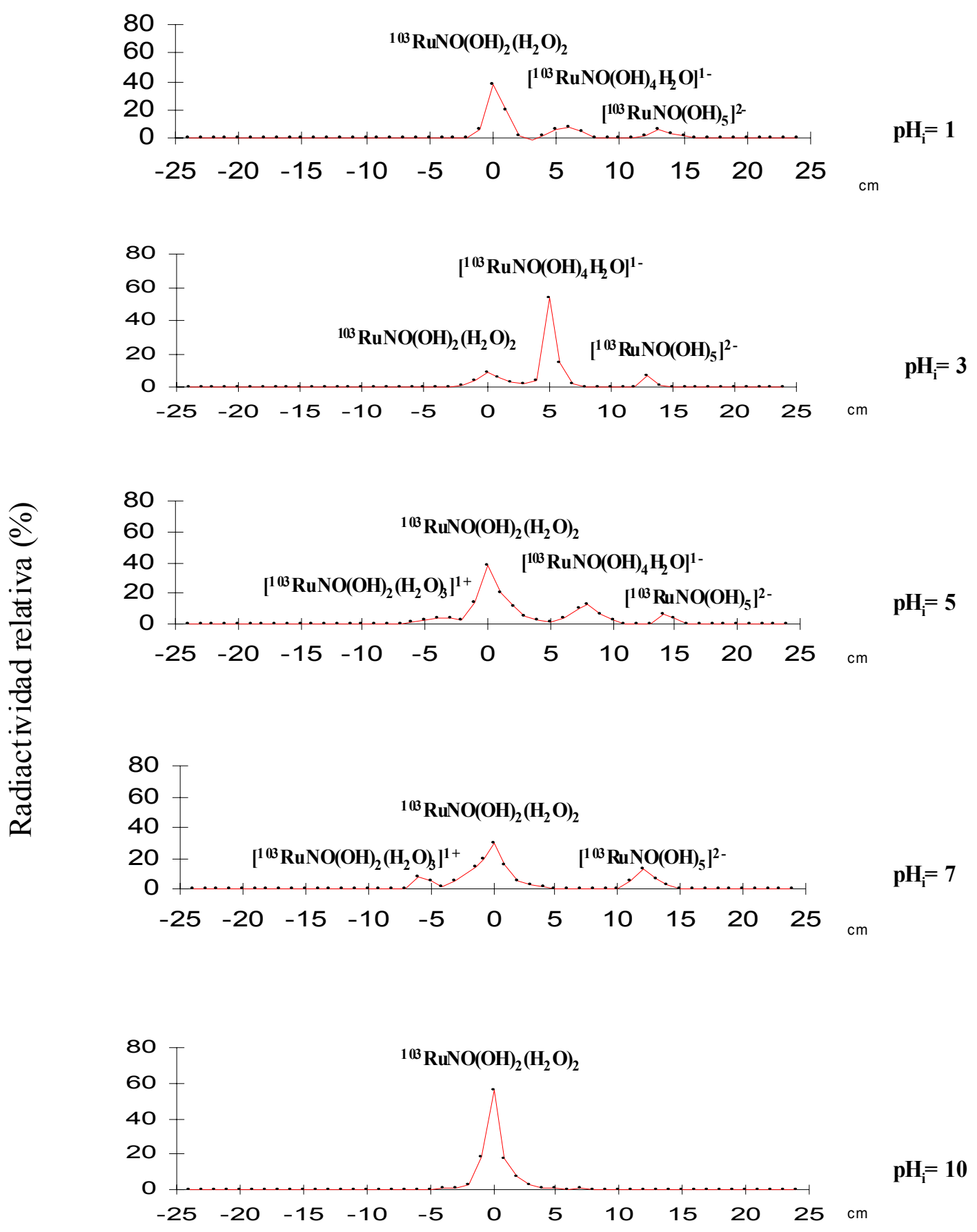

Fig. 13. Electroforegramas del ${ }^{103} \boldsymbol{R} \boldsymbol{u}$ a diferentes valores de $p H_{i}$. 
Dejar para tabla 3 


\subsection{Sorción de ${ }^{60} \mathrm{Co}$ y de los productos de fisión del ${ }^{235} \mathrm{U}$ en materiales inorgánicos.}

Los $\mathrm{pH}_{\mathrm{i}}$ de las soluciones de ${ }^{60} \mathrm{Co} \mathrm{y}$ de los productos de fisión: ${ }^{132} \mathrm{Te},{ }^{95} \mathrm{Zr},{ }^{99} \mathrm{Mo}$ y ${ }^{103} \mathrm{Ru}$ cambiaron al alcanzar el equilibrio después de poner en contacto las soluciones con los materiales inorgánicos. En la Tabla 4, se muestran los valores de $\mathrm{pH}$ iniciales, $\mathrm{pH}_{\mathrm{i}}$, y finales, $\mathrm{pH}_{\mathrm{f}}$, de los experimentos de sorción. En los párrafos siguientes se discuten los resultados obtenidos.

Tabla 4. Valores de $p H_{i}$ y $\mathrm{pH}_{f}$ de las soluciones de cobalto y de los productos de fisión del ${ }^{235} U$ antes y después de ponerlos en contacto con los materiales inorgánicos.

\begin{tabular}{|c|c|c|c|c|c|c|}
\hline \multirow[b]{3}{*}{ pH $H_{\text {inicial }}$} & \multicolumn{6}{|c|}{$p H_{\text {final }}$} \\
\hline & \multicolumn{6}{|c|}{ Materiales inorgánicos } \\
\hline & $\mathrm{MnO}_{2}$ & $\mathrm{TiO}_{2}$ & $\mathrm{MgO}$ & $\operatorname{SnO}$ & $\begin{array}{c}\text { Hidrotalcita } \\
\text { calcinada }\end{array}$ & $\begin{array}{l}\text { Carbón } \\
\text { activado }\end{array}$ \\
\hline 1 & $1.27 \pm 0.27$ & $1.31 \pm 0.42$ & $9.84 \pm 0.12$ & $1.31 \pm 0.11$ & $8.78 \pm 0.14$ & $1.40 \pm 0.32$ \\
\hline 3 & $3.02 \pm 0.5$ & $3.16 \pm 0.20$ & $10.71 \pm 0.19$ & $3.01 \pm 0.01$ & $10.42 \pm 0.23$ & $3.18 \pm 0.24$ \\
\hline 5 & $5.42 \pm .0 .45$ & $5.48 \pm 0.76$ & $10.62 \pm 0.21$ & $5.70 \pm 0.09$ & $10.45 \pm 0.22$ & $4.95 \pm 0.24$ \\
\hline 7 & $6.71 \pm 0.23$ & $6.57 \pm 0.45$ & $10.55 \pm 0.29$ & $6.64 \pm 0.21$ & $10.52 \pm 0.14$ & $6.57 \pm 0.42$ \\
\hline 10 & $9.67 \pm 0.5$ & $9.04 \pm 0.87$ & $10.87 \pm 0.19$ & $9.26 \pm 0.25$ & $10.54 \pm 0.16$ & $9.17 \pm 0.15$ \\
\hline
\end{tabular}




\subsubsection{Sorción de ${ }^{60} \mathrm{Co}$.}

La Figura 14 muestra la sorción de ${ }^{60} \mathrm{Co}$ en varios materiales inorgánicos a diferentes valores de $\mathrm{pH}_{\mathrm{f}}$. Como se observa en la Figura $14 \mathrm{a}$, el ${ }^{60} \mathrm{Co}$ no presentó una eficiente sorción en $\mathrm{MgO}$ en el intervalo de $\mathrm{pH}$ estudiado, alcanzó una máxima sorción de $35.4 \pm 3.3 \%$ a $\mathrm{pH}_{\mathrm{f}}$ de 10.8. Se observó que la sorción de ${ }^{60} \mathrm{Co}$ se incrementó de $8.5 \pm 1.3 \%$ hasta $35.4 \pm 1.3 \%$ al aumentar el valor de $\mathrm{pH}_{\mathrm{f}}$.

Se encontró en cambio que el ${ }^{60} \mathrm{Co}$ mostró una eficiente sorción en el $\mathrm{TiO}_{2}$ a valores de $\mathrm{pH}$ alcalinos (Fig. 14b), alcanzó una máxima sorción de $59.1 \pm 3.8 \%$. La sorción de ${ }^{60} \mathrm{Co}$ en $\mathrm{MnO}_{2}$ fue la más eficiente y se favoreció también en medio alcalino, alcanzando un máximo de $90.8 \pm 2.1 \%$ a $\mathrm{pH}_{\mathrm{f}}$ de 9.3 . En el caso del $\mathrm{SnO}$, su capacidad de sorción es muy baja, solamente se alcanzó un máximo de $9.6 \pm 2.9 \%$ a valores de $\mathrm{pH}$ alto, este material presentó un comportamiento de sorción similar al de los otros óxidos hidratados estudiados, su sorción aumentó con el $\mathrm{pH}_{\mathrm{f}}$.

La sorción de ${ }^{60} \mathrm{Co}$ sobre carbón activado, presenta un comportamiento semejante al de los óxidos hidratados antes mencionados, se favorece en condiciones alcalinas, alcanzando un máximo valor de $90.1 \pm 1.3 \%$ (Fig. 14b).

La sorción de ${ }^{60} \mathrm{Co}$ en la hidrotalcita calcinada fue poco eficiente (Fig. 14c), solamente alcanzó un máximo de $20.3 \pm 2.7 \%$, al $\mathrm{pH}_{\mathrm{f}}$ más alcalino, de 10.5 . 
${ }^{60} \mathrm{Co}$

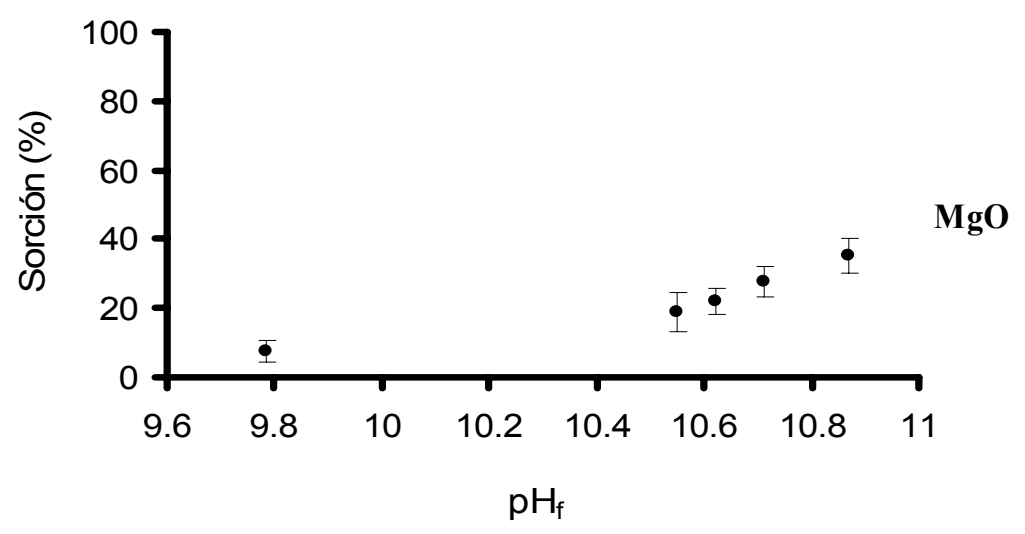

a)

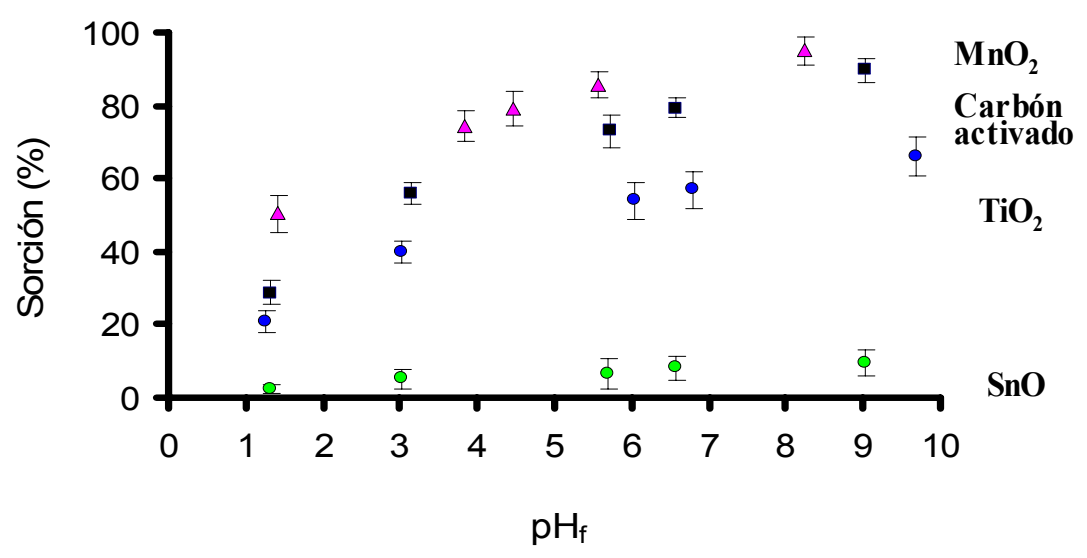

b)

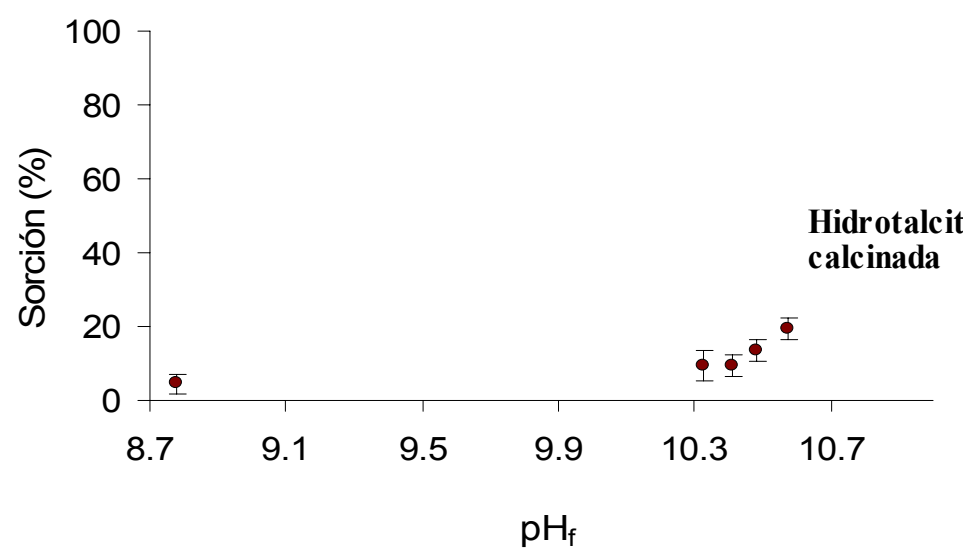

c)

Fig. 14. Sorción de ${ }^{60} \mathbf{C o}$ en sólidos inorgánicos a diferentes valores de $p H_{f}$. 
Para explicar el comportamiento de sorción del ${ }^{60} \mathrm{Co}$ en los sorbentes estudiados, se considera que la eficiencia de sorción de cobalto en los sólidos inorgánicos, puede ser debido a las diferentes características de los sorbentes (área específica, porosidad, potencial de carga cero (zpc), entre otras), así como de la concentración y tipo de especies químicas del radioisótopo que se encuentran en solución acuosa. Son por lo tanto, varios factores los que intervienen en la sorción. En primer lugar tenemos que considerar que el ${ }^{60} \mathrm{Co}$ está presente en las soluciones en concentraciones relativamente bajas. Un segundo factor es el efecto del $\mathrm{pH}_{\mathrm{f}}$ sobre la distribución de las especies químicas del cobalto. Un tercer factor, que también influye en el proceso de sorción, es el potencial eléctrico de la superficie del sorbente (zpc) y la superficie cargada en la interface óxido/ $\mathrm{H}_{2} \mathrm{O}$ que depende del $\mathrm{pH}_{\mathrm{f}}$ de la solución.

Como una consecuencia, cada uno o todos estos factores afectan la sorción del ${ }^{60} \mathrm{Co}$ en los materiales inorgánicos estudiados. En general podemos distinguir tres tipos de comportamientos de sorción muy diferentes según el material, primero en los óxidos hidratados: $\mathrm{MnO}_{2}, \mathrm{TiO}_{2}, \mathrm{MgO}$ y $\mathrm{SnO}$, segundo en la hidrotalcita calcinada y tercero en el carbón activado. A continuación discutiremos el comportamiento de sorción del ${ }^{60} \mathrm{Co}$, en estos tres tipos de sorbentes.

$\mathrm{Al}$ examinar el efecto del $\mathrm{pH}$ sobre la sorción del ${ }^{60} \mathrm{Co}$ sobre los sorbentes propuestos, como se observa en la Fig. 14, los mejores sorbentes para el ${ }^{60} \mathrm{Co}$ fueron $\mathrm{MnO}_{2}$, carbón activado y $\mathrm{TiO}_{2}$. Específicamente para los óxidos hidratados $\left(\mathrm{TiO}_{2}, \mathrm{MnO}_{2}, \mathrm{MgO}\right.$ y $\mathrm{SnO}$ ), se observó que la sorción se incrementa al incrementar el valor del $\mathrm{pH}$ de las soluciones. Como los óxidos hidratados adquieren carga eléctrica, por reacciones que involucran grupos funcionales $\left(\mathrm{H}^{+}, \mathrm{OH}^{-}\right)$sobre la superficie del mineral y los iones presentes en la solución; este tipo de carga es variable y depende considerablemente del $\mathrm{pH}$ de la solución y del punto de carga cero (zpc) de los materiales. Se conocen los puntos de carga cero (zpc) de algunos óxidos metálicos (Parks, 1965), estos valores son importantes 
en la sorción ya que reflejan la naturaleza de las especies sorbidas. A valores de $\mathrm{pH} \leq \mathrm{zpc}$, la superficie del sorbente estará cargada positivamente y a valores de $\mathrm{pH} \geq \mathrm{zpc}$ la superficie estará cargada negativamente. La sorción de cationes será por lo tanto favorable a valores de $\mathrm{pH}$ mayores que el zpc y lo contrario para los aniones. Por otro lado, los grupos hidroxilo presentes en la superficie de los óxidos permiten la interacción de las especies químicas en la solución debido a procesos de atracción o repulsión electrostática de cargas que puede estar acompañado por un mecanismo de intercambio iónico que es representado por la siguiente ecuación general:

$$
\mathbf{M O}_{\mathrm{x}} \cdot \mathrm{n}\left(\mathrm{H}_{2} \mathrm{O}\right)+\mathrm{mCo}^{2+} \leftrightarrows \mathrm{MO}_{\mathrm{x}} \cdot\left((\mathrm{n}-\mathrm{m}) \mathrm{H}_{2} \mathrm{OmCoO}+2 \mathrm{mH}^{+}\right.
$$

En donde $\mathbf{M}$ es el metal central del óxido hidratado, $m$ y $n$ son las cantidades molares del agua y de las especies químicas de intercambio, $x$ es la cantidad de átomos de oxígeno en la molécula. Experimentalmente se ha establecido, que el intercambio iónico que presentan los óxidos metálicos hidratados, se debe a que éstos adsorben el agua en la superficie de las partículas al contacto con ésta, creando una nueva superficie. El oxígeno del agua se enlaza con el metal mientras que los hidrógenos del agua quedan expuestos y son los que se intercambian por los iones metálicos de la solución (Kosowa, 1959; Guy et al., 1975). En una investigación sobre la sorción de $\mathrm{Cd}^{2+}$ en $\mathrm{MnO}_{2}$ (Contreras, 1999), se establece que el agua que contienen el sorbente, es la responsable del intercambio iónico. El agua que se presenta en los óxidos hidratados es de dos tipos: el agua adsorbida y el agua combinada (estructural) (Covington et al., 1962; Sasaki y Kosowa, 1957). Al sumergir las partículas en la solución, el agua adsorbida pasa a formar parte del agua de la solución (Fig. 15a). En cambio el agua combinada, que se mantiene en la partícula, es la principal responsable del intercambio iónico, efectuándose la reacción de intercambio iónico con el catión. Este mismo comportamiento puede ser aplicable al $\mathrm{Co}^{2+}$ de acuerdo al esquema mostrado en la Figura $15 \mathrm{~b}$. 

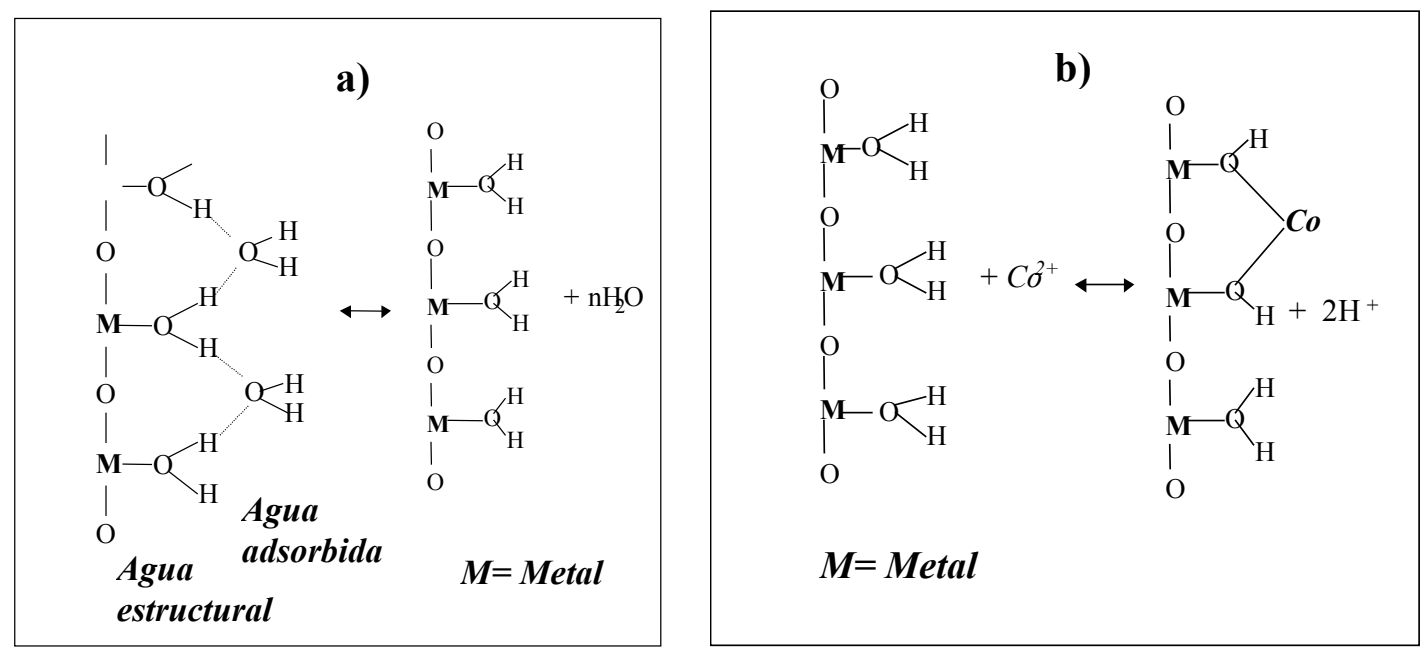

Fig. 15. a). Comportamiento del agua sorbida en el $\mathrm{MnO}_{2}$ al contacto con la solución. b). Reacción de intercambio iónico entre el $\mathrm{MnO}_{2}$ y el cobalto de la solución (Contreras, 1999).

La reacción de intercambio iónico que ocurre en el $\mathrm{MnO}_{2}$ con el $\mathrm{Co}^{2+}$ es:

$$
\mathrm{MnO}_{2} .5 \mathrm{H}_{2} \mathrm{O}+\mathrm{Co}^{2+} \leftrightarrows \mathrm{MnO}_{2} \cdot 4 \mathrm{H}_{2} \mathrm{OCoO}+2 \mathrm{H}^{+}
$$

Por lo tanto, la reacción de intercambio iónico que entre el $\mathrm{MnO}_{2}$ y el catión en solución, ocurre al ser intercambiado el ión hidrógeno adquirido por el $\mathrm{MnO}_{2}$ en presencia de agua y el cation $\mathrm{Co}^{2+}$ de la solución. Por lo tanto como se mencionó anteriormente, el agua estructural es la principal responsable del intercambio iónico ocurrido entre el $\mathrm{MnO}_{2}$ y el $\mathrm{Co}^{2+}$ en la solución, ya que es el agua la aportadora del ión hidrógeno que se intercambia por el catión en solución, sin embargo no toda el agua estructural participa en el intercambio, porque el agua está distribuida en todo el grano del dióxido hidratado y el intercambio ocurre superficialmente. 
En forma general, el mecanismo de sorción que presenta el $\mathrm{MnO}_{2}$ frente al cobalto, es debido a un proceso de intercambio iónico, este comportamiento de sorción ha sido observado por los óxidos hidratados para una variedad de cationes presentes en solución acuosa.

Por otra parte, el $\mathrm{TiO}_{2}$, es un sorbente ampliamente estudiado ya que se han probado sus propiedades de intercambio iónico para algunos iones metálicos en solución acuosa. Las propiedades de intercambio iónico del $\mathrm{TiO}_{2}$ también son debidas a la presencia de grupos hidroxilo en su superficie obtenidos por hidratación (Jakobsson y Albinsson, 1998; Samanta, 1996; Mishra y Singh, 1995; Bhutani, et al., 1994; Hasany et al., 1997). El comportamiento que se presenta en condiciones ácidas (intercambio catiónico) o en condiciones alcalinas (intercambio aniónico) del grupo $\mathrm{M}-\mathrm{OH}$ de los óxidos metálicos al estar hidratados, es determinado por la naturaleza del metal central $(M)$ y por las fuerzas relativas de los enlaces del metal con el oxígeno y los grupos hidroxilo; $\mathrm{M}-\mathrm{O}$ y $\mathrm{M}-\mathrm{OH}$ (Samanta, 1996). En el dióxido de titanio (IV), el potencial iónico grande del ion titanio (IV) confiere una densidad electrónica baja en el enlace $O-H$. Esto facilita el desprendimiento de iones $\mathrm{H}^{+}$y entonces el dióxido de titanio hidratado actúa como un intercambiador catiónico de acuerdo al siguiente esquema propuesto por Mishra et al., 1992:

$$
\begin{gathered}
\mathrm{TiOH}_{2}^{+} \underset{H^{+}}{\stackrel{O H}{\longrightarrow}} \mathrm{TiOH}^{0}+\mathrm{H}^{+} \\
\mathrm{TiOH}^{0} \stackrel{O H}{\longleftarrow} \mathrm{TiO}^{-}+\mathrm{H}^{+} \\
\mathrm{TiO}^{-}+\mathrm{M}_{\mathrm{e}}^{\mathrm{n}+} \stackrel{O H}{\longleftarrow} \mathrm{TiOM}_{\mathrm{e}}^{(\mathrm{n}-1)+}
\end{gathered}
$$


En la ecuación (9) el dióxido de titanio bajo la hidratación puede protonarse o desprotonarse en su superficie debido a la dependencia del $\mathrm{pH}$ del medio. A altos valores de pH de la solución, se lleva a cabo la reacción (10) y esto facilita la sorción de los iones metálicos de acuerdo a la reacción (11). Es por lo tanto posible establecer que a valores de $\mathrm{pH}$ altos, los grupos hidroxilos de la superficie del dióxido de titanio se disocian en $\mathrm{TiO}^{-}$ que tiende a experimentar un intercambio catiónico en caso particular con el cobalto. En otras palabras, en un medio alcalino (valores de $\mathrm{pH}$ mayores al punto de carga cero (zpc) del $\left.\mathrm{TiO}_{2}=6.7\right)$ el sorbente posee una superficie cargada negativamente, la cual es responsable de la creación de sitios de sorción, y a medida de que la solución se hace más alcalina, se sorben más iones. Por otro lado, a bajos valores de pH (debajo del zpc) la superficie del dióxido es positiva y presenta una gran afinidad por los aniones, y como resultado la sorción de cationes es mínima en las regiones ácidas. Por lo que la fijación de los cationes $\mathrm{Co}^{2+}$ sobre el $\mathrm{TiO}_{2}$ es principalmente atribuido al intercambio directo de los iones con un grupo especifico sobre la superficie del óxido. Las especies predominantes del ${ }^{60} \mathrm{Co}$ presentes en la solución acuosa, analizadas por electroforesis de alto voltaje, corresponden a la especie octaédrica $\mathrm{Co}\left(\mathrm{H}_{2} \mathrm{O}\right)_{6}{ }^{2+}$ según Baes y Mesmer, (1976); Flores, et al., (1998). Es importante notar que la presencia de esta especie catiónica, influye sobre la eficiencia de sorción del ${ }^{60} \mathrm{Co}$ sobre el $\mathrm{TiO}_{2}$ en medio alcalino. Por otro lado se observa, en condiciones alcalinas, la presencia de la especie neutra $\mathrm{Co}(\mathrm{OH})_{2}$ en solución acuosa, que se precipita sobre la superficie del sorbente, provocando la sorción del cobalto a estos altos valores de $\mathrm{pH}$, comportamiento que fue observado en nuestros resultados. Este comportamiento de sorción de cationes bivalentes en el $\mathrm{TiO}_{2}$ con el incremento del $\mathrm{pH}$, ha sido también observado por (Tiwary et al., 1972; Yamazaki et al., 1995; James y Healy, 1972; Kinniburgh et al., 1975).

Los mecanismos de intercambio iónico para los óxidos hidratados: $\mathrm{MgO}$ y $\mathrm{SnO}$ son semejantes a los descritos anteriormente para el $\mathrm{TiO}_{2}$, sin embargo, las diferencias en la eficiencia de sorción entre estos sorbentes, puede ser debido a la propia naturaleza del metal o a las propias características superficiales del sorbente. En el caso específico del $\mathrm{SnO}$, este material no tiene buenas propiedades de sorción de ${ }^{60} \mathrm{Co}$ probablemente: 1) 
debido a que tiene una muy baja área específica comparada con los otros óxidos hidratados (Tabla 2) o 2) debido al potencial iónico del estaño en el sorbente, que es menor al de los otros óxidos. Esta propiedad le confiere una alta densidad electrónica en el enlace $O-H$, de su superficie la cual no facilita la liberación del hidrógeno disponible para el intercambio catiónico. Sin embargo se puede observar un muy ligero incremento en la sorción al aumentar el valor de $\mathrm{pH}$ de la solución, como sucede con los otros óxidos metálicos, que a medida que se incrementa el $\mathrm{pH}$, se incrementan los sitios negativos de sorción en la superficie, es decir el incremento de sorción con el incremento del $\mathrm{pH}$ es debido a la acumulación de cargas negativas sobre la superficie.

Para el caso del carbón activado, la sorción del ${ }^{60} \mathrm{Co}$, fue eficiente, considerando que este material se caracteriza por contar con una alta área específica $\left(1247.7 \mathrm{~m}^{2} / \mathrm{g}\right)$ que le provee gran cantidad de sitios activos, que permiten la sorción de una considerable concentración del sorbato. Además este material cuenta con una alta porosidad, que le provee de más sitios activos en la superficie, disponibles para un fácil acceso del sorbato (Slejko, 1985).

La sorción de ${ }^{60}$ Co sobre hidrotalcita calcinada (Fig. 14c), es escasa. Como se describió anteriormente, la especie químicas predominante del cobalto presente en solución acuosa, es la especie catiónica bivalente, $\mathrm{Co}^{2+}$, que no puede, por su carga positiva, ubicarse en el espacio interlaminar de la hidrotalcita calcinada evitando que se regenere la estructura laminar original, por el llamado "efecto de memoria" (Sato et al., 1998). Sin embargo como se observa en la Figura 14c, se encontró una pequeña sorción de cobalto sobre la hidrotalcita calcinada, debido esto a la precipitación de la especie neutra $\mathrm{Co}(\mathrm{OH})_{2}$ presente en la solución. Esta especie fue observada mediante electroforesis de alto voltaje (Fig. 9). Por lo tanto la sorción de iones sobre la superficie de los materiales puede involucrar la precipitación de las especies neutras sobre las superficies de los sorbentes. 
$\mathrm{Al}$ estudiar la caracterización del $\mathrm{MnO}_{2}$ original y del $\mathrm{MnO}_{2}$ intercambiado con el $\mathrm{Co}^{2+}$ mediante un análisis térmico, se observó lo siguiente:

La curva del análisis termogravimétrico (TGA) de la muestra de $\mathrm{MnO}_{2}$ original (Fig. 16a), muestra cambios que indican la pérdida de masa de la muestra en función de la temperatura. Se observa de 50 a $150{ }^{\circ} \mathrm{C}$ una pérdida atribuida a la humedad. De 200 a $250{ }^{\circ} \mathrm{C}$ es atribuida a la pérdida de agua de cristalización del sólido e inicio de la deshidroxilación del $\mathrm{MnO}_{2}$. Una tercera pérdida de peso observada a $442.55{ }^{\circ} \mathrm{C}$, es atribuida a la deshidroxilación total de la muestra con eliminación de agua.

La curva de análisis termogravimétrico obtenida con la muestra de $\mathrm{MnO}_{2}$ intercambiada con cobalto (Fig. 16b), mostró cambios notorios de la pendiente en varios puntos de la curva, como en el caso anterior. Entre $53{ }^{\circ} \mathrm{C}$ y $450{ }^{\circ} \mathrm{C}$ se observa una pequeña pérdida de peso del $2 \%$ atribuida a la pérdida de humedad. Se observa en el intervalo de 550 a $800{ }^{\circ} \mathrm{C}$, dos perdidas de peso principales, la primera entre 520 y 680 ${ }^{\circ} \mathrm{C}$ de $30 \%$ debido a la pérdida de agua de cristalización y la segunda entre 680 y 1000 ${ }^{\circ} \mathrm{C}$ debido a la eliminación de agua por deshidroxilación de la muestra. 

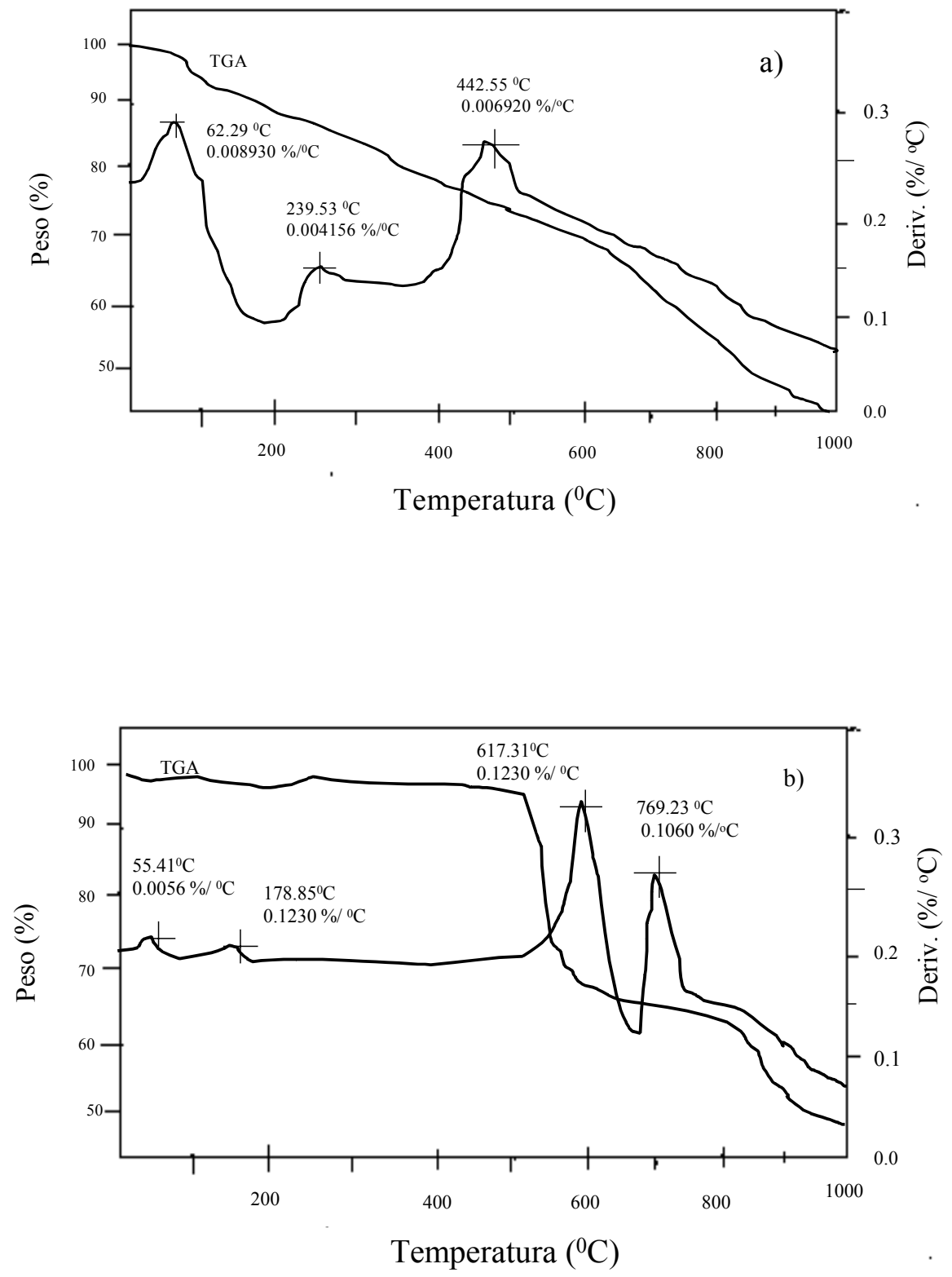

Fig. 16. Diagrama de $\mathrm{TGA}$ de a) $\mathrm{MnO}_{2}$ original y b) $\mathrm{MnO}_{2}$ intercambiado con cobalto. 
El patrón de difracción de rayos $\mathrm{X}$ del $\mathrm{MnO}_{2}$ original se muestra en la Figura 17a. Es un compuesto cristalino, con picos finos en su patrón de difracción, se identifica con el $\mathrm{MnO}_{2}$ pirolucita según la tarjeta JCPDS 24-0735. El patrón de difracción de rayos $\mathrm{X}$ del $\mathrm{MnO}_{2}$ intercambiado con cobalto (Fig. 17b), no muestra alteración en la estructura cristalina del $\mathrm{MnO}_{2}$ pirolucita después del proceso de sorción del $\mathrm{Co}^{2+}$. El cobalto no se detecta en el patrón de difracción, porque la concentración de cobalto es muy pequeña.

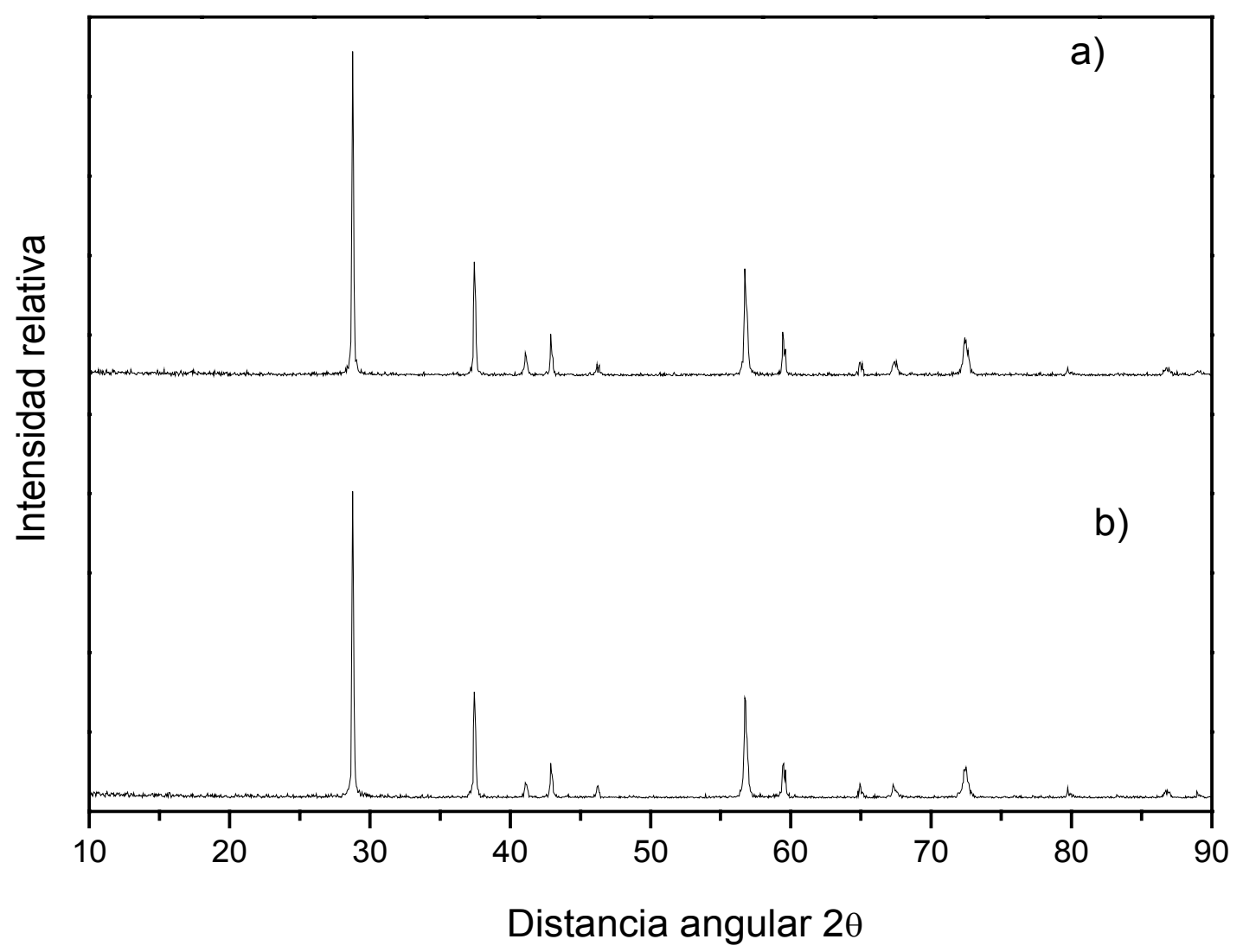

Fig. 17. Patrón de difracción del a) $\mathrm{MnO}_{2}$ original y b) $\mathrm{MnO}_{2}$ intercambiado con cobalto. 
La micrografía de la Fig. 18Aa nos muestra las partículas del $\mathrm{MnO}_{2}$ utilizado como sorbente del cobalto, con una ampliación de 200x. Se aprecia que las partículas presentan un sistema rugoso formado por aglomerados compactos de cristales, con un tamaño aproximado de $100 \mu \mathrm{m}$. El aglomerado es homogéneo y compactado y existe una concentración de pequeños cristales dispersos a su alrededor. El microanálisis elemental de este material (Fig. 18Ab), muestra semicuantitativamente los porcentajes en peso de los elementos. En éste, se aprecia que los principales elementos contenidos en las partículas son oxígeno y manganeso.
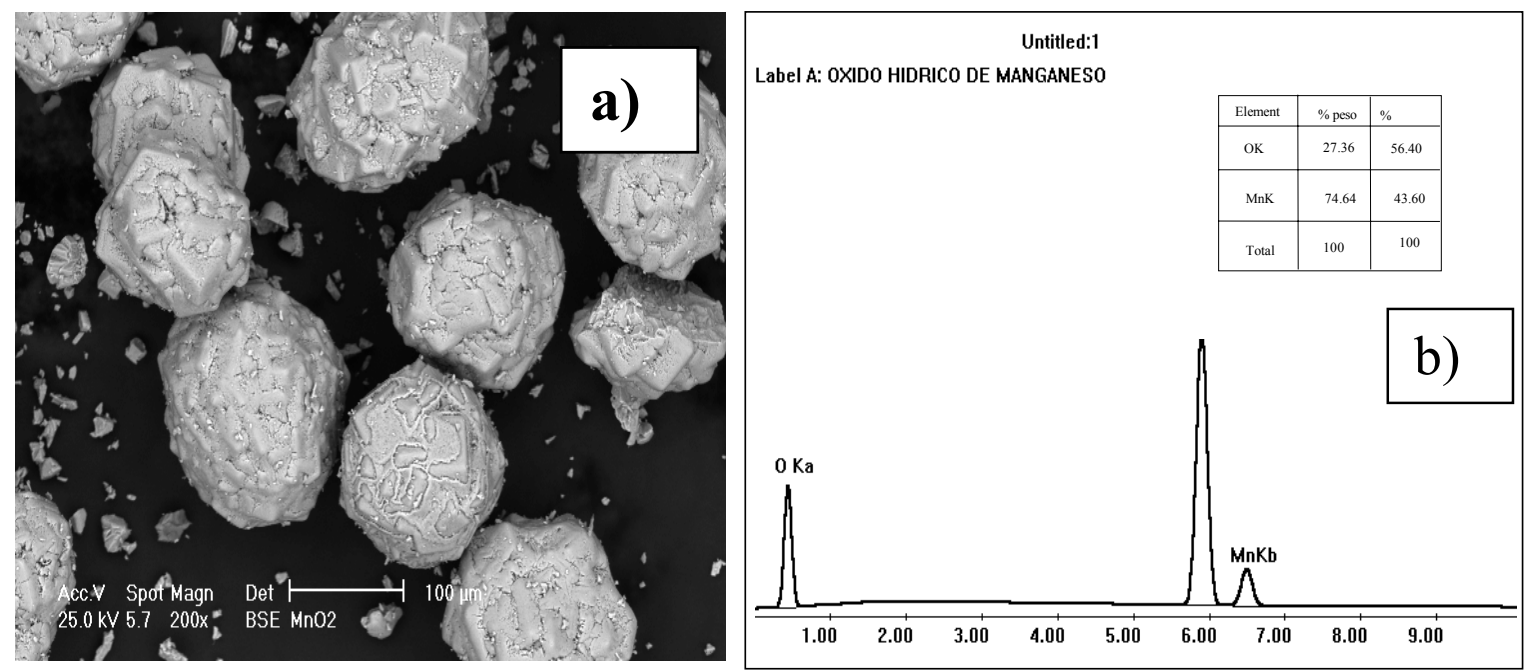

Fig. 18A. a) Imagen obtenida por microscopía electrónica de barrido de una muestra de $\mathrm{MnO}_{2}$ antes de la sorción con cobalto y b) análisis microelemental. 
La Figura 18Ba muestra una imagen obtenida por microscopía electrónica de barrido del dióxido de manganeso después de utilizarlo como sorbente del cobalto, con una ampliación de 200x. La morfología del material es similar al $\mathrm{MnO}_{2}$ original con cristales homogéneos y compactados de tamaño aproximado de $100 \mu \mathrm{m}$ como se muestra en la Fig. 18A. Sin embargo en la presente micrografía, es notorio la presencia de otros cristales lisos y claros, que podrían ser atribuidos a una sal de cobalto. El resultado del análisis microelemental realizado a esta muestra, indica la presencia de cobalto (Fig. 18Bb)
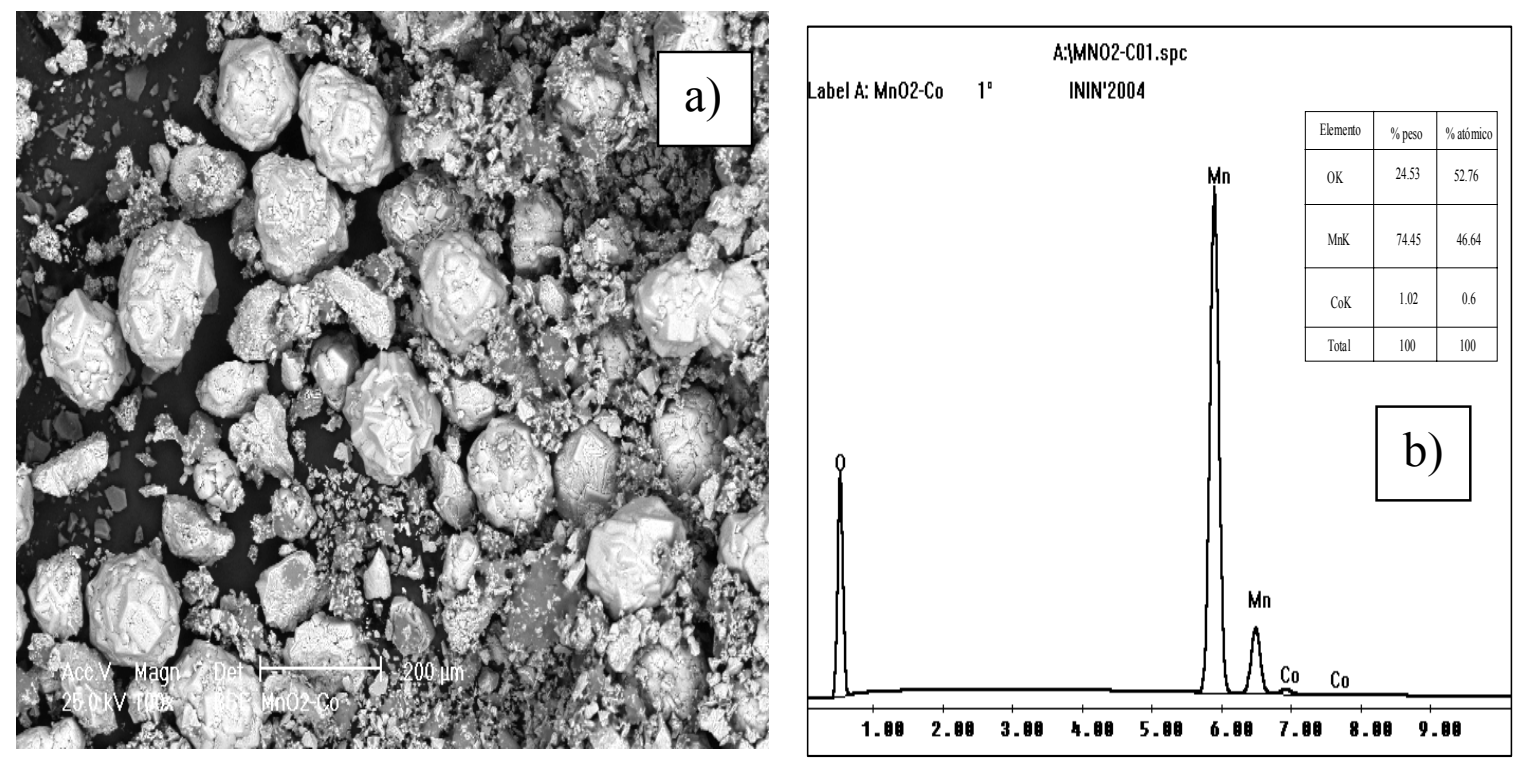

Fig. 18B. a) Imagen obtenida por microscopía electrónica de barrido de una muestra de $\mathrm{MnO}_{2}$ después de la sorción de cobalto y b) análisis microelemental. 


\subsubsection{Sorción de ${ }^{132}$ Te.}

La Figura 19 muestra la sorción de ${ }^{132} \mathrm{Te}$ en varios materiales inorgánicos a diferentes valores de $\mathrm{pH}_{\mathrm{f}}$. $\mathrm{El} \mathrm{MgO}$ retuvo al ${ }^{132} \mathrm{Te}$, con una eficiencia de sorción del $98.9 \pm 0.4 \%$ a $\mathrm{pH}_{\mathrm{f}} 10.8$ y $71.2 \pm 0.3 \%$ a $\mathrm{pH}_{\mathrm{f}} 9.8$ (Fig. 19a). Por lo tanto el ${ }^{132} \mathrm{Te}$ de la solución acuosa, se sorbió en el sólido con un valor máximo en el intervalo de $\mathrm{pH}_{\mathrm{f}}$ de 10.5 a 10.8 .

El carbón activado alcanzó una máxima sorción de $90.4 \pm 2.6 \%$ a $\mathrm{pH}_{\mathrm{f}} 8$, mientras que a $\mathrm{pH}_{\mathrm{f}} 1.4$, la sorción fue de sólo $50.4 \pm 2.2 \%$ (Fig. 19b).

$\mathrm{El} \mathrm{TiO}_{2}$ logró una máxima sorción de $83.9 \pm 1.1 \% \mathrm{a} \mathrm{pH}_{\mathrm{f}} 9$, mientras que entre $\mathrm{pH}_{\mathrm{f}}$ 1 y 3 disminuyó considerablemente, logrando un $13.8 \pm 1.9 \%$ a pH 1 (Fig. 19b).

Por otro lado, los resultados mostraron que el $\mathrm{MnO}_{2}$ y $\mathrm{SnO}$ presentan muy bajos rendimientos de sorción de ${ }^{132} \mathrm{Te}$, ya que en condiciones alcalinas se alcanza una máxima sorción de $33.4 \pm 1.4 \%$ para $\mathrm{MnO}_{2}$ y de $25.9 \pm 3.5 \%$ para $\mathrm{SnO}$ respectivamente (Fig. 19b).

La sorción de ${ }^{132} \mathrm{Te}$ sobre hidrotalcita calcinada alcanzó un máximo de $99.3 \pm 0.3 \%$ a $\mathrm{pH}_{\mathrm{f}} 10.6$, y se observa una ligera disminución hasta $85.6 \pm 0.2 \%$, cuando la solución se hace menos alcalina (Fig. 19c). 
${ }^{132} \mathrm{Te}$

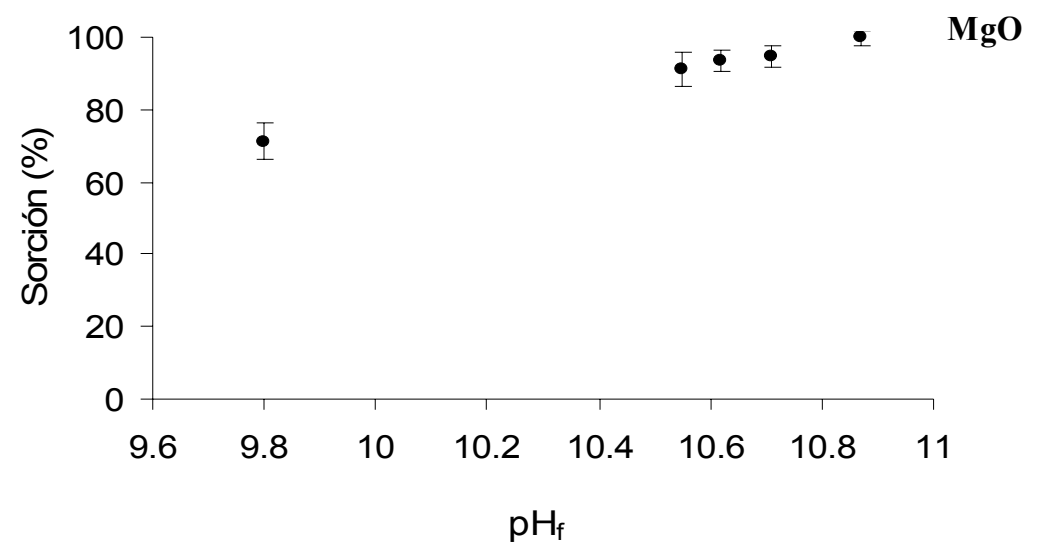

a)

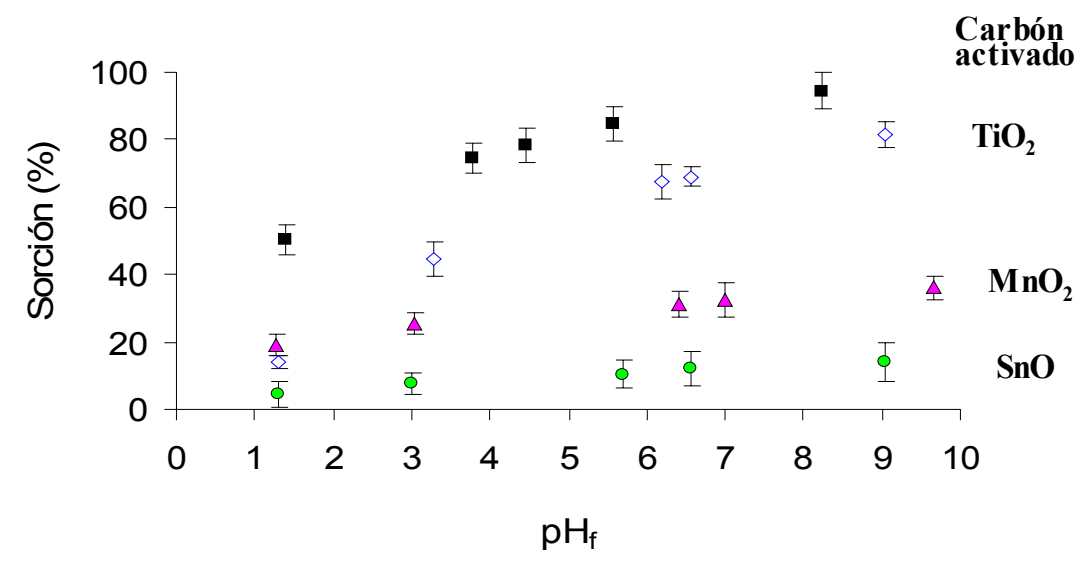

b)

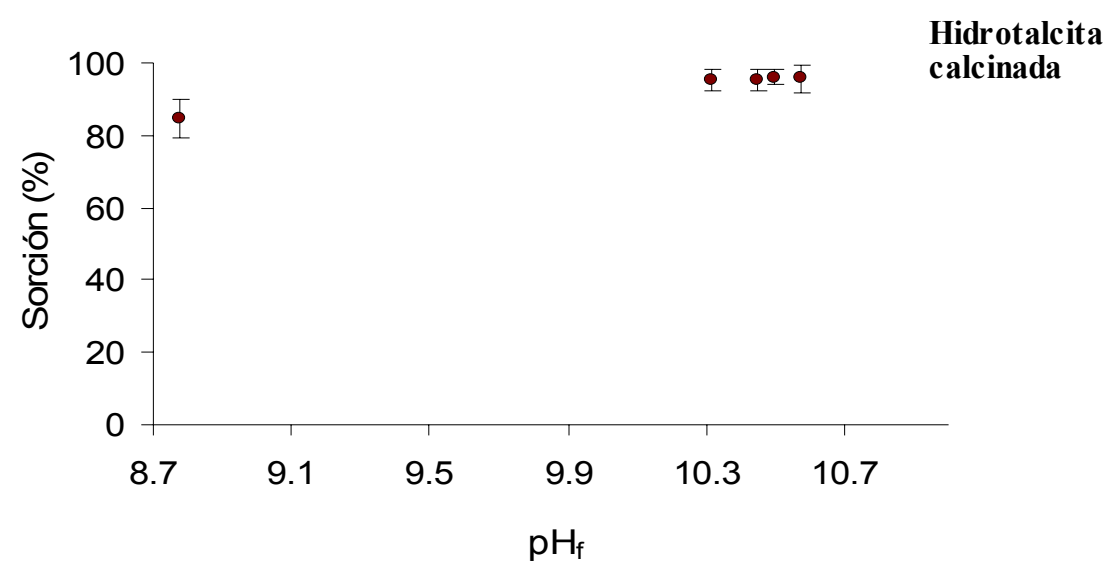

c)

Fig. 19. Sorción de ${ }^{132}$ Te en sólidos inorgánicos a diferentes valores de $p H$. 
En la sorción de ${ }^{132} \mathrm{Te}$, se observó que cuando el $\mathrm{MgO}$ se pone en contacto con las soluciones acuosas de los productos de fisión del ${ }^{235} \mathrm{U}$, el valor de $\mathrm{pH}$ de las soluciones en equilibrio, aumentan considerablemente, tal como se muestra en los resultados obtenidos en la Tabla 4. Este comportamiento es debido a que parte del óxido de magnesio se hidroliza y empieza a formarse una mezcla de $\mathrm{Mg}(\mathrm{OH})_{2}$ y $\mathrm{MgO}$, incrementando así el pH de las soluciones, que está en función directa con la cantidad de $\mathrm{MgO}$ presente en la solución acuosa (Lin et al., 1998). En el presente estudio fue clara la presencia de especies aniónicas del ${ }^{132} \mathrm{Te}$ a valores de $\mathrm{pH}$ altos (Tabla 3), tales como $\left(\mathrm{TeO}(\mathrm{OH})_{3}{ }^{-}\right.$y $\left.\mathrm{TeO}_{2}(\mathrm{OH})_{2}{ }^{2-}\right)$; no se encontró ninguna especie catiónica a valores de $\mathrm{pH}$ altos. La sorción de estas especies aniónicas fue muy eficiente en $\mathrm{MgO}$ (mayor del 97\%). Este comportamiento de sorción, se puede explicar en base a que la superficie de óxido de magnesio en la solución acuosa presenta una carga superficial que depende de su punto de carga cero (zpc) y del pH de la solución. El MgO tiene un zpc a pH 12.4 (Parks, 1965) lo que significa que debajo del $\mathrm{pH}$ 12.4, la superficie se carga positivamente, mientras que arriba del pH 12.4 se carga negativamente. Así, la sorción de todas las especies aniónicas del ${ }^{132} \mathrm{Te}$ puede atribuirse principalmente a la atracción natural de especies cargadas negativamente con la superficie del óxido cargada positivamente. Observamos que cuando el $\mathrm{pH}_{\mathrm{f}}$ es 9.8 , la sorción del ${ }^{132} \mathrm{Te}$ es de $70 \%$, probablemente porque no existen especies aniónicas y la sorción se deba sólo a que se empieza a formar el $\mathrm{Te}(\mathrm{OH})_{4}$ que es una especie neutra y que se precipita sobre la superficie del MgO.

El $\mathrm{TiO}_{2}, \mathrm{MnO}_{2}$ y $\mathrm{SnO}$ tienen valores de zpc de 6.7, 4.5 y 6.6 respectivamente de acuerdo a Parks, (1965). Si las especies de ${ }^{132}$ Te fueran capturadas en estos sólidos por las propiedades de carga superficial, solamente las especies aniónicas podrían ser atraídas sobre el $\mathrm{TiO}_{2}, \mathrm{MnO}_{2}$ y $\mathrm{SnO}$ a valores más bajos que estos $\mathrm{pH}$, y las especies catiónicas por encima de estos valores de $\mathrm{pH}$. Sin embargo no hay especies aniónicas del ${ }^{132} \mathrm{Te}$ debajo de $\mathrm{pH} 6.7$, y no hay especies catiónicas arriba del $\mathrm{pH}$ 4.5. Por lo tanto las especies catiónicas y aniónicas del ${ }^{132} \mathrm{Te}$ no son atraídas sobre la superficie cargada de 
los óxidos $\mathrm{TiO}_{2}, \mathrm{MnO}_{2}$ y $\mathrm{SnO}$, lo que prueba que las propiedades eléctricas de las superficies de los óxidos, no son responsables de la sorción del ${ }^{123} \mathrm{Te}$. Es decir, la sorción de las especies del ${ }^{132} \mathrm{Te}$ sobre los óxidos $\mathrm{MnO}_{2}, \mathrm{TiO}_{2}$ y $\mathrm{SnO}$, no puede ser atribuida a la atracción directa de los iones con un grupo específico sobre la superficie del sorbente, de acuerdo con el concepto de punto de carga cero (zpc) descrito anteriormente. Este comportamiento solamente puede explicarse en función de las propiedades superficiales de los sorbentes, tales como el área específica de los óxidos, parámetro que nos indica la proporción de sitios activos en su superficie. Los porcentajes de sorción de ${ }^{132} \mathrm{Te}$ sobre el $\mathrm{TiO}_{2}$ son más altos que sobre el $\mathrm{MnO}_{2}$ y $\mathrm{SnO}$, comportamiento qué se debe a las diferencias entre las características superficiales de estos materiales: porosidad, área específica y a los radios promedio de poro, como se muestran en la Tabla 2, lo cual indica que la sorción de ${ }^{132} \mathrm{Te}$ se incrementa y se fija más en aquel óxido que tiene la mayor área especifica del $\mathrm{TiO}_{2}\left(10.57 \pm 2.5 \mathrm{~m}^{2} / \mathrm{g}\right)$ comparada con los otros óxidos metálicos, ya que cuenta con un mayor número de sitios activos en su superficie, disponibles para el ${ }^{132} \mathrm{Te}$. De acuerdo con este mecanismo el ${ }^{132} \mathrm{Te}$ se fija en el $\mathrm{MnO}_{2}$ (área específica de $0.56 \pm 0.2 \mathrm{~m}^{2} / \mathrm{g}$ ) con menor intensidad y en el $\mathrm{SnO}$ $\left(0.47 \pm 0.34 \mathrm{~m}^{2} / \mathrm{g}\right)$ se fija muy escasamente.

Los valores de $\mathrm{pH}_{\mathrm{i}}$ de las soluciones de los productos de fisión después del contacto con la hidrotalcita calcinada, aumentan considerablemente en todos los casos (Tabla 4) debido al consumo de protones en la reconstrucción de la estructura laminar de la hidrotalcita (Hermosín et al., 1996), como se aprecia en la siguiente reacción:

$$
2 \mathrm{Mg}_{3} \mathrm{AlO}_{4}(\mathrm{OH})+8 \mathrm{H}_{2} \mathrm{O}+\boldsymbol{A} \boldsymbol{n}^{2-} \rightarrow\left[\mathrm{Mg}_{6} \mathrm{Al}_{2}(\mathrm{OH})_{16}\right][\boldsymbol{A n}]+2 \mathrm{OH}^{+}
$$


Donde $\boldsymbol{A n}$ es un ion negativo de carga 2. La sorción en la hidrotalcita calcinada de las especies aniónicas del ${ }^{132} \mathrm{Te}$ (Tabla 3), puede atribuirse a la regeneración del material inorgánico al ponerse en contacto con la solución de los productos de fisión. En esta forma el espacio interplanar de la hidrotalcita está disponible para fijar las especies aniónicas del telurio como: $\mathrm{TeO}\left(\mathrm{OH}_{3}\right)^{-}$y $\mathrm{TeO}_{2}(\mathrm{OH})_{2}{ }^{2-}$. Observamos que cuando los $\mathrm{pH}_{\mathrm{f}}$ disminuyen a 8.9 la sorción de ${ }^{132} \mathrm{Te}$ también disminuye a $83 \%$, debido a que se encuentran presentes menos cantidad de especies aniónicas en solución y la sorción ahora es debido al $\mathrm{Te}(\mathrm{OH})_{4}$ que se precipita sobre el sorbente.

La sorción de ${ }^{132} \mathrm{Te}$ en el carbón activado es eficiente (más del $80 \%$ ). Podemos concluir que sobre el carbón activado se sorben tanto los aniones, como las especies neutras y especies catiónicas, ya que es una material que cuenta con un área específica grande y es altamente poroso.

Cada especie química del ${ }^{132} \mathrm{Te}$ en solución acuosa, presenta diferente comportamiento de sorción en los diferentes materiales inorgánicos y valores de $\mathrm{pH}_{\mathrm{f}}$. En general, el $\mathrm{MgO}$, la hidrotalcita calcinada y el carbón activado tienen alta eficiencia para la sorción de ${ }^{132} \mathrm{Te}$ en solución acuosa en el intervalo de pH estudiado. 


\subsubsection{Sorción de ${ }^{95} \mathrm{Zr}$.}

La influencia del $\mathrm{pH}_{\mathrm{f}}$ en la sorción de ${ }^{95} \mathrm{Zr}$ sobre los materiales inorgánicos, se muestra en la Fig. 20. Se observó que la mayor sorción de ${ }^{95} \mathrm{Zr}$, de $91.4 \pm 1.5 \%$, ocurre sobre el $\mathrm{MgO}$ a $\mathrm{pH}_{\mathrm{f}}$ entre 10.5 a 10.8. A valores de $\mathrm{pH}_{\mathrm{f}}$ menores a 10.5, la sorción sobre este material disminuye a $75 \pm 2.8 \%$ (Fig. 20a).

La sorción de ${ }^{95} \mathrm{Zr}$ sobre carbón activado, es eficiente con un máximo de $83.3 \pm 5.1 \%$ a $\mathrm{pH}_{\mathrm{f}} 5.5$, y su comportamiento de sorción se mantuvo constante para casi todos los valores de $\mathrm{pH}_{\mathrm{f}}$ estudiados. La sorción de ${ }^{95} \mathrm{Zr}$ es eficiente sobre $\mathrm{TiO}_{2}$, alcanzando un máximo de $80.1 \pm 3.7 \%$. Sin embargo la sorción de ${ }^{95} \mathrm{Zr}$ sobre $\mathrm{MnO}_{2}$ y $\mathrm{SnO}$ fue considerablemente baja, especialmente con el SnO, con eficiencias de $10.1 \pm 1.3$ y $1.5 \pm 0.2 \%$ respectivamente. Este comportamiento puede ser explicado solamente por el área específica y los tamaños de poro de los sólidos. El área específica del $\mathrm{TiO}_{2}$ es $10.57 \pm 2.5 \mathrm{~m}^{2} / \mathrm{g}$ y su tamaño de poro de $3.800 \pm 0.789 \mathrm{~nm}$, mientras que los valores correspondientes al $\mathrm{MnO}_{2}$ son de $0.56 \pm 0.2 \mathrm{~m}^{2} / \mathrm{g}$ y $3.559 \pm 0.464 \mathrm{~nm}$ respectivamente y en el $\mathrm{SnO}$ estos valores son muy pequeños. 


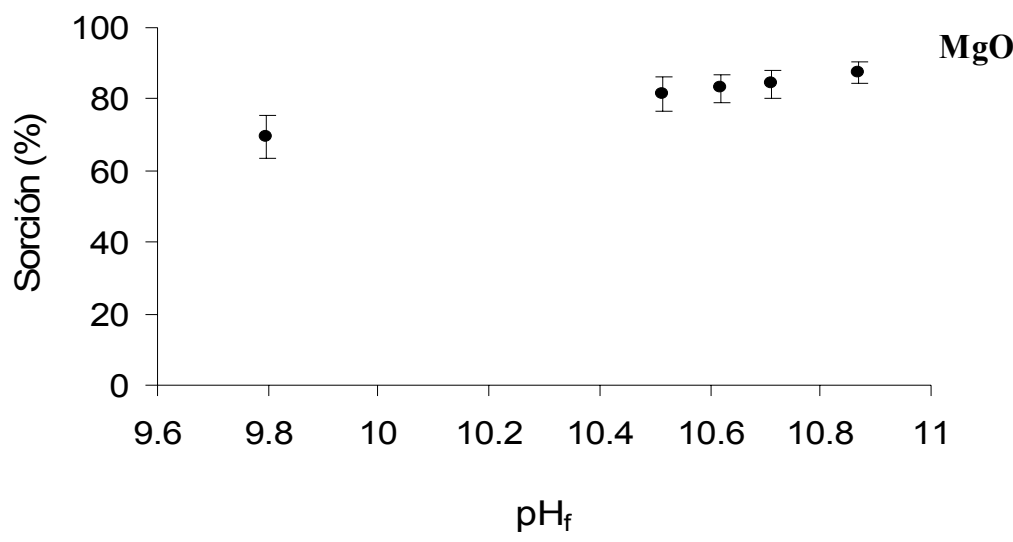

a)

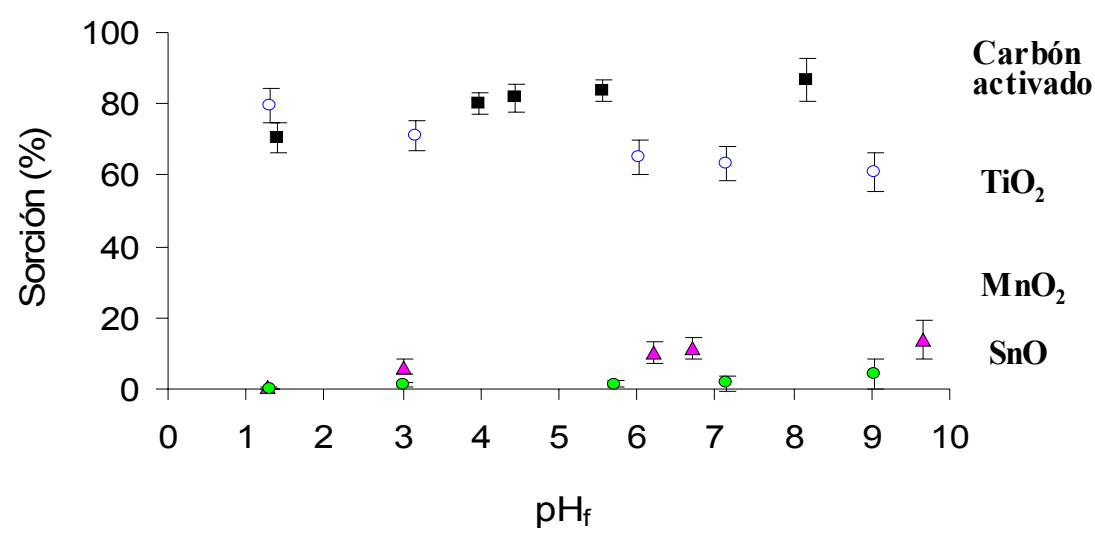

b)

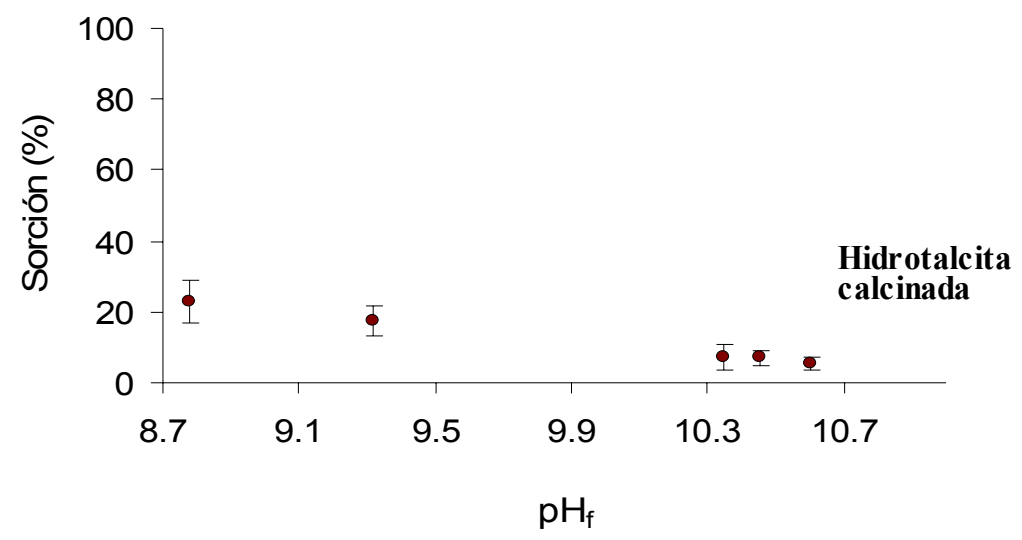

c)

Fig. 20. Sorción de ${ }^{95} \mathrm{Zr}$ en sólidos inorgánicos a diferentes valores de $p H_{f}$. 
Los resultados experimentales muestran que la más alta sorción de ${ }^{95} \mathrm{Zr}$ se produjo en el $\mathrm{MgO}$ a valores de $\mathrm{pH}$ altos (Fig. 20a). A valores por debajo de $\mathrm{pH} 12.4$ (valor del zpc), la superficie del óxido de magnesio tendrá un carácter positivo y las especies aniónicas pueden ser sorbidas en su superficie. El valor de $\mathrm{pH}_{\mathrm{f}}$ de la solución después del contacto con $\mathrm{MgO}$ se encuentra en el intervalo de 9.8 a 10.8; por consiguiente, la sorción de la especie negativa $\mathrm{Zr}(\mathrm{OH})_{5}{ }^{-}$(Tabla 3) es eficiente sobre la superficie del $\mathrm{MgO}$. Sin embargo en general la sorción de ${ }^{95} \mathrm{Zr}$ decrece ligeramente a $\mathrm{pH}_{\mathrm{f}}$ 9.8, debido a que a este $\mathrm{pH}$ van disminuyendo la presencia de especies aniónicas y la sorción se debe sólo a la presencia de la especie neutra $\mathrm{Zr}(\mathrm{OH})_{4}$, que precipita sobre la superficie del $\mathrm{MgO}$.

Las sorción de las especies químicas del ${ }^{95} \mathrm{Zr}$ es escasa en el $\mathrm{MnO}_{2}$, a semejanza de las especies químicas del telurio, la sorción no puede ser atribuida a la atracción directa de los iones con un grupo específico de la superficie del sorbente, de acuerdo con el concepto de punto de carga cero. La sorción del ${ }^{95} \mathrm{Zr}$ puede explicarse en función de las propiedades superficiales de los sorbentes; área específica y radio de poro, de la misma manera que vimos anteriormente con las especies del telurio, la sorción del ${ }^{95} \mathrm{Zr}$ es mayor en el $\mathrm{TiO}_{2}$ que en los óxidos $\mathrm{MnO}_{2}$ y $\mathrm{SnO}$ respectivamente.

Las hidrotalcita calcinada es un sorbente muy pobre del ${ }^{95} \mathrm{Zr}$ ya que no existen especies aniónicas de ${ }^{95} \mathrm{Zr}$ de $\mathrm{pH}_{\mathrm{f}} 8.7$ a 10.7 y por lo tanto no pueden quedar en la región interlaminar de la hidrotalcita regenerada. La sorción de zirconio sobre este material sólo se debe a la precipitación de las especies neutras $\mathrm{Zr}(\mathrm{OH})_{5}$ sobre la superficie del sólido.

Se observó que la máxima sorción del ${ }^{95} \mathrm{Zr}$ en carbón activado, fue de $85.2 \pm 0.3 \%$, debido a la gran área específica y porosidad de este material. 
En forma general, podemos deducir que como en el caso de la sorción de especies del ${ }^{132} \mathrm{Te}$ sobre $\mathrm{TiO}_{2}, \mathrm{MnO}_{2}$ y $\mathrm{SnO}$ la sorción del ${ }^{95} \mathrm{Zr}$ no puede ser atribuida a las propiedades de carga en la superficie de los sólidos.

\subsubsection{Sorción de ${ }^{99}$ Mo.}

En la Fig. 21 se muestran las propiedades de sorción del ${ }^{99}$ Mo sobre los materiales inorgánicos estudiados; en especial, el $\mathrm{MgO}$ fue el material con las mejores propiedades de sorción de ${ }^{99} \mathrm{Mo}$ a todos los valores de $\mathrm{pH}$ estudiados, siendo el más alto de $98.7 \pm 1.9 \%$ a $\mathrm{pH}_{\mathrm{f}} 10.8$ (Fig. 21a). También el $\mathrm{TiO}_{2}$, mostró una eficiente sorción a todos los valores de $\mathrm{pH}_{\mathrm{f}}$ estudiados, con un máximo de $91.4 \pm 1.8 \%$ a $\mathrm{pH}_{\mathrm{f}}$ de 8.7 (Fig. 21b).

La sorción de ${ }^{99} \mathrm{Mo}$ sobre $\mathrm{MnO}_{2}$, fue de $59.0 \pm 8.9 \%$ a $\mathrm{pH}_{\mathrm{f}}$ 1. A valores de $\mathrm{pH}_{\mathrm{f}}$ altos disminuyó considerablemente, hasta un $19.8 \pm 9.3 \% \mathrm{a} \mathrm{pH}_{\mathrm{f}}$ de 9.6. La sorción de

${ }^{99} \mathrm{Mo} \mathrm{sobre} \mathrm{SnO}$ fue muy baja, siguiendo el mismo patrón de comportamiento que en el $\mathrm{MnO}_{2}$ pero con valores de sorción todavía más bajos (Fig. 21b).

En general la sorción de ${ }^{99}$ Mo sobre carbón activado es alta, 79.8 $\pm 1.2 \%$, (Fig. 21b). La sorción fue eficiente sobre la hidrotalcita calcinada, alcanzando un máximo de $98.0 \pm 1.0 \%$ y mantuvo este comportamiento en forma constante en todo el intervalo de pH estudiado, tal como se muestra en la Fig. 21c. 
${ }^{99} \mathrm{Mo}$

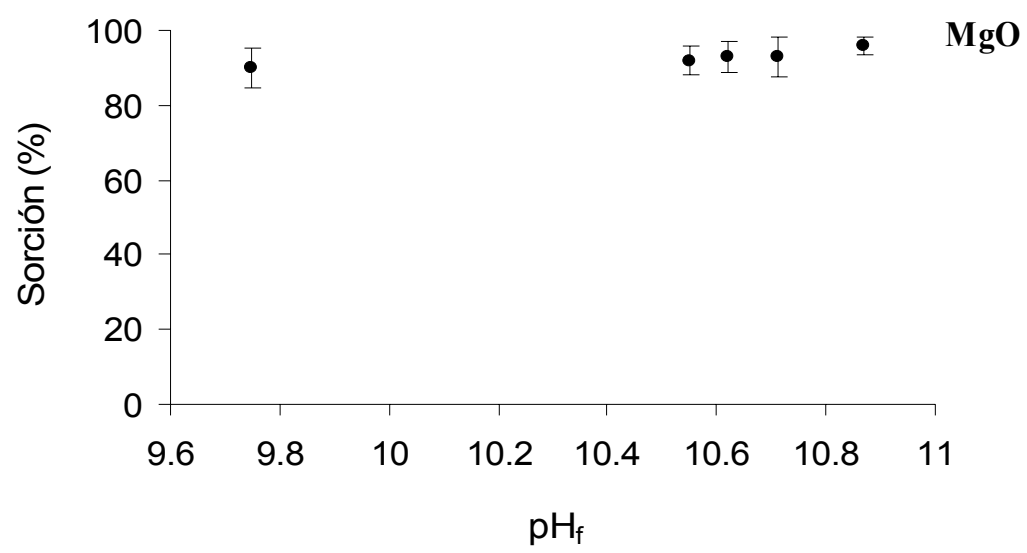

a)

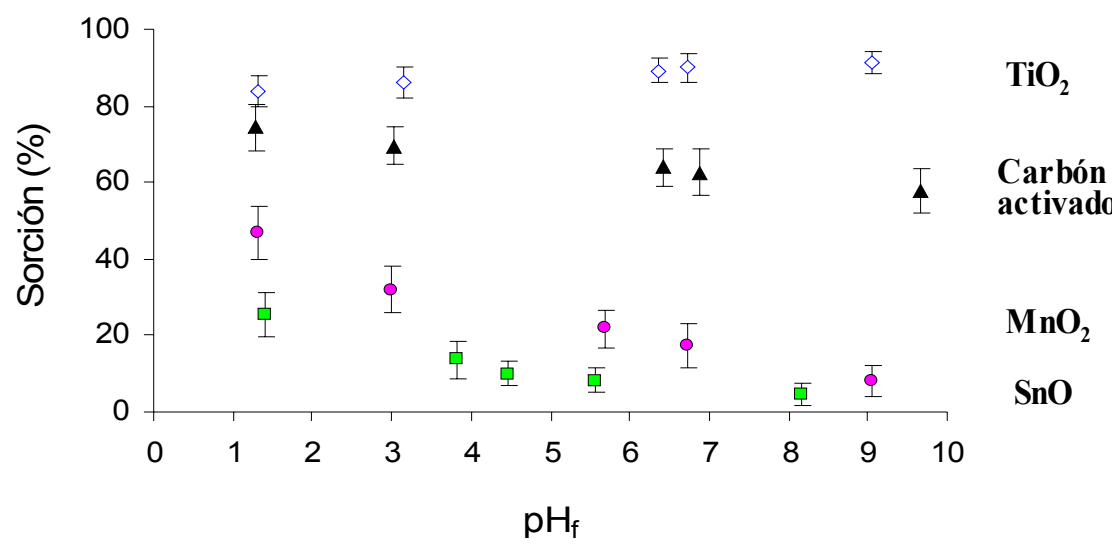

b)

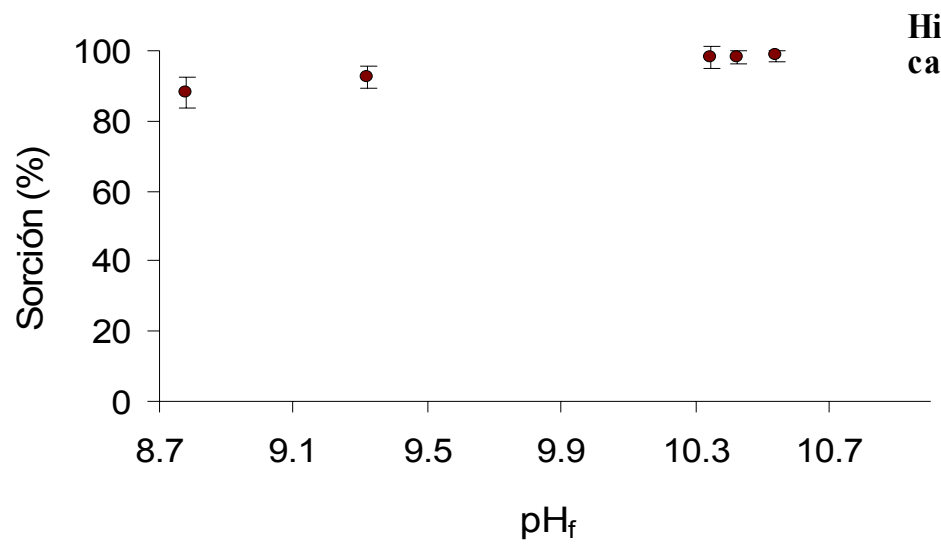

c)

Fig. 21. Sorción de ${ }^{99}$ Mo en sólidos inorgánicos a diferentes valores de $p H_{f}$ 
La sorción del ${ }^{99} \mathrm{Mo}$ se observó al poner en contacto el $\mathrm{MgO}$ con la solución acuosa de los productos de fisión. La sorción del $\mathrm{MoO}_{4}{ }^{2-}$ en medio alcalino es eficiente debido a una atracción mutua entre las especies de ${ }^{99}$ Mo cargadas negativamente y la superficie del $\mathrm{MgO}$ cargada positivamente. Sin embargo también se encontró una especie neutra $\mathrm{H}_{2} \mathrm{MoO}_{4}$ que se precipita sobre la superficie del $\mathrm{MgO}$.

La sorción del ${ }^{99} \mathrm{Mo}$ en el $\mathrm{TiO}_{2}$ fue eficiente a todos los valores de $\mathrm{pH}_{\mathrm{f}}$ estudiados (Fig. 21b) debido a la precipitación del $\mathrm{H}_{2} \mathrm{MoO}_{4}$. La sorción de esta especie de ${ }^{99} \mathrm{Mo}$ sobre $\mathrm{MnO}_{2}$ y $\mathrm{SnO}$ es escasa, debido a su área específica baja y al pequeño radio de poro de estos materiales.

El carbón activado es un sorbente universal con una estructura de poro grande, que le favorece el proceso de sorción. Nuestros resultados muestran que la sorción en carbón activado de especies de ${ }^{99}$ Mo encontradas en solución acuosa, es eficiente con un máximo de $79.8 \pm 1.2 \%$.

La sorción de ${ }^{99} \mathrm{Mo}$ fue eficiente en la hidrotalcita calcinada. Aumentó gradualmente al aumentar el $\mathrm{pH}$, alcanzando un valor máximo a $\mathrm{pH}_{\mathrm{f}}$ de 10.5. La inspección de especies químicas de ${ }^{99}$ Mo por electroforesis de alto voltaje, reveló que el ${ }^{99}$ Mo está presente principalmente en forma de especies aniónicas en la solución, a valores de $\mathrm{pH}$ altos (Tabla 3). La sorción de $\mathrm{MoO}_{4}{ }^{2-}$ se debe a que durante la regeneración de la hidrotalcita, éste anión queda en la región interlaminar de la hidrotalcita. Estos resultados están de acuerdo con los resultados experimentales de Serrano et al., (2000); ellos encontraron que los iones ${ }^{99} \mathrm{MoO}_{4}{ }^{2-}$ se retuvieron eficientemente en la estructura de la hidrotalcita. La especie neutra de ${ }^{99} \mathrm{Mo}$, precipita en la hidrotalcita. 


\subsubsection{Sorción de ${ }^{103}$ Ru.}

La Fig. 22 muestra la sorción de ${ }^{103} \mathrm{Ru}$ en los materiales inorgánicos estudiados sobre $\mathrm{MgO}$ (Fig. 22b) aumenta en medios alcalinos. Se observó más del $80 \%$ de sorción a $\mathrm{pH}_{\mathrm{f}}$ entre 9.8 y 10.9. En el caso del carbón activado la sorción de ${ }^{103} \mathrm{Ru}$ fue eficiente y varía de $45 \pm 3.7$ a $70.5 \pm 9.8 \%$ aumentando cuando se incrementa el valor de $\mathrm{pH}_{\mathrm{f}}$ (Fig. 22b).

La sorción del ${ }^{103} \mathrm{Ru}$ en medio ácido, es escasa en $\mathrm{TiO}_{2}, \mathrm{MnO}_{2}$ y $\mathrm{SnO}$, especialmente en el $\mathrm{SnO}$. Aumentando el pH, aumenta la sorción de ${ }^{103} \mathrm{Ru}$ en $\mathrm{TiO}_{2}$ y baja en $\mathrm{MnO}_{2}$. En SnO la sorción máxima es de 17.6 $\pm 3.8 \%$ en medio alcalino (Fig. 22b).

La sorción de ${ }^{103} \mathrm{Ru}$ en la hidrotalcita calcinada alcanzó rendimientos superiores a $60 \%$ a todos los valores de $\mathrm{pH}_{\mathrm{f}}$. Aumentando el $\mathrm{pH}_{\mathrm{f}}$ de 8.7 a 10.5 , aumenta a $80.9 \pm 9.6 \%$ la sorción, tal como se muestra en la Figura 22c. 


\section{${ }^{103} \mathrm{Ru}$}

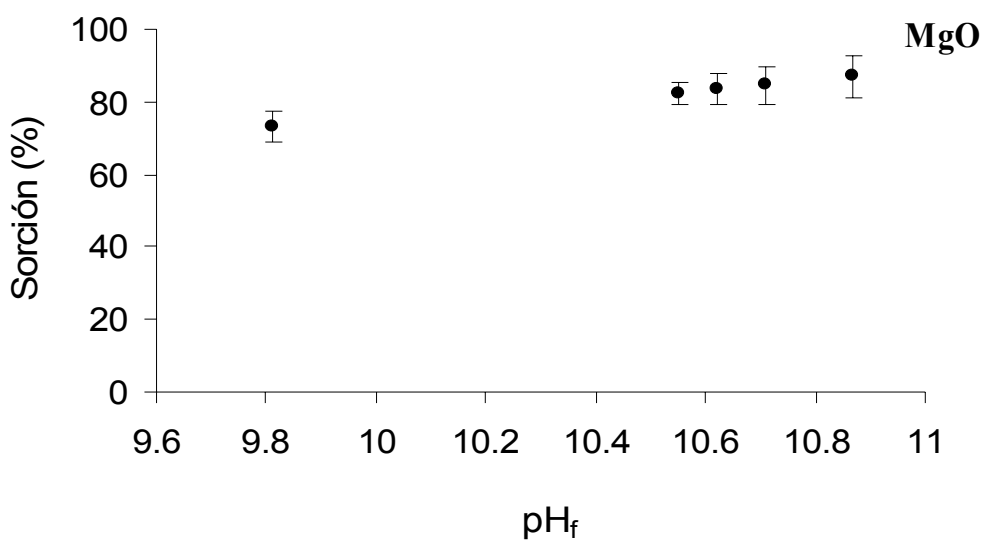

a)

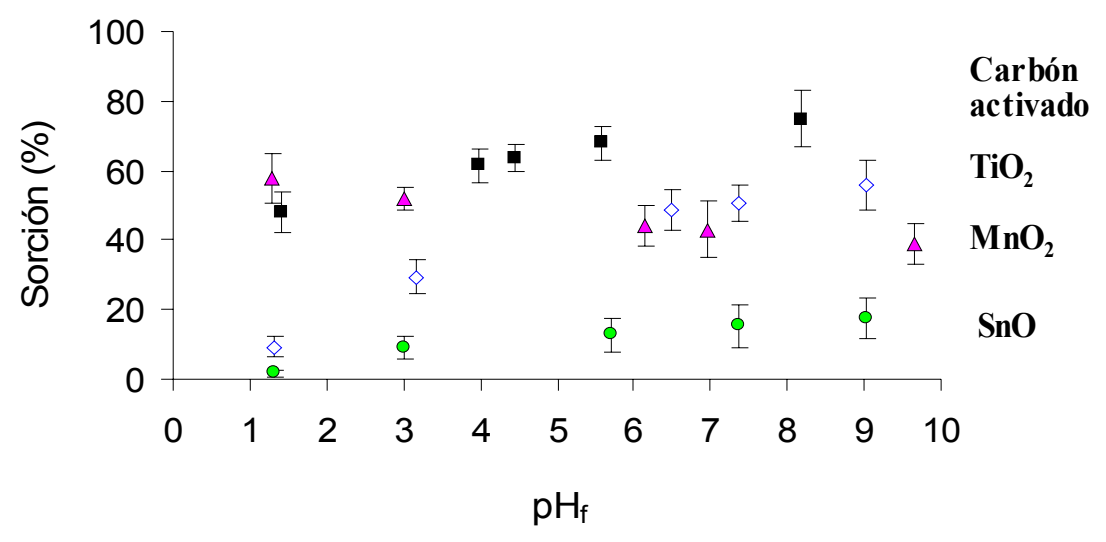

b)

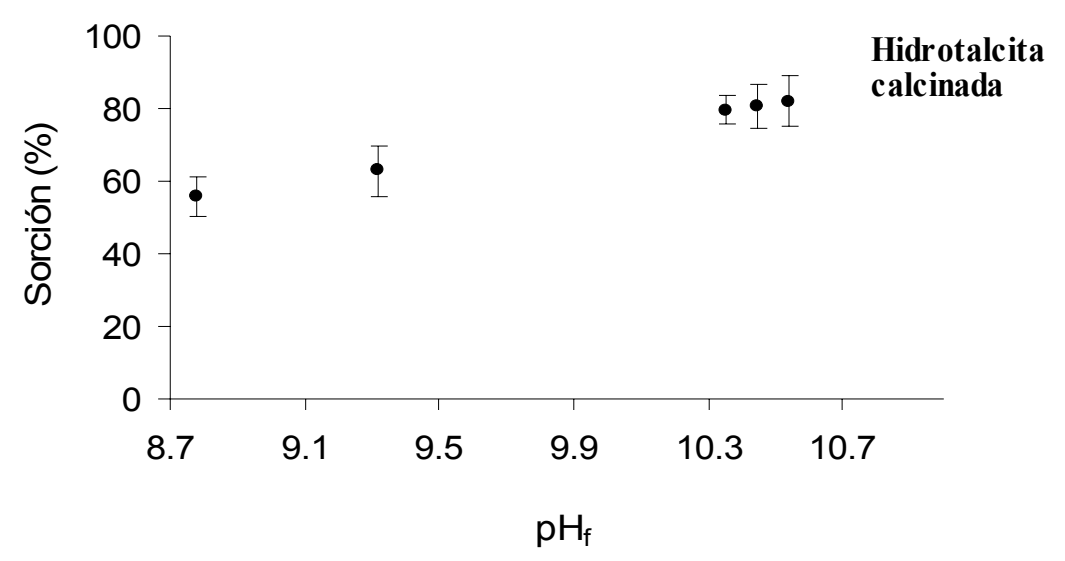

c)

Fig. 22. Sorción de ${ }^{103} \boldsymbol{R} \boldsymbol{u}$ en sólidos inorgánicos a diferentes valores de $p H_{f}$. 
Como se mencionó anteriormente, la solución de los productos de fisión contiene iones $\mathrm{NO}_{3}{ }^{-}$, por consiguiente el ${ }^{103} \mathrm{Ru}$ está probablemente presente en la solución formando complejos del nitrato de nitrosilo (Cotton y Wilkinson, 1988; Seddon y Seddon, 1984; Blasius et al., 1981). La interpretación de la sorción de ${ }^{103} \mathrm{Ru}$ en los materiales inorgánicos se dificulta por el gran número de especies químicas complejas presentes en la solución acuosa ya que rápidamente se transforman unas en otras (Blasius et al., 1981; Sato y Motoki, 1989). En la Tabla 3, se muestran las especies complejas de nitrosilo neutras, aniónicas y catiónicas a diferentes valores de $\mathrm{pH}$.

El ${ }^{103} \mathrm{Ru}$ está presente principalmente en la solución acuosa como la especie neutra $\left[{ }^{103} \mathrm{RuNO}(\mathrm{OH})_{2}\left(\mathrm{H}_{2} \mathrm{O}\right)_{2}\right]$ (Tabla 3), la cual se precipita sobre la superficie del $\mathrm{MgO}$.

Tanto en el $\mathrm{TiO}_{2}$ como en el $\mathrm{SnO}$, la sorción de ${ }^{103} \mathrm{Ru}$ se favoreció para valores de $\mathrm{pH}_{\mathrm{f}}$ altos (Fig. 22b) se incrementa en los sólidos hidratados al incrementarse el $\mathrm{pH}_{\mathrm{f}}$, siendo más alta la sorción sobre el $\mathrm{TiO}_{2}$ debido a su mayor área específica.

A $\mathrm{pH}_{\mathrm{f}} 1$, el ${ }^{103} \mathrm{Ru}$ en los fragmentos de fisión, se sorbe sobre el $\mathrm{MnO}_{2}$ aparentemente debido a la atracción de la especie negativa ${ }^{103} \mathrm{Ru}\left[{ }^{103} \mathrm{RuNO}(\mathrm{OH})_{4} \mathrm{H}_{2} \mathrm{O}\right]^{-1}$ sobre la superficie de $\mathrm{MnO}_{2}$ que a ese $\mathrm{pH}$ está cargada positivamente (zpc=4.5). A mayores valores de $\mathrm{pH}_{\mathrm{f}}$ la sorción de la especie de ${ }^{103} \mathrm{Ru}$ cargada negativamente es menor, probablemente debido a que compite con las especies del uranio las cuales se sorben en el óxido a valores de $\mathrm{pH}$ entre 2 y 5 , tal como fue observado por Lieser et al., (1992). A valores de pH arriba de 4.5 la sorción decrece debido a las pocas especies cargadas positivamente $\left[{ }^{103} \mathrm{RuNO}(\mathrm{OH})_{2}\left(\mathrm{H}_{2} \mathrm{O}\right)_{2}\right]^{+1}$ que existen a estos valores de $\mathrm{pH}, \mathrm{y}$ las especies neutras $\left[{ }^{103} \mathrm{RuNO}_{3}(\mathrm{OH})_{2}\left(\mathrm{H}_{2} \mathrm{O}\right)_{2}\right]$ son las que se precipitan sobre la superficie del $\mathrm{MnO}_{2}$. La sorción de las especies de ${ }^{103} \mathrm{Ru}$ en la hidrotalcita calcinada se lleva a cabo por regeneración de su estructura original con las especies aniónicas o precipitación. 
La sorción de ${ }^{103} \mathrm{Ru}$ sobre el carbón activado es eficiente a pH alcalino (10.7) de 78\%. A pH ácido (1), la sorción disminuyó a 42\%, como se muestra en la Figura 22b. 


\subsection{Cinética de sorción del ${ }^{60} \mathrm{Co}$ sobre dióxido de manganeso hidratado.}

\subsubsection{Efecto de la concentración.}

Los resultados de la sorción del ${ }^{60} \mathrm{Co}$ en el dióxido de manganeso hidratado se muestran en la Fig. 23. La sorción depende del tiempo de agitación de la solución de $\mathrm{Co}\left(\mathrm{NO}_{3}\right)_{2}$ a diferentes concentraciones.

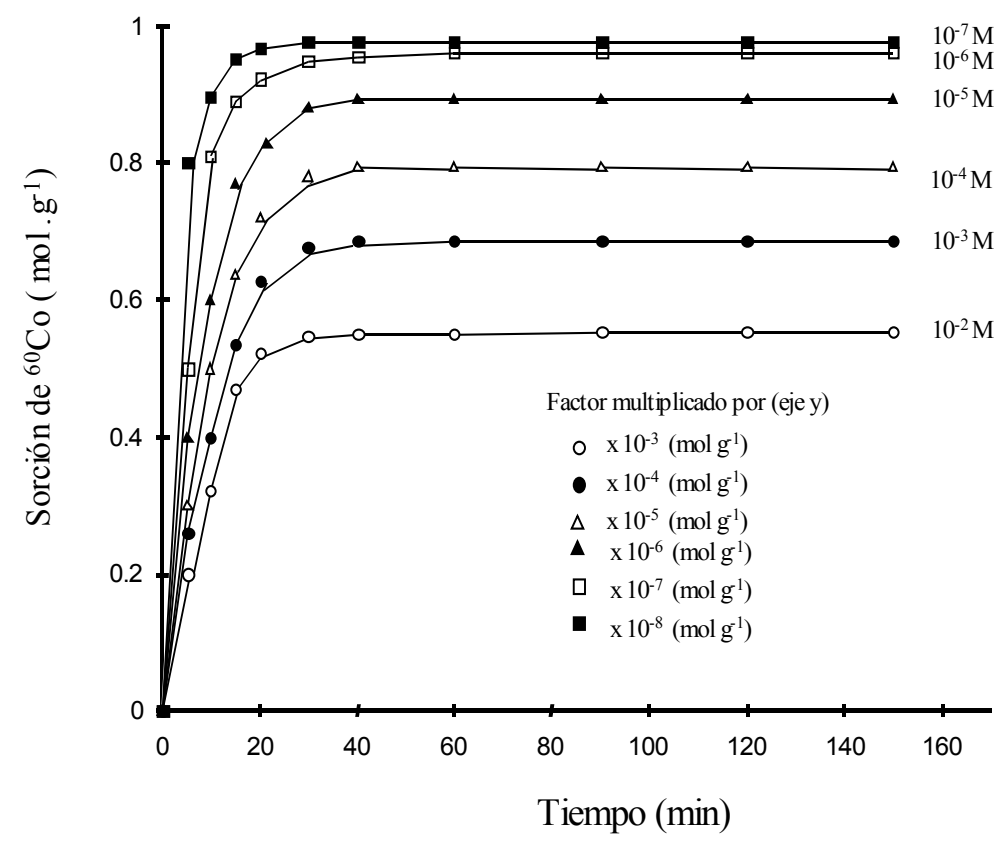

Fig. 23. Sorción del ${ }^{60}$ Co sobre dióxido de manganeso hidratado en función del tiempo de agitación para diferentes concentraciones. Temperatura $303 \mathrm{~K} ; \mathrm{pH} 6.2$. 
$\mathrm{Al}$ estudiar el comportamiento de sorción de ${ }^{60} \mathrm{Co}$ en solución acuosa como una función del tiempo de agitación y concentración del nitrato de cobalto $\left(10^{-2}-10^{-7} \mathrm{M}\right)$ (Fig. 23) se observó que esta sorción fue muy rápida, dentro de los primeros minutos de tiempo de agitación entre las fases, estableciéndose un completo equilibrio a los 40 minutos, para todas las concentraciones estudiadas. De este comportamiento se infiere que la sorción del ${ }^{60} \mathrm{Co}$ ocurre en una sola etapa. La aparente saturación observada indica que los sitios activos del dióxido los ocupan los iones $\mathrm{Co}^{2+}$ con rapidez, al transcurrir el tiempo, el proceso de sorción se vuelve más lento lográndose una meseta en las últimas etapas al alcanzarse el equilibrio entre las dos fases, a una concentración específica del sorbente. La sorción en el equilibrio aumenta de $9.78 \pm 0.08 \times 10^{-9}$ a $5.52 \pm 0.06 \times 10^{-4}$ mol. $\mathrm{g}^{-1}$, cuando las concentraciones de cobalto disminuyen. El máximo valor de sorción de ${ }^{60}$ Co obtenido en el presente caso fue de $97.8 \%$ para la solución $10^{-7} M$ de $\mathrm{Co}\left(\mathrm{NO}_{3}\right)_{2}$. Este incremento se debe al hecho de que se disponen más sitios activos en la superficie por gramo del dióxido para la deposición de un número menor de especies de ${ }^{60} \mathrm{Co}$ presentes en solución acuosa a altas diluciones.

La misma Figura 23, nos muestra los resultados del efecto de la concentración del ${ }^{60} \mathrm{Co}$ sobre la sorción en el dióxido de manganeso hidratado, los cuales fueron analizados en términos de los modelos de isotermas de sorción de Langmuir y Freundlich (Hasany et al., 1998). Los datos obtenidos gráficamente para la ecuación de la isoterma de Langmuir, no se ajustan. Sin embargo, los puntos obtenidos gráficamente mediante la ecuación de Freundlich (Ecuación 13), se ajustaron a una línea recta describiendo adecuadamente la sorción del ${ }^{60} \mathrm{Co}$ bajo las condiciones de concentración probadas. La gráfica obtenida de la isoterma de Freundlich, se muestra en la Fig. 24, los datos se ajustaron a la isoterma, indicando su validez sobre el intervalo de concentración del cobalto estudiado $\left(10^{-7}\right.$ a $10^{-2}$ $M$ ). Se obtuvo una línea recta que en su forma logarítmica es la siguiente: 


$$
\log a_{e}=1 / n \log C_{e}+\log K
$$

La línea se ajustó a los valores experimentales por el método de regresión lineal, obteniendo la correspondiente ecuación de la línea recta: $(y=0.9473 x+1.3004)$, con un valor de correlación de $r^{2}=0.9997$. En la ecuación (13) $a_{e}$ muestra la sorción de especies iónicas en el equilibrio (mol. $\mathrm{g}^{-1}$ ), $C_{e}$ es la concentración de la solución radiactiva en el equilibrio $\left(\mathrm{mol} . \mathrm{L}^{-1}\right)$ y $K$ y $1 / n$ son las constantes de Freundlich (Reynolds, 1982). Los valores de $1 / n$ y $K$, corresponden a la intensidad de sorción y la capacidad de sorción respectivamente, valores que se obtienen de la pendiente y la intersección de la línea recta de la gráfica de la ecuación (13) esto permite calcular las constantes de Freundlich antes descritas. El valor de la pendiente $b$, fue de $(0.947 \pm$ $0.004)$ y el de la intersección con el eje $y$, de $(5.0 \pm 0.05) \times 10^{-2} \mathrm{~mol} . \mathrm{g}^{-1}$. 


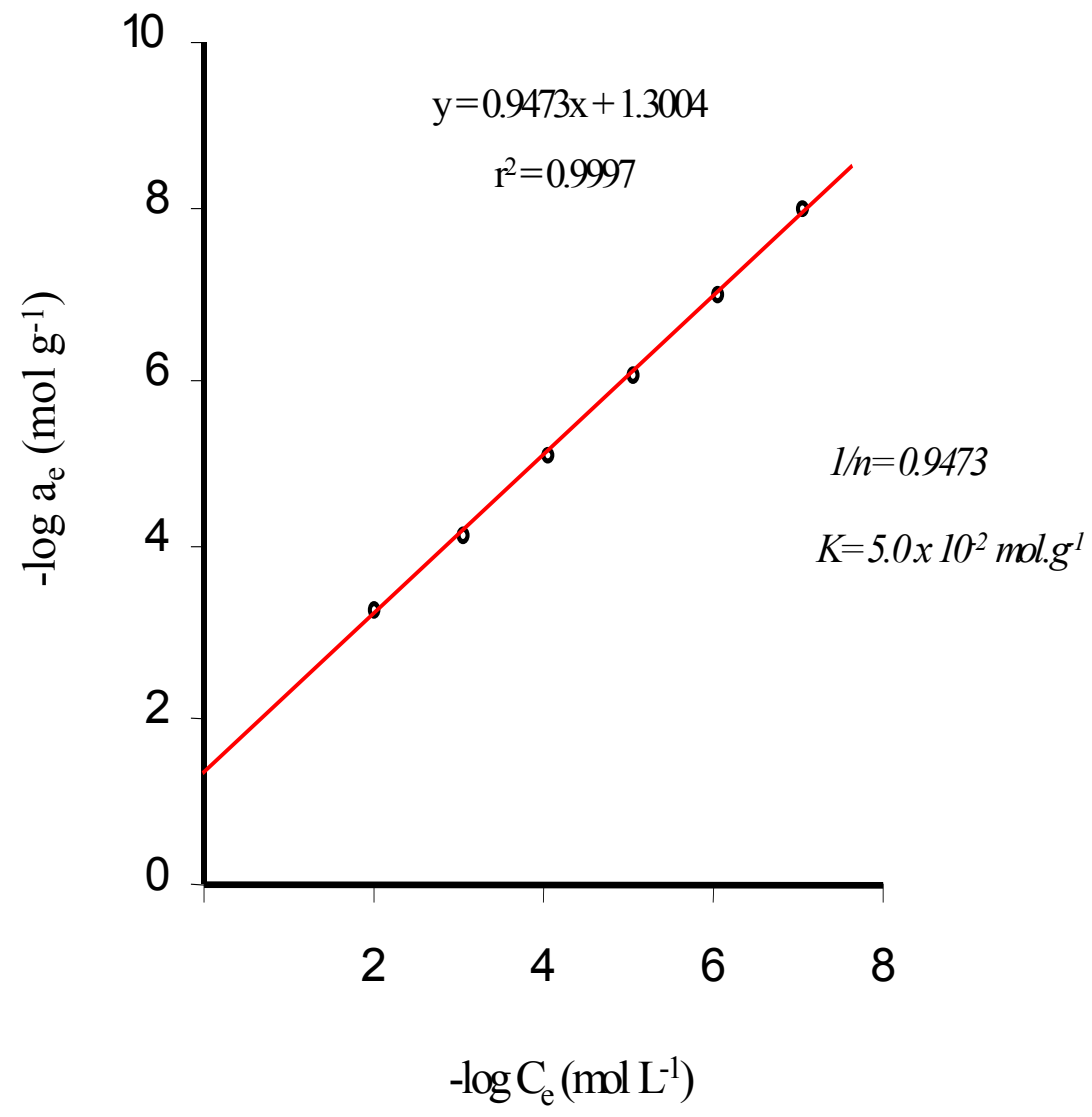

Fig. 24. Isoterma de sorción de Freundlich para el ${ }^{60}$ Co sobre dióxido de manganeso hidratado. 
El valor fraccional $1 / n$ obtenido, menor que la unidad, se atribuye a una estructura homogénea de la superficie del sorbente (Clark et al., 1980). Uno de los más importantes aspectos de la isoterma de Freundlich es obtener directamente los valores numéricos de sus constantes $1 / n$ y $K$ que son datos importantes para investigar el comportamiento de sorción de cualquier sorbente, estas constantes indican respectivamente en forma directa la intensidad o facilidad que presenta el sorbente para sorber el soluto y la máxima capacidad de sorción del sorbente que presenta frente al sorbato por gramo de material (Reynolds, 1982). El modelo de Freundlich nos indica que la forma en que se cubre la superficie del sorbente por parte del soluto, es por multicapas y que las especies químicas en la superficie no reaccionan entre si. Por el alto valor obtenido de la constante $K$ de Freundlich (Mishra et al., 1992), se infiere que existe una eficiente sorción de ${ }^{60} \mathrm{Co}$ en el dióxido de manganeso.

\subsubsection{Efecto de la temperatura.}

Se presentan en la Tabla 5 , los resultados de la sorción de ${ }^{60} \mathrm{Co}$ en el dióxido de manganeso hidratado a diferentes temperaturas del sistema (303 a $333 \mathrm{~K}$ ), con una concentración inicial constante a todas las temperaturas de ${ }^{60} \mathrm{Co}$ de $1.0 \times 10^{-5} \mathrm{M}$. Estos resultados revelan que la sorción de ${ }^{60} \mathrm{Co}$ al equilibrio aumenta al subir la temperatura del sistema. 
Tabla 5. Estudio del efecto de la temperatura sobre la sorción y de la desorción del ${ }^{60} \mathrm{Co}$ en el dióxido de manganeso hidratado en el equilibrio: Concentración inicial de la solución radiactiva $1.0 \times 10^{-5}$ $M ; p H_{i} 6.2$.

\begin{tabular}{|c|c|c|}
\hline \multirow{2}{*}{ Temperatura } & \multicolumn{2}{|c|}{ Cantidad de ${ }^{60}$ Co sorbida } \\
\cline { 2 - 3 }$($ K) & $\left(\mathbf{m o l ~ g}^{-1}\right) \times \mathbf{1 0}^{-6}$ & Sorción \\
& & (\%) \\
\hline 303 & $0.891 \pm 0.003$ & $89.1 \pm 0.8$ \\
313 & $0.910 \pm 0.006$ & $91.0 \pm 0.6$ \\
323 & $0.926 \pm 0.007$ & $92.6 \pm 0.3$ \\
333 & $0.946 \pm 0.004$ & $94.6 \pm 0.4$ \\
\hline
\end{tabular}

La cinética de sorción del ${ }^{60} \mathrm{Co}$ se examinó mediante la expresión de primer orden de Largergren (Chang, 1997) en su forma logarítmica, adoptando una ecuación de la línea recta.

$$
\log \left(a_{e}-a_{t}\right)=\log a_{e}-\frac{k_{1}}{2.303} t
$$

donde $a_{e}$ y $a_{t}$ indican la sorción en el equilibrio y al tiempo $t$ respectivamente, $k_{1}$ es la constante de velocidad para la sorción. La gráfica de $\log \left(a_{e}-a_{t}\right)$ vs. tiempo, corresponde a una línea recta sobre el intervalo de temperaturas estudiado, indicando que el proceso es 
de primer orden con respecto a la concentración de cobalto. Los valores de las constantes de velocidad $\left(k_{1}\right)$ que se obtienen de la pendiente de estas rectas, en las que los valores experimentales fueron ajustados por el método de regresión lineal, para diferentes temperaturas, se muestran en la Tabla 6.

Tabla 6. Parámetros cinéticos para la sorción del ${ }^{60}$ Co sobre dióxido de manganeso hidratado en función de la temperatura: Concentración inicial de la solución radiactiva: $1.0 \times 10^{-5} ; \mathrm{pH}_{i} 6.2$.

\begin{tabular}{c|c|c}
\hline Temperatura & $\begin{array}{c}\text { Constantes de velocidad } \\
\left(\mathbf{m i n}^{-1}\right) \times \mathbf{1 0}\end{array}$ & $\begin{array}{c}\text { Energía de } \\
\text { activación }\end{array}$ \\
\hline (K) & $\left(\right.$ kJ mol $\left.^{-1}\right)$ \\
\hline 303 & $5.0 \pm 0.1$ & \\
313 & $5.6 \pm 0.4$ & $10.5 \pm 0.4$ \\
323 & $6.6 \pm 0.3$ & \\
333 & $7.2 \pm 0.2$ & \\
\hline
\end{tabular}

Los resultados del efecto de la temperatura en la cinética de sorción, se utilizaron para deducir la energía de activación de la sorción a través de la pendiente de Arrhenius obtenida al graficar $\left(\log k_{1}\right.$ contra $\left.1 / T\right)$ para este sistema (Fig. 25), utilizando la ecuación de Arrhenius en su forma logarítmica y tomando la forma de la ecuación de la recta.

$$
k=A e^{-E a / R T}
$$




$$
\log K=\left(-\frac{E a}{R}\right)\left(\frac{1}{T}\right)+\log A
$$

donde $E_{a}$ es la energía de activación del proceso de sorción en $(\mathrm{kJ} / \mathrm{mol}), R$ es la constante de los gases $(8.314 \mathrm{~J} / \mathrm{K} . \mathrm{mol}), T$ es la temperatura absoluta y $e$ es la base de la escala de logaritmos naturales. La cantidad $A$ representa la frecuencia de colisiones o llamado factor de frecuencia.

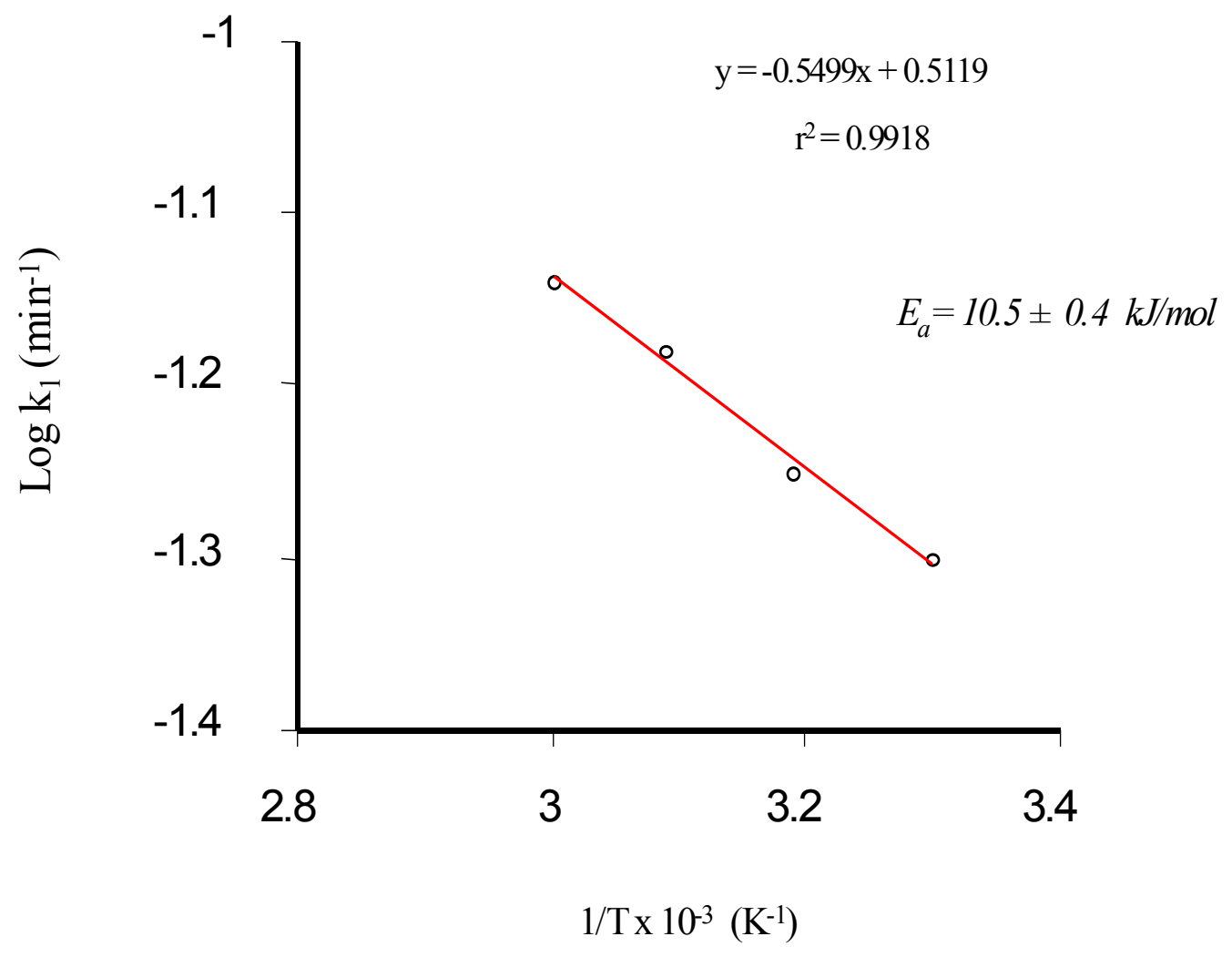

Fig. 25. Gráfica de Arrhenius para la energía de activación de la sorción del ${ }^{60}$ Co sobre el dióxido de manganeso hidratado. Concentración de la solución radiactiva $1.0 \times 10^{-5} \mathrm{M}, \mathrm{pH} 6.2$ 
Adicionalmente se dedujeron otros parámetros termodinámicos, utilizando los datos de dependencia de la temperatura. El cambio de entalpía estándar $\left(\Delta \mathrm{H}^{0}\right)$ para el proceso de sorción, fue de $12.5 \pm 0.2 \mathrm{~kJ} \mathrm{~mol}^{-1}$. Este valor se obtuvo de la pendiente de la línea recta obtenida al graficar $\log K_{d}$ contra 1/T (Fig. 26), derivada de la aplicación de la ecuación de Van't Hoff en su forma linearizada y ajustados los valores experimentales para la obtención de la línea recta por el método de regresión lineal, se obtuvo la ecuación de la recta $(y=$ $0.6617 x+5.1435)$ con un factor de correlación $\mathrm{r}^{2}=0.9265$ :

$$
\begin{aligned}
& \log K_{d}=\frac{-\Delta H^{0}}{2.303 R T}+\text { cte. } \\
& y \quad K_{d}=\frac{A_{b}-A_{a}}{A_{a}} \cdot \frac{V}{m}
\end{aligned}
$$

donde $K_{d}$ es la distribución en $\mathrm{mL} / \mathrm{g}$, a la temperatura $T$ en grados Kelvin y $R$ es la constante de los gases $(R=8.31434 \mathrm{~J} / \mathrm{K} . \mathrm{mol}), \mathrm{A}_{\mathrm{b}}$ es la actividad del ${ }^{60} \mathrm{Co}$ en solución después de la sorción, $\mathrm{A}_{\mathrm{a}}$ es la actividad del ${ }^{60} \mathrm{Co}$ en solución antes de la sorción, $m$ es la masa del sorbente en gramos y $V$ es el volumen de la solución de cobalto puesta en contacto con el sorbente. 


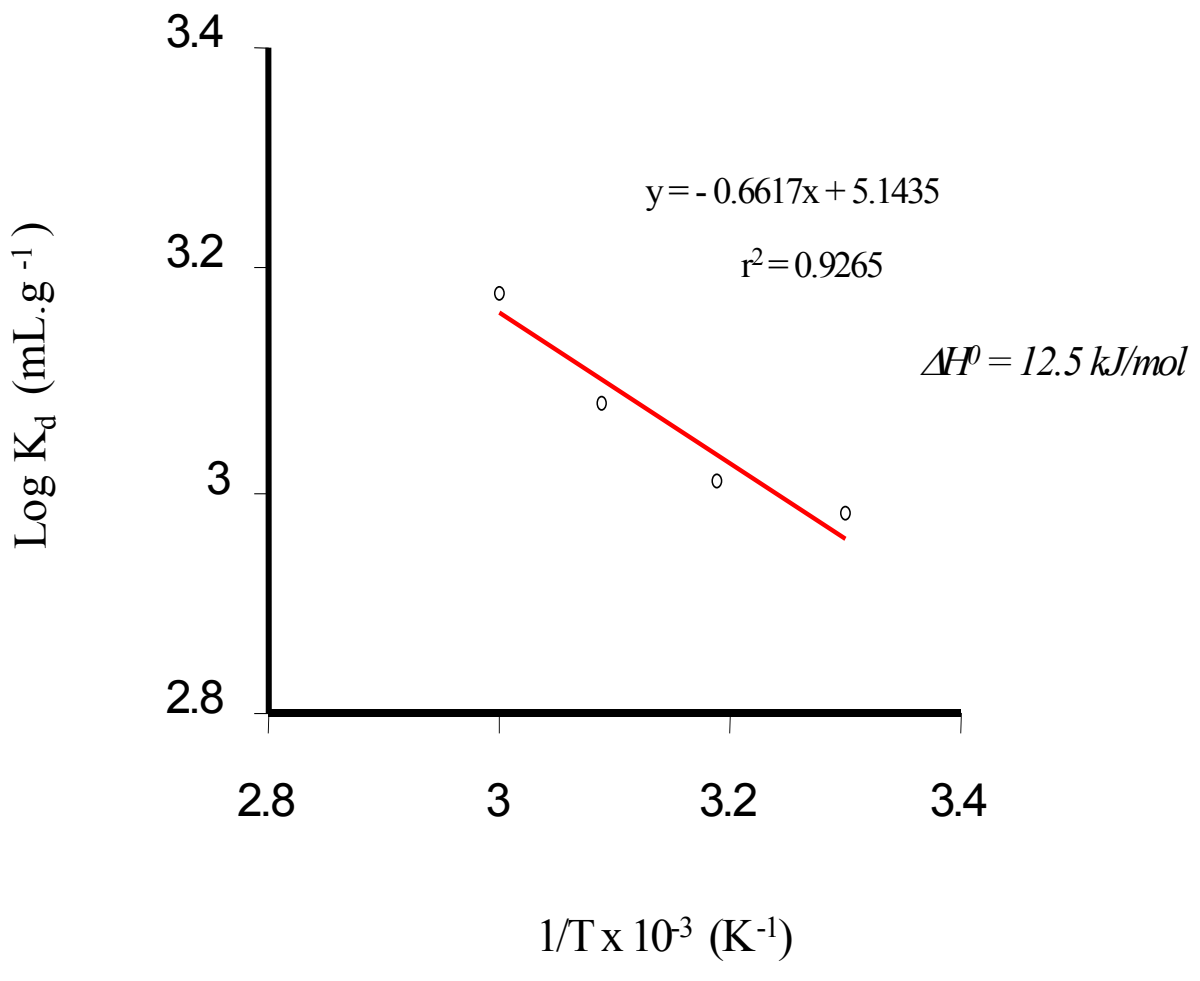

Fig. 26. Variación del $\log K_{d}$ con $1 /$ T para la sorción del ${ }^{60}$ Co sobre dióxido de manganeso hidratado. Concentración de la solución radiactiva $1.0 x$ $10^{-5} \mathrm{M}, \mathrm{pH} 6.2$

Los cambios en la energía estándar libre de Gibbs $\left(\Delta \mathrm{G}^{0}\right)$ y entropía del proceso de sorción $\left(\Delta \mathrm{S}^{0}\right)$ se evaluaron también usando las siguientes ecuaciones de la termodinámica: 


$$
\begin{gathered}
\Delta G^{0}=-2.303 R T \log K_{d} \\
\Delta G^{0}=\Delta H^{0}-T \Delta S^{0}
\end{gathered}
$$

Combinando ambas ecuaciones, resulta la expresión lineal:

$$
\log K_{d}=-\frac{\Delta H^{0}}{2.303 R}\left(\frac{1}{T}\right)+\frac{\Delta S^{0}}{2.303 R}
$$

Graficando $\log K_{d}$ contra $1 / T$, es posible obtener el valor de $\Delta \mathrm{S}^{0}$ de la sorción determinando la intersección de la recta con el eje $\log K_{d}$ en el eje $y$ de la línea recta obtenida $(y=-0.6617 x+5.1435)$, con una correlación $\mathrm{r}^{2}=0.9265$, en la que se ajustaron los valores experimentales por el método de regresión lineal para la obtención de la línea recta, empleando el valor de la intersección de la línea recta con el eje " $y$ " de (5.1453) por la ecuación obtenida en la (Fig. 26), y por un simple calculo con $\mathrm{R}=8.31434 \mathrm{~J} / \mathrm{K}$. mol, se encuentra que $\Delta S^{0}=9.8 \pm 0.2 \times 10^{-2} \mathrm{~kJ} / \mathrm{mol}$ que al relacionarlo con la ecuación (18), se obtiene el valor de la energía libre de Gibbs del proceso de sorción $\Delta \mathrm{G}^{0}=-17.0 \pm 3.0 \mathrm{x}$ $10^{-2} \mathrm{~kJ} / \mathrm{mol}$.

Como se observó en la Fig. 23, el incremento de sorción de ${ }^{60} \mathrm{Co}$ con la temperatura, puede atribuirse a que aumentó la velocidad de reacción en la etapa inicial del proceso activándose el mecanismo por el aumento de la movilidad de las especies iónicas en el medio. Al haber más movilidad, las especies se acercan más rápidamente a los sitios activos en la superficie del sorbente. Este fenómeno fue descrito por Arrhenius (Chang, 1997), quién comprobó que la velocidad de reacción (sorción) es directamente proporcional a la temperatura del sistema. 
Como se mencionó anteriormente, la cinética de sorción del ${ }^{60} \mathrm{Co}$, corresponde a un proceso de primer orden respecto a la concentración de cobalto, esto quiere decir, que es un proceso cuya velocidad depende de la concentración de los reactivos elevados a la primera potencia (Chang, 1997). El valor de la energía de activación obtenido (10.5 \pm 0.4$) \mathrm{kJ}$. mol ${ }^{1}$, indica que las barreras para la sorción son bajas y que la velocidad que determina el proceso de sorción involucra una reacción sencilla entre los reactivos, tal como se observó en el proceso de sorción del ${ }^{60} \mathrm{Co}$ en función de la concentración, donde se alcanzó el equilibrio en unos cuantos minutos después de poner en contacto la solución de cobalto y el sorbente (Fig. 23).

El valor positivo del cambio de entalpía estándar $\left(\Delta \mathrm{H}^{0}\right)$ de $12.5 \pm 0.2 \mathrm{~kJ} \mathrm{~mol}^{-1}$, indica que el proceso de sorción del cobalto es endotérmico en naturaleza y por su magnitud, sugiere que la sorción procede por vía intercambio iónico, tal como lo indican las leyes de la entalpía para un proceso de sorción por intercambio iónico que se encuentra

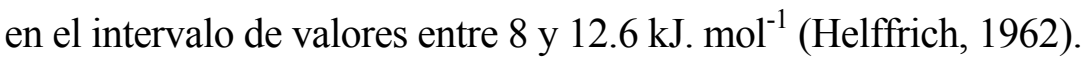

El valor negativo del cambio en la energía estándar libre de Gibbs $\left(\Delta \mathrm{G}^{0}\right)(-17.0 \pm$ $3.0 \mathrm{~kJ}^{\mathrm{mol}}{ }^{-1}$ ) revela la espontaneidad del proceso de sorción. Por otro lado el valor positivo de cambio de entropía $\left(\Delta \mathrm{S}^{0}\right)$ del sistema de $(9.8 \pm 0.2) \times 10^{-2} \mathrm{~kJ}^{-1} \mathrm{~K}^{-1} \mathrm{~mol}^{-1}$, indica que el grado de libertad de los iones sobre la superficie del sólido se incrementa por el proceso de sorción. 


\subsubsection{Estudio de desorción.}

El porcentaje de desorción del ${ }^{60} \mathrm{Co}$ en el dióxido de manganeso hidratado, fue calculado usando las siguientes relaciones:

$$
\begin{gathered}
\text { \%Desorción }=\frac{A_{2}}{\left(A_{0-} A_{1}\right)} \cdot \frac{1}{a_{e}} \cdot C \cdot \frac{V}{m} \times 100 \\
\mathrm{y} \quad a_{t}=\frac{\left(A_{0}-A_{t}\right)}{A_{o}} \cdot C \cdot \frac{V}{m}
\end{gathered}
$$

donde $A_{0}$ y $A_{t}$ son las actividades específicas de la solución al tiempo cero y tiempo $\mathrm{t}$ respectivamente; $C$ es la concentración inicial de la solución radiactiva $\left(m o l . \mathrm{L}^{-1}\right) ; V$ es el volumen total de la solución radiactiva; $m$ es la masa del sorbente (g); $A_{l}$ y $a_{e}$ son las actividades relativas de la solución acuosa y de la sorción del ${ }^{60} \mathrm{Co}$ al equilibrio respectivamente; $A_{2}$ es la actividad de la solución acuosa al tiempo t.

En la Tabla 7, se muestran los porcentajes de desorción obtenidos del cobalto en el dióxido de manganeso hidratado, se observa que un pequeño porcentaje de cobalto fue transferido del dióxido de manganeso hidratado a la solución acuosa, indicando la formación de una fase estable. 
Tabla 7. Estudio de variación de temperatura sobre la desorción del ${ }^{60} \mathrm{Co}$ del dióxido de manganeso hidratado en el equilibrio: Concentración inicial de la solución $1 \times 10^{-5}$; pH 6.2.

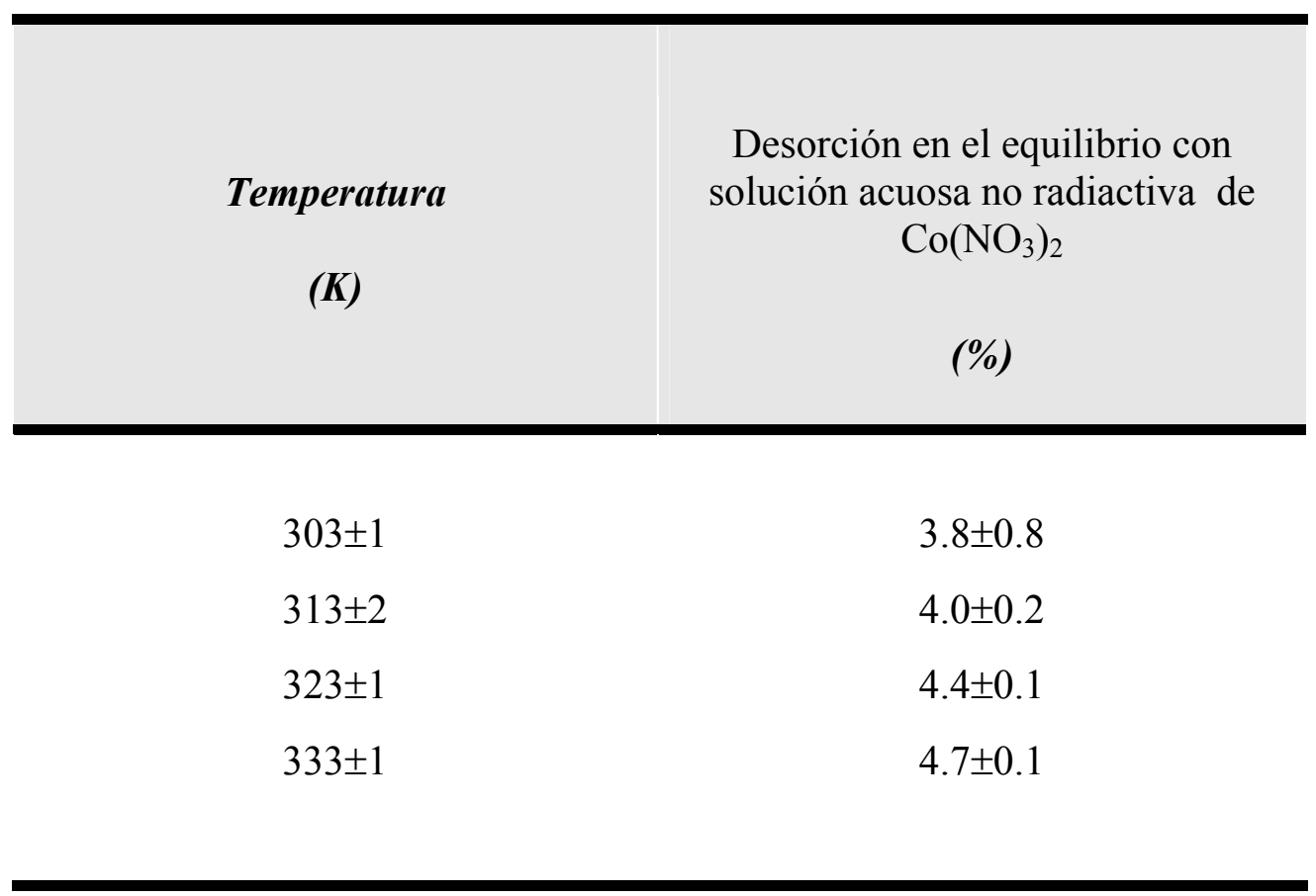

Los bajos porcentajes de desorción obtenidos en el sistema estudiado, (Tabla 7), indican la formación de una fase estable. Estos resultados muestran la sorción del cobalto específicamente sobre la superficie de dióxido de manganeso hidratado, y procede por vía intercambio iónico ya que la desorción de cobalto en la solución de nitrato de cobalto es mínima. Estos valores bajos de desorción, indican que el proceso de sorción es irreversible, confirmando los resultados obtenidos en la determinación de la entalpía estándar del proceso de sorción del cobalto. 


\section{CONCLUSIONES}

De acuerdo a los resultados generales obtenidos en esta investigación, podemos concluir que la mayoría de los materiales inorgánicos estudiados, fueron capaces de remover al ${ }^{60} \mathrm{Co}$ y los productos de fisión del ${ }^{235} \mathrm{U}$ presentes en solución acuosa, a diferentes valores de $\mathrm{pH}$, con diversos grados de eficiencia. La sorción del ${ }^{60} \mathrm{Co}$ y de los productos de fisión del ${ }^{235} \mathrm{U}$ sobre materiales inorgánicos está asociada a: 1) a los diferentes valores de $\mathrm{pH}$ de la solución de nitrato de cobalto y nitrato de uranilo, lo que contribuye a la formación de diferentes especies químicas en la solución (cationes, aniones y especies neutras que pueden precipitarse) las que pudieron ser determinadas mediante estudios de electroforesis de alto voltaje. 2) a las propiedades superficiales de los sólidos inorgánicos que son: carga superficial, área específica, porosidad y tamaño de poro. Como consecuencia de la capacidad de sorción de los sorbentes estudiados, se evidenciaron diferentes esquemas de sorción tales como: atracción electrostática, intercambio iónico y precipitación. El mecanismo que explica la sorción del ${ }^{60} \mathrm{Co}$ y de los productos de fisión del ${ }^{235} \mathrm{U}$ sobre el $\mathrm{MgO}$ es la atracción electrostática directa de los iones con la superficie cargada de acuerdo con el concepto de punto de carga cero (zpc).

Algunos sorbentes inorgánicos, como el $\mathrm{SnO}$, mostraron que no son adecuados para la sorción de los iones ${ }^{60} \mathrm{Co}$ y los productos de fisión del ${ }^{235} \mathrm{U}$ en solución acuosa. Específicamente la sorción de los radioisótopos ${ }^{132} \mathrm{Te}$ y ${ }^{95} \mathrm{Zr}$ sobre $\mathrm{TiO}_{2}, \mathrm{MnO}_{2}$ y $\mathrm{SnO}$ no puede atribuirse a la atracción electrostática directa de los iones con un grupo específico sobre su superficie de acuerdo con el concepto de punto de carga cero (zpc). Con respecto al carbón activado, su alta efíciencia de sorción tanto del ${ }^{60} \mathrm{Co}$ y de los 
productos de fisión del ${ }^{235} \mathrm{U}$ estudiados, se debe a su gran área específica y porosidad. Finalmente la hidrotalcita calcinada mostró una eficiente capacidad de sorción de los aniones de los radioisótopos presentes en solución acuosa, debido a la regeneración de la hidrotalcita en su estructura laminar con los aniones de los radioisótopos.

El estudio cinético de sorción del ${ }^{60} \mathrm{Co}$ sobre el dióxido de manganeso hidratado, nos permitió concluir, que la sorción se favorece a bajas concentraciones de ${ }^{60} \mathrm{Co}$ en solución y al aumentar la temperatura. La cinética de la sorción de ${ }^{60} \mathrm{Co}$ en el $\mathrm{MnO}_{2}$ muestra que alcanza el equilibrio a los 40 minutos y que obedece una velocidad de sorción de primer orden que se ajusta al modelo de isoterma de Freundlich en el intervalo de concentración de cobalto estudiado.

El proceso de sorción del ${ }^{60} \mathrm{Co}$ sobre dióxido de manganeso hidratado es endotérmico e irreversible y el posible mecanismo ocurre vía intercambio catiónico. Esto se concluye de los datos termodinámicos obtenidos de la entalpía estándar del sistema $\left(\Delta \mathrm{H}^{0}=12.5 \pm 0.2 \mathrm{~kJ}\right.$. mol $\left.{ }^{-1}\right)$, y por los bajos valores de desorción del ${ }^{60} \mathrm{Co}$ del dióxido de manganeso hidratado en agua.

El valor obtenido de la energía de activación del proceso de sorción del ${ }^{60} \mathrm{Co}$ $\left(12.5 \mathrm{~kJ} \mathrm{~mol}^{-1}\right)$, indica que las fuerzas de atracción que operan, son bastante fuertes para que el proceso se lleve a cabo bajo condiciones ordinarias. Los parámetros termodinámicos de energía libre de Gibbs, $\left(\Delta \mathrm{G}^{0}=-17.0 \pm 3.0 \mathrm{~kJ} \cdot \mathrm{mol}^{-1}\right)$, y de entropía del sistema $\left(\Delta \mathrm{S}^{0}=(9.8 \pm 0.2) \times 10^{-2} \mathrm{~kJ} \cdot \mathrm{K}^{-1} \mathrm{~mol}^{-1}\right)$, indican la espontaneidad del proceso $\mathrm{y}$ que el grado de libertad de los iones se incrementa por la sorción, resultando una gran interacción de las especies químicas del cobalto con el sorbente. El dióxido de manganeso hidratado puede ser usado como un sorbente efectivo para tratamiento de desechos líquidos radiactivos que contengan ${ }^{60} \mathrm{Co}$. 
Los resultados tienen importantes consecuencias prácticas: desde el punto de vista del tratamiento de los desechos radiactivos líquidos, bajo diferentes condiciones del $\mathrm{pH}$ de las soluciones acuosas y en particular para estudios sobre el abatimiento de contaminantes radiactivos a nivel traza, que posean una vida media radiactiva larga. Debido al eficiente comportamiento de sorción exhibidos por algunos de los materiales inorgánicos se justifica su uso como buenos sorbentes para la sorción de diferentes materiales radiactivos. 


\section{REFERENCIAS}

- Abou-Mesalam, M. M., J. Radioanal. Nucl. Chem. 252, 3, (2002).

- Akcay, H., J. Radioanal. Nucl. Chem. 237, 1-2, (1998).

- Aly, H. F., El-Naggar, I. M., J. Radioanal. Nucl. Chem. 228 (1-2), (1998).

- Aslani, M. A. A., Akyil, S., Eral, M., J. Radioanal. Nucl. Chem. 250, 1, (2001).

- Atkins, P. W., Fisicoquímica, $3^{\mathrm{a}}$. Edición. Addison-Wesley Iberoamericana, EUA, (1994).

- Atun, G., Bodur, N., J. Radioanal. Nucl. Chem. 253, 2, (2002).

- Baes, C. F., Mesmer, R. E., The Hydrolysis of Cations; Wiley and Sons; New York, (1976).

- Bayri, B., Rosset, R., El Kacemi, K., Radiochim. Acta. 89, (2001).

- Bernhard, G., J. Radioanal. Nucl. Chem. 177 (2), (1994).

- Bhutani, M. M., Kumari, R., J. Radioanal. Nucl. Chem. 180 (1), (1994).

- Bhutani, M. M., Mitra, A. K., Kumari, R., Radiochim. Acta. 56 (1992).

- Blasius, E., Glatz, J. P., Neumann W., Radiochim. Acta. 29, (1981).

- Butani, M. M., Kumari, R., J. Radioanal. Nucl. Chem. 180, 1, (1994).

- Carrera, L. M., Gómez, S., Bosch, P., Bulbulian, S., Zeolites. 13, (1993).

- Cavani, F., Trifiro, F., and Vaccari, A., Catalysis Today. 11, (1991).

- Clark, E. R., Al-Zubaidi, K. A., Al-Shahristani, H., J. Radioanal. Nucl. Chem. 60 (1), (1980).

- Chang, R., Química, Mc Graw Hill, México, (1997). 
- Chatelet, L., Bottero, J. Y., Yvon, J., Bouchelaghem, A., Colloids and Surfaces (A), 3, (1996).

- Choppin, G. R., Nash, K. L., Radiochim. Acta. 70-71, (1995).

- Contreras, B. R. Producción de dióxido de manganeso por ozonización y estudio de sus propiedades de intercambio iónico. Tesis doctoral. UAM, (1999).

- Cotton, F.A., Wilkinson, G., The elements of the Second and Third Series. In Advances of Inorganic Chemistry, $2^{\text {nd }}$. Ed.; John Wiley and Sons. Inc.; New York, (1988).

- Covington, A. K., Cressey, T., Lever, B. G., Thirsk, H. R. Trans. Faraday Soc. 58, 1975 (1962).

- Custodio E. y Llamas M. R. Hidrología subterránea, $2^{\mathrm{a}}$ edición , Ed. Omega, Barcelona (1983).

- Donaldson, J. D., Fuller, M. J., J. Inorganic . Nucl. Chem. 30, 1083, (1968).

- Droguett, S. E. Elementos de catálisis heterogénea, Serie de Química, Monografía No. 26, OEA, Washington, 1983.

- Dyer A., Kadhim F. H., J. Radioanal. Nucl. Chem. 131 (1), (1989).

- Dyer, A., Aggarwal, S., J. Radioanal. Nucl. Chem. 198 (2), (1995).

- El-Absy, M. A., Aly, H. F., Radiochim. Acta. 57, (1992).

- El-Said, N., Siliman, A. M., El-Sherif E., Mikhail, A. S., Radiochim. Acta. 89,(2001).

- Fetter, G., Ramos, E., Olguín, M. T., Bosch, P., López, T., Bulbulian, S., J. Radioanal. Nucl. Chem. 221, 1-2, (1997).

- Flores, E. R.M., Olguín, M. T., Solache-Ríos, M., Longoria, G. S. C., Bulbulian, S., J. Radioanal. Nucl. Chem., 238, 1-2, (1998).

- Fukuda, T., Nagasaki, S., Satta, H., Tanaka, S., Suzuki, A., Tanaka, T., Muraoka, S., Radiochim. Acta. 82, (1998).

- Ganzerli, M. T. V., Caramella V. C., Maggi L., J. Radioanal. Nucl. Chem. 254, 1,3, (2002). 
- Greenwood N. N., Earnshaw, A., Chemistry of the Elements. Pergamon Press, Cambridge, (1984).

- Gregg, S.J., Sing, K.S.W., Adsorption, Surface area and porosity, Academic Press Limited, San Diego CA, (1995).

- Griffith, W.P., The Chemistry of the Rarer Platinum Metals (Os, Ru, Ir and Rh), Interscience Publishers; Great Britain, (1967).

- Guiin, R., Das, S.K. and Saha, S.K., Radiochim. Acta, 90, (2002).

- Guy, R. D., Chakrabarti, C. L., Schramm, L. L. Can J. Chem. 53, 661 (1975).

- Halliday, D., Introductory Nuclear Physics, John Wiley and Sons, New York, (1950).

- Hasany, S. M., Shamsi, A. M., Rauf, M. A., Appl. Radiat. Isot. 48, 5, (1997).

- Hasany, S.M., Saed M. M., Ahmed, M., Radiochim. Acta. 83, (1998)

- Hayden, E. B., Lu, G., J. Chem. Soc. Faraday Trans. 92, 23, (1996).

- Heitner-Wirguin, Albu-Yaron, A., J. Inorganic. Nucl. Chem., 28, 2379, (1966).

- Helffrich, F., Ion Exchange. McGraw Hill, New York, (1962).

- Hernández, B. E., Granados, C. F., J. Radioanal. Nucl. Chem. 242, 1, (1999).

- Hermosín, M.C., Pablovic, I., Ulibarrri, M.A., Cornejo, J., Wat. Res. 30, 1, (1996).

- Hyun, S. P., Cho, Y. H., Hahn, P.S. Kim, S. J., J. Radioanal. Nucl. Chem., 250, 1, (2001).

- Jakobsson, A. M., Albinsson, Y., Radiochim. Acta. 82, (1998).

- James, R. O., Healy, T. W., J. Colloid Interface Sci. 40, (1972).

- Kang, M. J., Rhee, S. W., Moon, H., Radiochim. Acta, 75, (1996).

- Kaplan, D. I., Gervais, T. L., Krupka K. M., Radiochim. Acta, 80, (1998).

- Khalid, N., Rahman, A., Ahmad, S., Radiochim. Acta, 83, (1998).

- Kim, D. W., Kim, C. S., Lee, N. S., Ryu, H. I., Radiochim. Acta. 90, 179 (2002). 
- Kim, D. W., J. Radioanal. Nucl. Chem. 252, 3 (2003).

- Kinniburgh, D. G., Syers, J. K. Jakobson, M.L., Soli. Sci. Am. Proc. 39, (1975).

- Kirk, E., Encyclopeidia of Chemistry Technology. Vol. 14, (1992).

- Kooli, F., Depege, C., Ennaqadi, A., De Roy, A., Besse, J. P., Clays Clay Miner. 45, (1997).

- Kosowa, A. J., Electrochem. Soc. 106, 552, (1959).

- Lederer, C. M., Holander, J. M., Perlman, I. Tables of isotopes, Willey, 1968.

- Lieser, K. H., Quandt-Klenk, S., Thybusch, B., Radiochim. Acta. 57, (1992).

- Lin, C. P., Hsieb, B. T., Ting, G., Yeh, S. J., J. Radioanal. Nucl. Chem. 236, 1-2, (1998).

- Loos-Neskovic, C., Fedoroff, M., Radioactive Waste Management and the Nuclear Fuel Cycle. 11, 4, (1989).

- López, F. O., Canoba, A. C., J. Radioanal. Nucl. Chem. 252, 3, (2002)

- Lowell, S., Introduction to Powder Surface Area; Interscience Publishers, Toronto, Canada, (1979).

- Malati, M. A., Yousef, A. A., Arafa, M. A., Chem. Ind. (London), 459, (1969).

- Mishra, S. P., Singh, V. K., Appl. Radiat. Isot. 46, 9, (1995).

- Mishra, S. P., Tiwary, D., J. Radioanal. Nucl. Chem. 196, 2, (1995).

- Mishra, S. P., Singh, S. N., Tiwary, D., Appl. Radiat. Isot. 42, 12, (1991).

- Mishra, S. P., Srinivasu, N., Tiwary, D., Appl. Radiat. Isot. 43, 12, (1992).

- Mishra, S. P., Tiwary, D., J. Radioanal. Nucl. Chem. 170, 1, (1993).

- Mishra, S. P., Tiwary, D., Radiochim. Acta. 80, (1998).

- Miyake, C., Sugiyama, D., Taniguchi, K., J. Nucl. Sci. and Technol. 31, 10, (1994).

- Miyata, S., Clays Clays Miner. 23,(1975). 
- Miyata, S., Clays Clays Miner. 28, (1980).

- Miyata, S., Okada, A. Clays Clays Miner. 125, (1977).

- Momma, T., Iwashima, K., Radioisotopes (Tokyo). 16, 68, (1967).

- Mondino, A. V., Manzini, A. C., Cerutti, G. L., Iglicki, F. A., Novello, N. A., J. Radioanal. Nucl. Chem. 253, 2, (2002).

- Moosa, H. S., Mufazzal, S. M., Ahmed, M., Radiochica Acta. 83, (1998).

- Murray, J. W., J. Colloid Interface Sci. 46, 3, (1974).

- Navarrete, M. T., Cabrera, L. Introducción al estudio de los radioisótopos, Ed. Sector eléctrico, México. (1979).

- Olguín, M. T., Bosch, P., Acosta, D., Bulbulian, S., Clay and Clay Minerals, 46, 5, 567-573, (1998).

- Olguín, M. T., Solache, M., Iturbe, J. L., Bosch, P., Bulbulian, S., Sep. Sci. and Technol. 31,15, (1996).

- Parks, G. A., Chem. Rev. 65, (1965).

- Pereira, G. C., Castro, H.R., Hidalgo, P, Gouvea, D., Appl. Surf. Sci. 95, 227, (2002).

- Pourbaix, M., Establishment and Interpretation of Potential-pH Equilibrium Diagrams: Atlas of Electrochemical Equilibria in Aqueous Solutions; 1st Ed.; Pergamon Press: London, (1966).

- Puigdomenech, I., Program MEDUSA: Make Equilibrium Diagrams Using Sophisticated Algorithms.http:/www.inorg.Kth.se/Reserach/Ignasi;/Index.html, (1999).

- Raje, N., Swain, K. K., J. Radioanal. Nucl. Chem. 253, 1, (2002).

- Rajec, P., Mátel, L., Orechovská, J., Súcha, J., Novák, I., J. Radioanal. Nucl. Chem. 208, 2, (1996).

- Rey, F., Fornés, V., Rojo, J. M., J. Chem. Soc., Faraday Trans., 88, 15, (1992).

- Reynolds, T. D., Unit Operations and Processes in Environmental Engineering; PWS Publishing Co.: Boston, (1982). 
- Saleem, M., Afzal, M., Qadeer, R., Hanif, J., J. Radioanal. Nucl. Chem.,172, 2, (1993).

- Samanta, S. K., J. Radioanal. Nucl. Chem. 209, 1, (1996).

- Sasaki, K., Kosowa, A. J. Electrochem. Soc. Japan, 25, 115 (1957).

- Sato, T., Fujita, H., Endo, T., Shimada, M., Tsunamishima, A., React. Solids. 5, (1998).

- Sato, T., Motoki, R., Radiochim. Acta.48, (1989).

- Seddon, E. A., Seddon, K. R., The Chemistry of Ruthenium; Elsevier: Amsterdam, (1984).

- Serrano, G. J., Bertin, V., Bulbulian, G. S., Langmuir. 16, (2000).

- Serrano, J., Granados, F., Bertin, V., Bulbulian, S., Sep. Sci. Technol. 37, 2, (2002).

- Serrano, G. J., Granados, C. F., J. Radioanal. Nucl. Chem. 254, 3, (2002).

- Shahwan, T., Erten, H. N., J. Radioanal. Nucl. Chem. 253, 1, 115, (2002).

- Singh, O. V., Tandon, S.N., Int. J. Appl. Radiat. Isot. 28, 701 (1977).

- Slejko, F. L. Adsorption Technology: A step-by-step approach to Process, evaluation and application. Marcel Dekker Inc. New York, (1985).

- Sun, C., Berg, J., J. Chromat. A., 969, (2002).

- Tiwari, P.H., Campbell, A.B., Lee, W. Can. J. Chem. 52 (1972).

- Tranter,T. J., Herbst, R. S., Todd, T. A., Olson, A. L., Advances in Environmental Research. 6, 2, (2002).

- Travesi, A., Análisis por activación neutrónica, teoría, practica y aplicaciones, Ed. Publicaciones científicas de la J.E.N. , España, (1975).

- Trivedi, P., Axe, L., Tyson, T. A., Environ. Sci. Technol. 35, (2001).

- Veselý, V., Pekárek, V., Talanta. 19, (1972).

- Vivien, D., Livage, J. Mazieres, Ch., J. Chim. Phys Physicochim. Biol. 67, (1970). 
- Yamazaki, H., Inove, Y., Hirano, T., Solv. Extract. Ion Exch. 13, (1995).

- Yllera de Llano, A., Benítez, A. H., Gutiérrez, M. G., Radioch.Acta., 82, (1998). 